\title{
Structural Health Monitoring of the Rebecca Street (William Anderson) Bridge
}

\author{
by \\ Canon Shafieyan \\ B.Eng, Ryerson University \\ A thesis \\ presented to Ryerson University \\ in partial fulfillment of the \\ requirements for the degree of \\ Master of Engineering \\ in the Program of \\ Civil Engineering
}

Toronto, Ontario, Canada, 2015

(C) Canon Shafieyan 2015 


\begin{abstract}
Authors Declaration
I hereby declare that I am the sole author of this project. This is a true copy of the project, including any required final revisions as accepted by examiner.

I hereby authorize Ryerson University to reproduce or lend this project by photocopying or by other means, in total or in part, at the request of other institutions or individuals for the purpose of scholarly research.
\end{abstract}




\begin{abstract}
This research investigation is to employ a Structural Health Monitoring (SHM) strategy for the Rebecca Street Bridge to provide accurate information regarding the structural behavior and performance of the bridge during regular operation. The research investigation included visual inspection and structural assessment using the MIRA 3D shear wave tomographer to evaluate the bridge structural condition. The overall structural condition of the bridge is good and no major deterioration was noted. However, the voids detected during the shear wave scans could form void clusters in the future, leading to potential cracking and delamination.

A monitoring strategy was developed based on the crack width and moment curvature of the concrete cross section using reliability analytical models that would allow for lifetime monitoring. The prediction models used the Bridge Condition Index (BCI) to evaluate the structural condition of the bridge. The future works for the Rebecca Street Bridge includes periodic monitoring as recommended.
\end{abstract}

Keywords: Structural Health Monitoring, Shear Wave Analysis, Crack Width Model, Moment Curvature, Crack Spacing Model, Dynamic Modulus of Elasticity, MIRA 3D Tomographer and Bridge Condition Index 


\section{Acknowledgement}

I would like to thank Professor Dr. Hesham Marzouk for providing me with definite direction, professional guidance, and constant encouragement from the beginning of the work and moral support in many ways during my study period.

I am also greatly indebted to Bobby $\mathrm{Yu}$ from Cole Engineering for his support and professional guidance throughout the project. This thesis would not have been possible without the support, encouragement and professional guidance of Dr. Saidur Rahman.

I am indebted to my many colleagues who supported me throughout the project in many ways including Rana Morsy, Azita Pourrastegar, Hesham Othoman, Mohammad Aldardari, Nidal Jaalouk and Min Yao.

I would also like to thank Erik Zutis and Anthony Lazzara from the Town of Oakville for their continuous support, encouragement and supervision through the project, aiding me with site access and providing professional guidance. 


\section{Table of Contents}

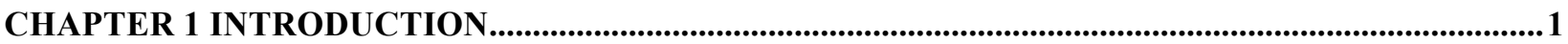

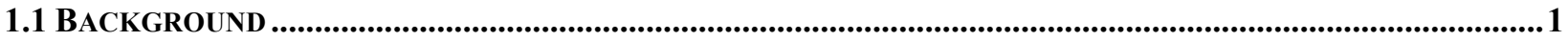

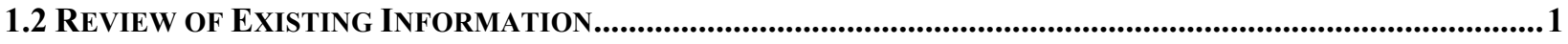

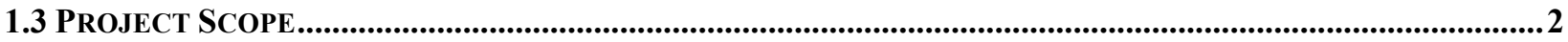

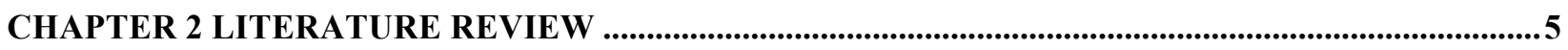

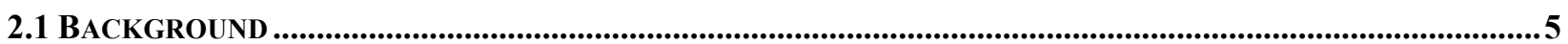

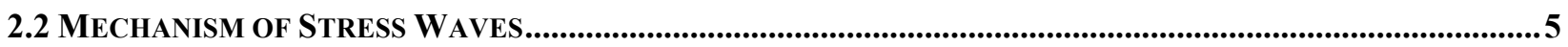

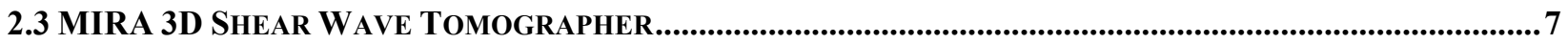

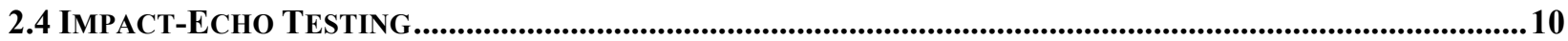

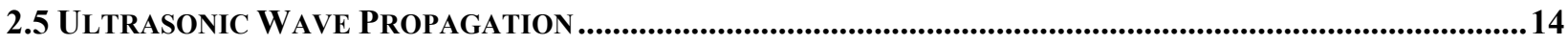

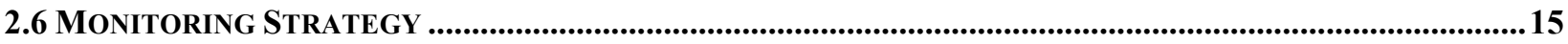

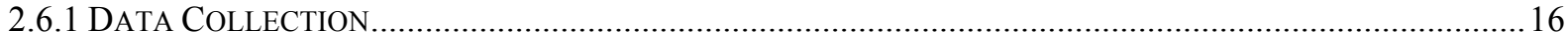

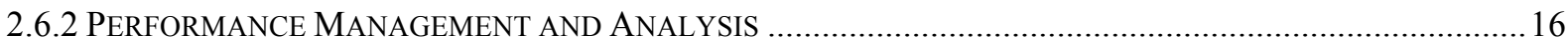

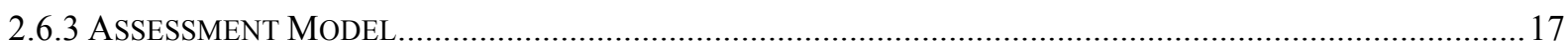

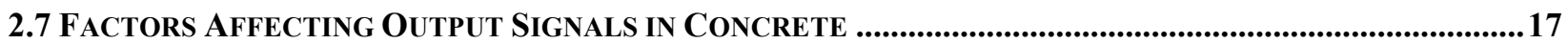

2.8 Models for Crack Width, CRack Spacing and Dynamic Modulus of Elasticity......................18

CHAPTER 3 ESTABLISHING CRACK SPACING AND WIDTH LIMITS .............................................19

3.1 CRACKING IN REINFORCED CONCRETE STRUCTURES ..............................................................................19

3.2 CRACK WIDTH MODEL FOR THICK REINFORCED CONCRETE MEMBERS ...............................................19

3.3 CRACK SPACING FOR CONCRETE BY USING NEURAL NETWORKS .............................................................21

3.4 STATIC AND DYNAMIC MODULUS OF ELASTICITY ..........................................................................................24

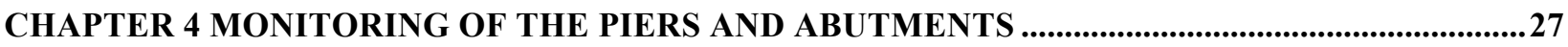

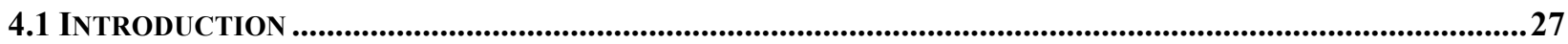

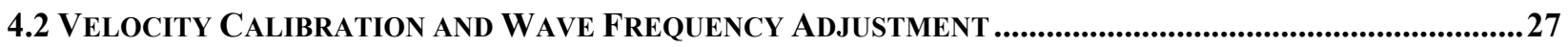

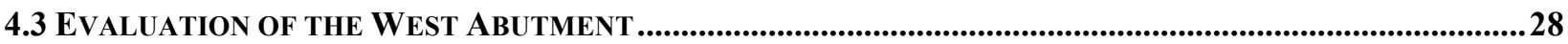

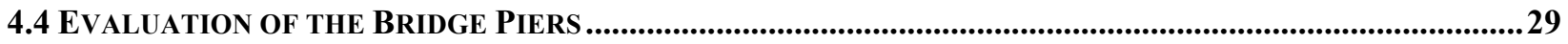

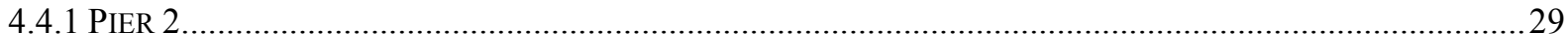

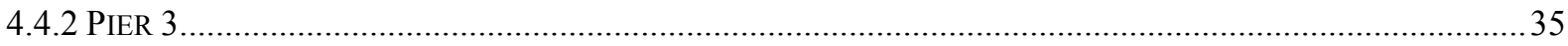

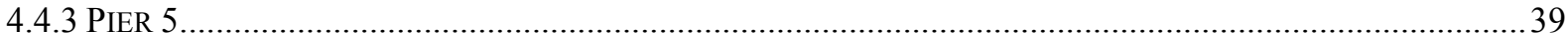

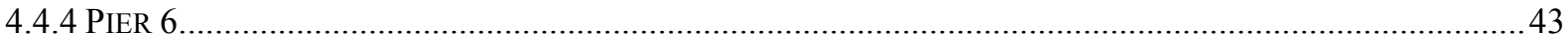




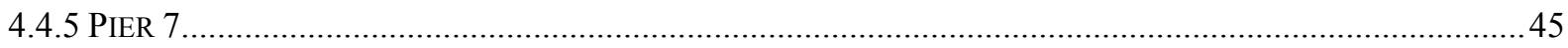

4.5 Crack Width, Spacing ANd Modulus of Elasticity OF The Piers ANd Abutments .......................51

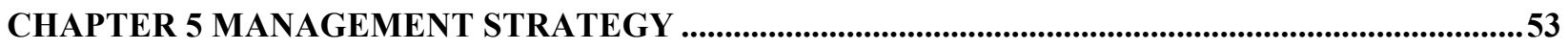

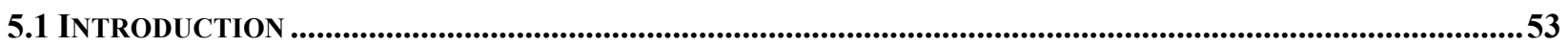

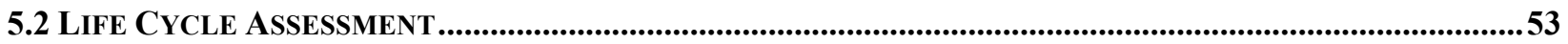

5.2.1 ESTIMATION OF THE DESIGN Life AND RESIDUAL LifE OF STRUCtURES .........................................54

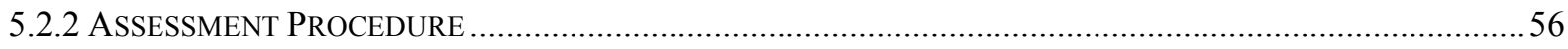

5.3 MoMent CURVATURe for Crack Modeling ..........................................................................................57

5.4 MANAGEMENT STRATEGY FOR THE REBECCA STREET BRIDGE .................................................................59

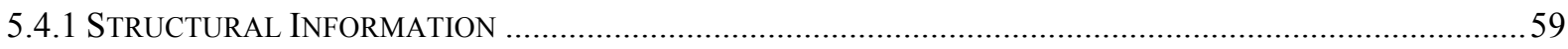

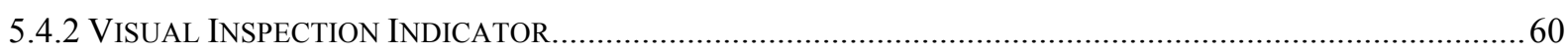

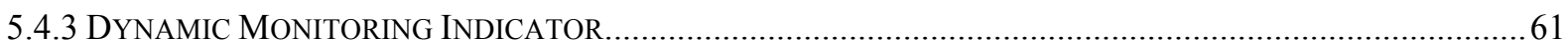

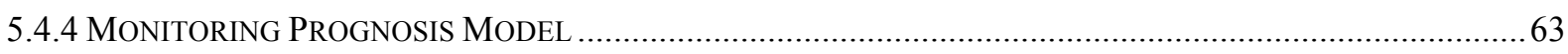

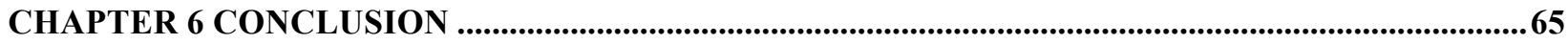

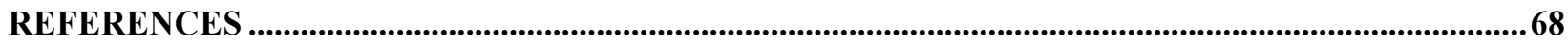

APPENDIX A CRACK WIDTH AND CRACK SPACING COMPUTATION ..........................................72

APPENDIX B MOMENT CURVATURE COMPUTATION ....................................................................74

APPENDIX C DYNAMIC AND STATIC MODULUS COMPUTATION .................................................77

APPENDIX D RECOMMENDED RETROFIT MEASURES _...............................................................

D1 REPAIR OF ABUTMENTS AND EXPANSION JOINTS ...........................................................................................78

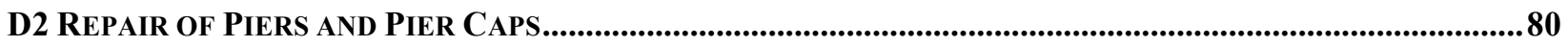

D3 REPAIR OF BRIDGE DECK, SIDEWALKS AND BARRIERS...............................................................................83

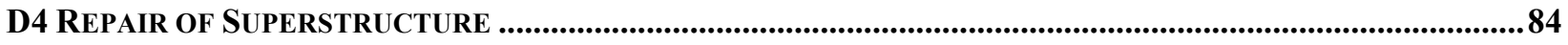




\section{List of Tables}

Table 2.1 - Impact-Echo Responses of Solid Structural Elements .......................................................14

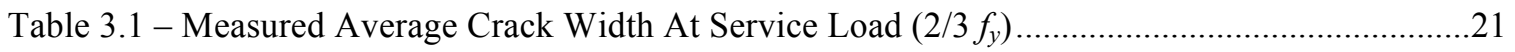

Table 4.1 - Dynamic and Static Modulus of Elasticity Computation .......................................................51

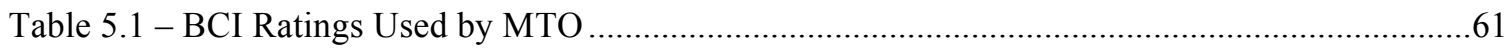

Table 5.2 - Performance Measure and Deterioration Type Vs. Weight Factor .....................................62

Table 5.3 - Rebecca Street Bridge Maintenance Strategies .................................................................63

Table A1 - Computation of Crack Width and Crack Spacing of the Bridge Piers ...............................72

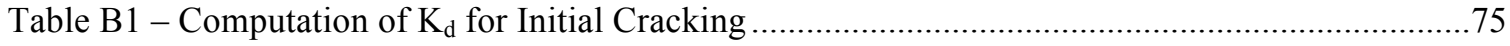

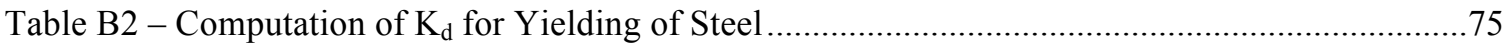

Table B3 - Computation of Additional Points for the Moment-Curvature Plot ....................................76

Table C1 - Computation of the Dynamic and Static Moduli of Elasticity ...........................................77

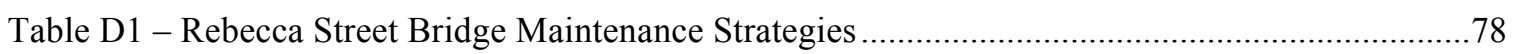

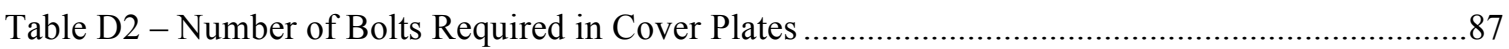




\section{List of Figures}

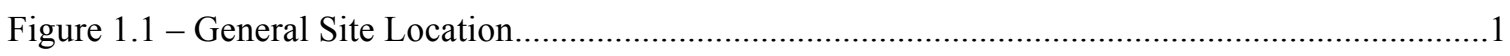

Figure 2.1 - Rayleigh Wave Propagation in Determining Cracks ........................................................6

Figure 2.2 - MIRA 3D Shear Wave Tomographer Apparatus.............................................................

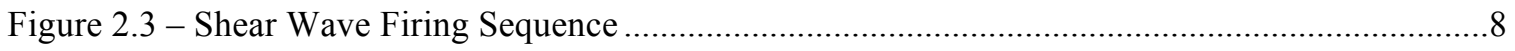

Figure 2.4 - Orthogonal Planes of the MIRA 3D Shear Wave Tomographer ......................................

Figure 2.5 - B, C and D Scan Results of a Typical Scan ................................................................

Figure 2.6 - Scan Results Indicating Cracks and Spalling of Concrete..............................................10

Figure 2.7 - Schematic Diagram of the Impact-Echo Method..........................................................12

Figure 2.8 - Stress Waves Caused by Impact at a Point on the Surface of Concrete Plate ...................12

Figure 2.9 - A Typical Impact-Echo Test System ............................................................................13

Figure 2.10 - P-Wave Speed Measurement Test Configuration ...........................................................13

Figure 2.11 - Typical Structural Health Monitoring Methodology ...................................................16

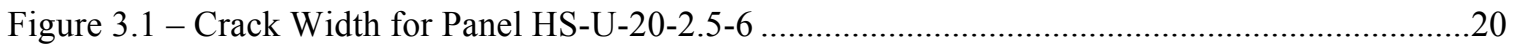

Figure 3.2 - Comparison Between $\mathrm{S}_{\mathrm{c}}$ From Experimental Results and Proposed Equation..................22

Figure 3.3 - Comparison Between $\mathrm{S}_{\mathrm{c}}$ From Experimental Results and CSA-2004 .............................23

Figure 3.4 - Comparison Between $\mathrm{S}_{\mathrm{c}}$ From Experimental Results and NS-1992 ...............................23

Figure 3.5 - Comparison Between $\mathrm{S}_{\mathrm{c}}$ From Experimental Results and EC-2004 ..............................23

Figure 3.6 - Comparison Between $\mathrm{S}_{\mathrm{c}}$ From Experimental Results and CEB-FIP 1990 ......................24

Figure 3.7 - Comparison Between $\mathrm{S}_{\mathrm{c}}$ From Experimental Results and ACI 224R-01 .......................24

Figure 4.1 - MIRA Scan Results from the West Abutment................................................................28

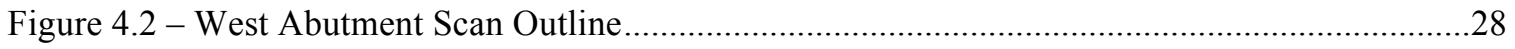

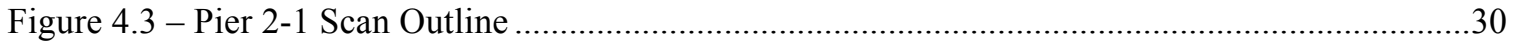

Figure 4.4 - $50 \mathrm{~Hz}$ Scan Results from Pier 2-1 ...........................................................................

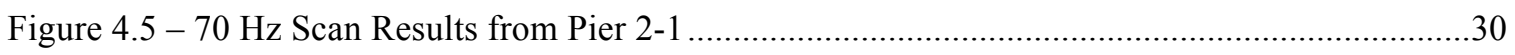

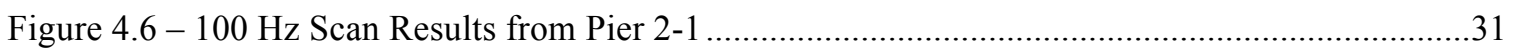

Figure 4.7 - Comparison of 50, 70 and $100 \mathrm{~Hz}$ Scans from Pier 2-1 ................................................

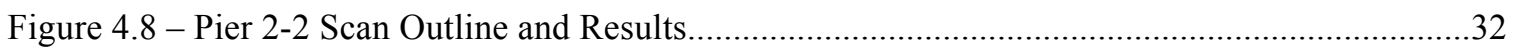

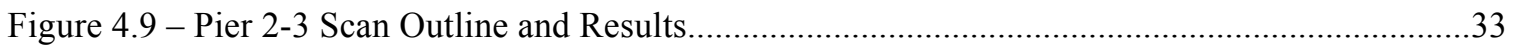

Figure 4.10 - Pier 2-4 Scan Outline Indicating a Small Surface Stain ..................................................

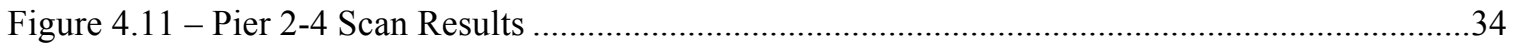

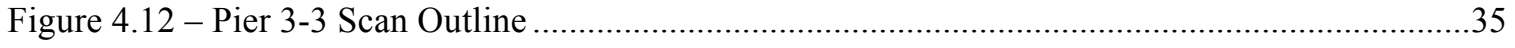

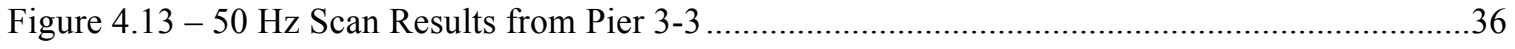

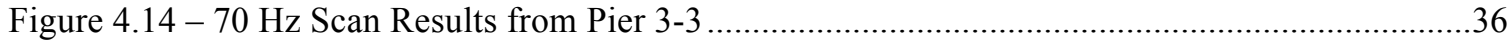

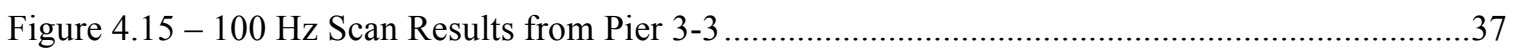




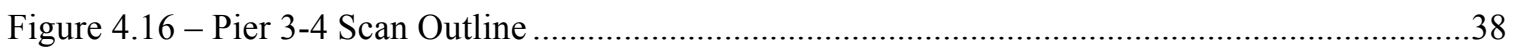

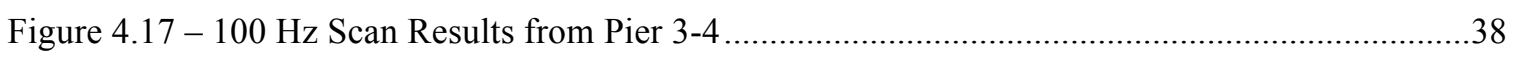

Figure 4.18 - Pier 5-1 Scan Results Indicating Void Presence and Void Formation .............................39

Figure 4.19 - Pier 5-2 Scan Results Indicating Minor and Major Voids Present ....................................40

Figure 4.20 - Pier 5-3 Scan Outline with a Crack Present on the Scan Face.........................................41

Figure 4.21 - Pier 5-3 Scan Results Indicating Minor and Major Voids Present ..................................41

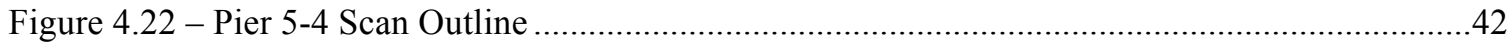

Figure 4.23 - Pier 5-4 Scan Results Indicating Surface Voids and Potential Crack Formation .............42

Figure 4.24 - Pier 6-1 Scan Results Indicating Void Cluster and Minor Voids Present ........................43

Figure 4.25 - Pier 6-2 Scan Results Indicating Minor Voids Present....................................................44

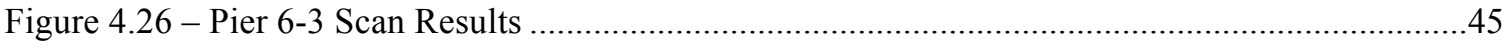

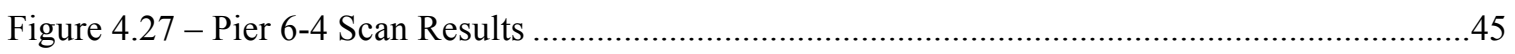

Figure 4.28 - Pier 7-1 Scan Outline with Surface Stains, Honeycombing and Scaling Present.............46

Figure 4.29 - Pier 7-1 Scan Results Indicating Major Void Clusters Present ........................................46

Figure 4.30 - Pier 7-2 Scan Outline with Vertical and Diagonal Cracks Present..................................47

Figure 4.31 - Pier 7-2 Scan Results Indicating Minor Voids Present....................................................47

Figure 4.32 - Pier 7-2 Scan Outline with Minor Cracks Noted ..........................................................48

Figure 4.33 - Pier 7-4 Scan Results Indicating Minor Voids Present...................................................48

Figure $4.34-50 \mathrm{~Hz}$ Scan Results from Pier 7-3 Indicating Major Voids Present................................49

Figure $4.35-100 \mathrm{~Hz}$ Scan Results Indicating Closely Spaced Voids from Pier 7-3 ...........................50

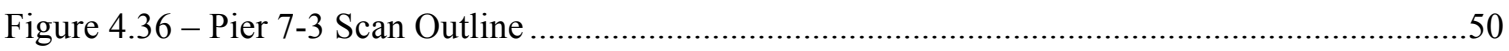

Figure 5.1 - Common Parameters for Structural Health Monitoring..................................................53

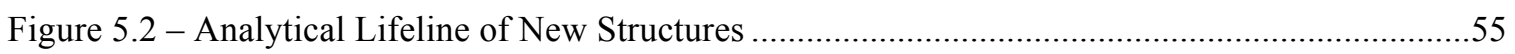

Figure 5.3 - Effects of Maintenance on the Lifeline of Structures .......................................................56

Figure 5.4 - Assessment Procedure Using Visual Inspections and SHM.............................................57

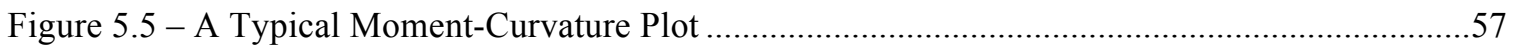

Figure 5.6 - Moment-Curvature Plot of the William Anderson Bridge Pier Columns..........................58

Figure 5.7 - General Principle of Gauge Length Selection Based on Purpose .....................................59

Figure 5.8 - Rebecca Street Bridge Plan View Drawing ...................................................................60

Figure 5.9 - Rebecca Street Bridge Elevation View Drawing .............................................................60

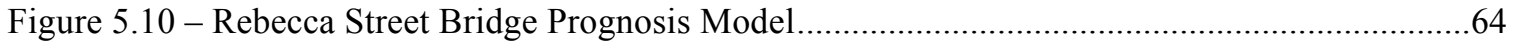

Figure D1 - Abutments and Expansion Joint Prognosis Model..........................................................79

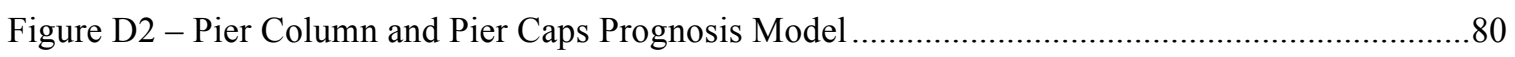

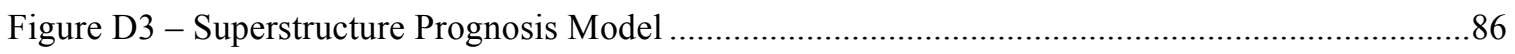

Figure D4 - Typical Flange Repair Procedure With Bolted Plates.....................................................8

Figure D5 - Typical Web Repair Procedure With Bolted Plates ..........................................................8 
Figure D6 - Schematic Cross-Section of a Typical High Performance Coating System ..... 


\section{Chapter 1 Introduction}

\subsection{Background}

The Rebecca Street Bridge (William Anderson Bridge) located in the Town of Oakville was constructed in 1961 over the Sixteen Mile Creek. The bridge is composed of steel girders with a composite concrete deck and concrete piers and abutments. The bridge also spans over Water Street, parking lots and the rowing club storage facility. A location map is shown in Figure 1.1. The bridge is supported by eleven simply supported spans (10@16.5 m and $1 @ 39.5 \mathrm{~m}$ ). The overall length of the bridge deck is $204 \mathrm{~m}$ with an asphalt-wearing surface of $14 \mathrm{~m}$ in width and a $2 \mathrm{~m}$ wide sidewalk cantilevered on both sides. The bridge also has a utility corridor (600 $\mathrm{mm}$ water main, $1000 \mathrm{~mm}$ sewer line and $170 \mathrm{~mm}$ gas main) provided below the bridge deck.

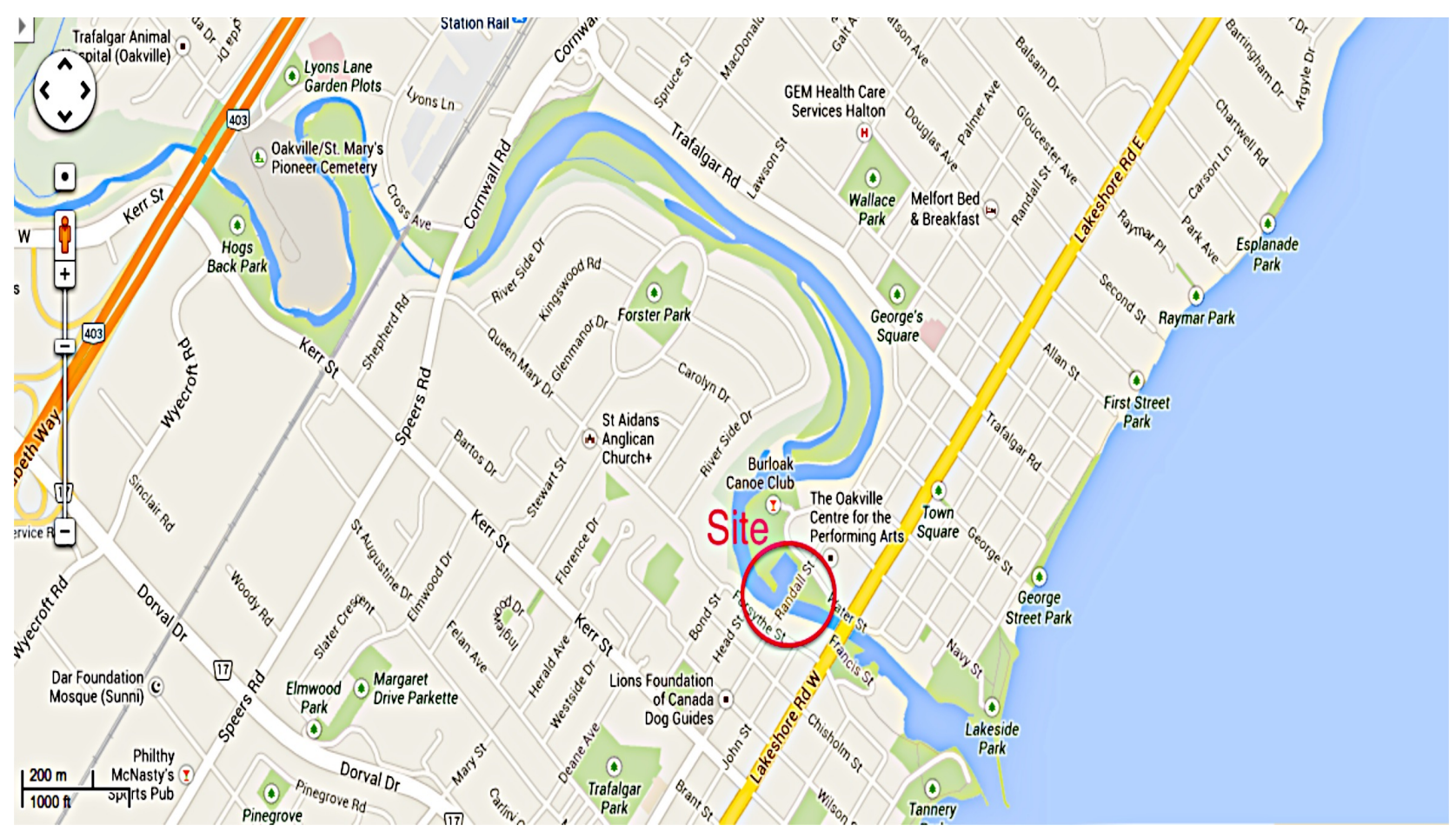

Figure 1.1 - General Site Location

\subsection{Review of Existing Information}

By reviewing the report from the bridge rehabilitation report prepared by Cole Engineering the following referenced information was obtained regarding previous rehabilitation works (Cole Engineering, 2013): 
1. Bridge Deck Replacement. The bridge deck was replaced in 1989. The construction was carried out in two stages with a construction joint provided along the centerline of the bridge deck to facilitate maintaining two lanes of traffic on the bridge during the construction. Expansion joints were replaced over each pier and abutment with strip seal expansion joint systems. The sidewalks contain embedded ducts for lighting and other services from the original construction. Localized patch repair of the piers was also included in the contract.

2. Emergency Repair. In the spring of 2011 Town initiated an emergency work to address removal of loose concrete on the piers and deck soffits on the bridge.

3. Bridge Rehabilitation. Following completion of the 2011 emergency repair on loose concrete, a follow up construction contract was carried out in 2012 to complete the rehabilitation of the structural elements underneath the bridge structure, including further removal of spalled and deteriorated concrete, concrete restoration and patch repair.

\subsection{Project Scope}

The scope of this study is to employ a structural health monitoring strategy for the Rebecca Street Bridge to provide accurate information regarding the structural behavior and performance during regular operation. Using the information from the nondestructive monitoring, effective planning and design of maintenance activities can be made. This project will provide the Town of Oakville with a new and effective monitoring technique that will not only be used on this bridge, but can be implemented on virtually any concrete structure.

The structural health monitoring (SHM) techniques is to detect the presence, size and location of any damage. SHM techniques detect damage in terms of changes in the structural and modal parameters. The damage detection can be categorized into several levels: identification of the damage existence, knowledge of its locations, identification of its type, determination of the significance of the damage and remaining serviceable life of the structure. Damage identification can be based on changes in natural frequency, vibration mode, structural flexibility or stiffness, transfer functions, static information or power flow. Through damage identification, SHM can be used to give a warning for the level of structural damage, which can be used for preventing the occurrence of sudden failure. The main objective of structural health monitoring is to measure the structural deterioration and to detect the presence of any defects earlier, which allows for appropriate and timely maintenance allocation. In addition, it provides data to model the 
remaining life of the structure and to analyze how different maintenance plans would affect the structural service life.

In general, modern non-destructive evaluation techniques are very effective at accurately detecting the nature, size and location of any damage. Common structural health monitoring techniques include fiber optic sensors, impact echo, ultrasonic emission, acoustic emission, thermography, the use of strain gauges, and visual inspections. The scope of this project will include visual inspections to capture the overall condition of the structure and the use of the MIRA 3D shear wave tomographer for in depth analysis of the bridge structural condition. The data obtained from the MIRA will provide:

- Detection of the existence and size of damage

- Location of the damage

- Identification of the type of damage

- Quantification of the severity of the damage

Employing a health monitoring strategy begins with periodic measurements for the critical structural members through a NDT tool (i.e. MIRA 3D shear wave tomographer) to collect data to be integrated into a management system to estimate the structural performance. This management system requires a monitoring strategy to model the structure in order to obtain the reliability and condition of the structure. The NDT technique will determine the presence of any anomalies such as cracks, which then trigger further investigation to determine the width/spacing of the crack present and compare them with the allowable limits. In general, it is desirable to limit cracks widths/spacing under serviceability limitations to avoid aesthetics and durability issues. The validity of code prescribed crack width and spacing computations have been studied extensively, and it has been found that code based computations can be modified for thick structural members, like the piers of the Rebecca Street Bridge. Thus, the Crack Width Model (Dawood and Marzouk, 2011) and Neural Analysis (Elshafey et al., 2013) will be utilized to compute the crack width and spacing respectively. In addition, the dynamic modulus of elasticity is computed using the shear wave velocities obtained for the piers and abutments during the scanning phase and are transformed into dynamic modulus of elasticity values using adopted models (Popovics et al., 2008; Birgul, 2009). The obtained dynamic modulus of elasticity values are used to compare them to the elasticity values at the time of construction in order to measure the deterioration of the piers and abutments over time. 
This investigation will develop a monitoring strategy for the structure based on reliability analytical models, which would allow for lifetime prediction models using probabilistic methods. The moment-curvature plot is obtained for the bridge piers in order to establish the allowable limits. Although the strains in these members are not monitored continuously, the plot serves as a comparative value for future analysis. Furthermore, a tailored prognosis model is developed for the bridge in order to address the various deteriorating members (i.e. abutments, piers, steel girders, deck). The prognosis model is based on the Bridge Condition Index (BCI) values obtained during the periodic visual inspections of the bridge, as required by the Ministry of Transportation of Ontario (MTO, 2014). A BCI value less than 65 is used as a trigger mechanism to initiate maintenance of the deteriorating members of the bridge. In addition, common maintenance procedures are discussed for the bridge deck, concrete piers and abutments, and steel girders. 


\section{Chapter 2 Literature Review}

\subsection{Background}

The aging and deterioration of existing structures is an ongoing phenomenon, and monitoring these structures is essential in prolonging their serviceability and life span. Structural health monitoring can be defined as the process of acquiring information regarding a structures behavior and performance to help maintain structural integrity. The two main purposes of SHM are:

- To measure the structural deterioration and to detect the presence of any defects using the MIRA 3D shear wave tomographer

- To develop a monitoring strategy (prognosis model) for the structure based on reliability analytical models, which would allow for lifetime prediction models using probabilistic methods

SHM techniques detect damage in terms of changes in the structural and modal parameters. As previously discussed, damage detection can be categorized into several levels: identification of the damage existence, knowledge of its locations, identification of its type, determination of the significance of the damage and remaining serviceable life. Damage identification can be based on changes in natural frequency, vibration mode, structural flexibility or stiffness, transfer function, or static information. Modern non-destructive evaluation techniques used these identification factors to detect the presence, nature, size and location of any damage.

\subsection{Mechanism of Stress Waves}

The scattering of ultrasonic waves within a concrete member allows for the collection of a vast amount of data, providing various characteristics of the interior quality of the member. Such information includes, the mix's gradation, de-bonding of reinforcement from the concrete paste, locating cracks within structural elements, and the overall internal structure of the concrete matrix. The significance of these waves is the ability to acquire data in real time, providing engineers with an effective method of determining the structural condition, to allow for timely and appropriate maintenance.

Acoustic stress waves have multiple forms of transmission within a solid specimen. In concrete samples, the main wave transmission methods are:

1. Pressure Wave (P-Wave) 
2. Rayleigh Wave (R-Wave)

3. Shear Wave (S-Wave)

\section{Pressure Wave (P-Wave)}

The Pressure wave, commonly referred to as a P-Wave is a linearly elastic wave, which travels within the bulk of the solid specimen. P-waves are transmitted longitudinally, and thus vibrate particles in the direction of travel. These waves are commonly utilized in non-destructive testing equipment such as the impact-Echo, providing useful one-dimensional imagery of the internal structure. The impact-echo utilizes a hammer to implement the stress wave into the specimen, from which a one-dimensional transducer receives the transmitted P-wave, providing information regarding the internal structure of the specimen. The P-wave velocity is usually around $4,000 \mathrm{~m} / \mathrm{s}$.

\section{Rayleigh Wave (R-Wave)}

The Rayleigh wave (R-Wave) is a surface wave, which travels in planes normal to the testing surface. The particles are vibrated normal to the direction of travel, thus making these waves useful in determining surface anomalies such as cracking. The depth of wave penetration is directly proportional to the wavelength. Any crack that spreads deeper into the test specimen than the wavelength of the transmitted wave would completely diminish the transmitted wave from a receiver placed on the opposite side of this crack (Aggelis and Shiotani, 2007). Figure 2.1a) illustrates how a wave with a smaller wavelength than the depth of the crack is blocked, with no transmission across the crack. Conversely, Figure 2.1b) illustrates how a wave transmits across when the wavelength is greater than the crack depth. Therefore, with this transmission, engineers can estimate the penetration depth of a given crack. The Rayleigh wave velocity is approximately $55-60 \%$ of the velocity of a pressure wave (P-Wave).
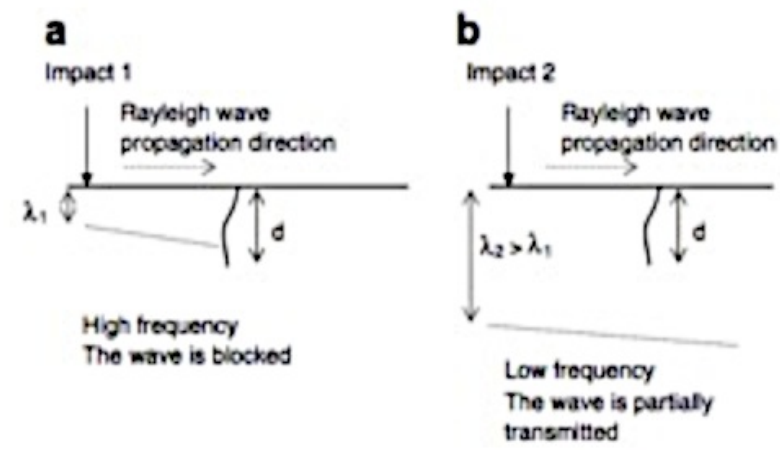

Figure 2.1 - Rayleigh Wave Propagation in Determining Cracks (Aggelis and Shiotani, 2007) 


\section{Shear Wave (S-Wave)}

The shear wave, also known as an S-wave or transverse wave, is a linearly elastic wave travelling within the bulk of the tested specimen. The shear wave vibrates particles perpendicular to the direction of travel, and provides a clearer image of the internal structure of the tested specimen than R-waves and P-waves. Due to the motion of the wave being perpendicular to the direction of travel, the shear wave would oscillate inside the sample. This oscillation provides a much higher chance that the wave will come in contact with an imperfection within the medium and reflect to the two dimensional transducer. Thus the shear wave is excellent when it comes to detecting small anomalies within the concrete specimen. Shear waves travel at approximately $60 \%$ of the velocity of P-waves.

\subsection{MIRA 3D Shear Wave Tomographer}

The MIRA 3D shear wave tomographer shown in Figure 2.2 is a non-destructive testing apparatus that utilizes 40 dry-point contact transducers that emit shear waves into the concrete member.

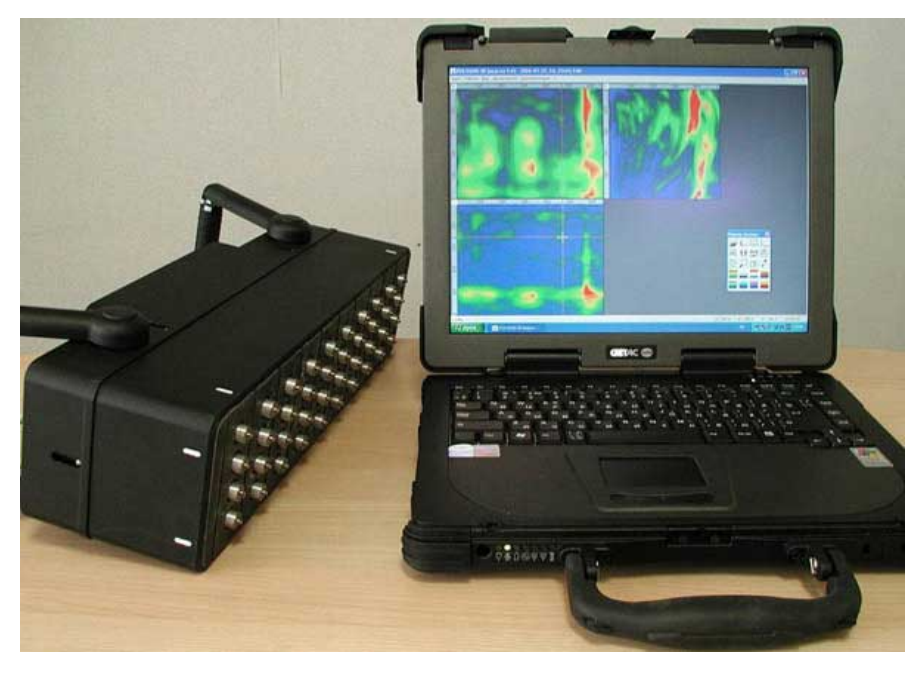

Figure 2.2 - MIRA 3D Shear Wave Tomographer Aparatus (Hoegh et al., 2012)

The transducers then receive the emitted waves, and the elapsed time is measured. The time elapsed for each reflected pulse is recorded and processed into a 3D representation of the tested member. The system is based on the transducers emitting and receiving stress-wave pulses in a "pitch-catch" configuration as shown in Figure 2.3. The process begins with the first row of transducers emitting a stress-wave, while the other 36 transducers receive the signal. Then, the 
next row sends a stress-wave, while the remaining 32 transducers receive the signal. The process is repeated until each of the nine rows of transducers have emitted stress-waves. The complete data acquisition, data processing, and data transfer takes less than 3 seconds.

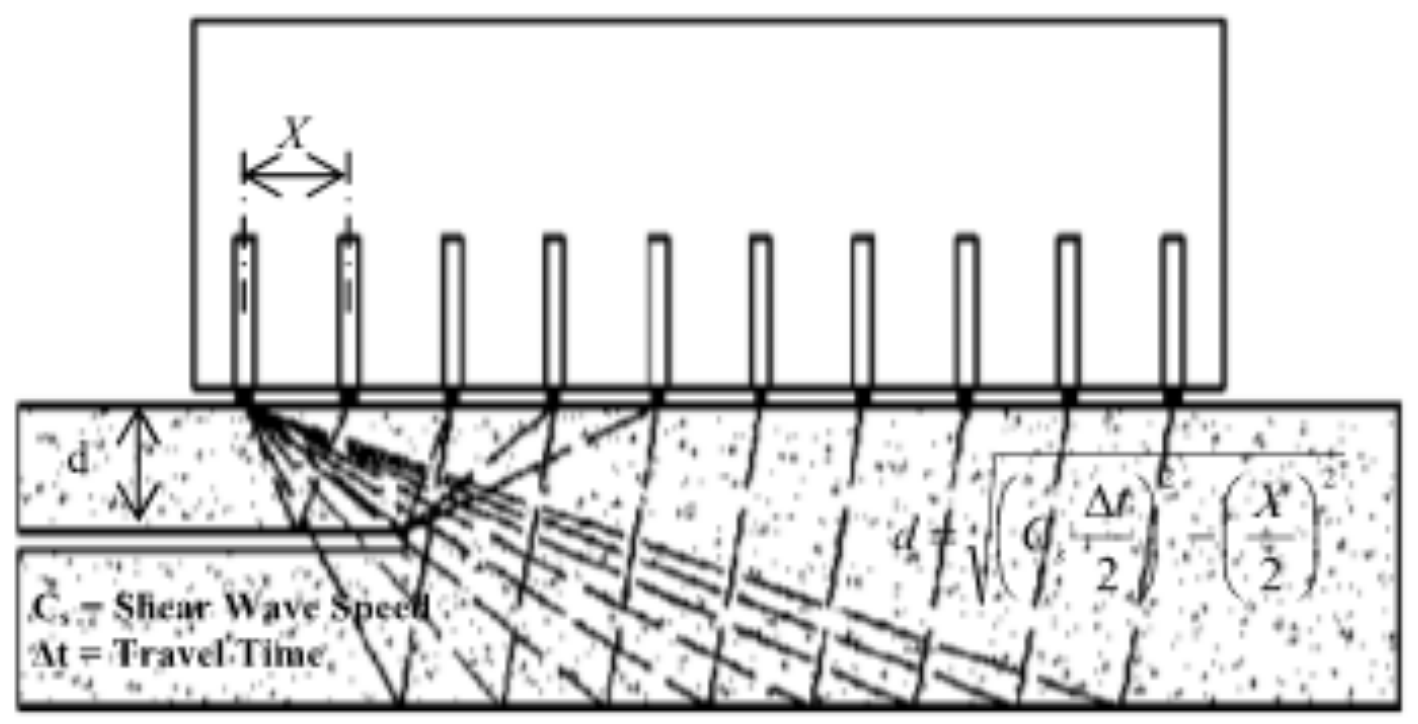

Figure 2.3 - Shear Wave Firing Sequence (Germann Instruments, 2014)

The inspection is carried out by predetermining a section of the member to be tested, and laying out a series of scan lines $500 \mathrm{~mm}$ apart on the testing surface. The antenna is oriented perpendicular to the scan direction and the data is recorded to create a 3D internal image of the member. The distance between successive antenna positions is dependent on the required nature of defects to be detected, with closer spacings for smaller defects.

The obtained data is processed using a technique known as synthetic aperture focusing (SAFT), which transforms the data along the scan lines into a 3D representation of the tested member. The main objective is to determine the depth and orientation of any anomalies within the tested specimen. Equation 2.1 is used to determine the depth (d) of the reflector by relating the pulse arrival times $(\Delta t)$, and the shear wave speed $\left(\mathrm{C}_{\mathrm{s}}\right)$. The shear wave speed is predetermined by the MIRA during the intial calibration for the test object. The calibration procedure is explained in detail in Chapter 4. The 3D image obtained is represented on three orthogonal places denoted as B-scan, C-scan and D-scan as showin in Figure 2.4 and 2.5.

$$
d=C_{s} \frac{\Delta t}{2}
$$




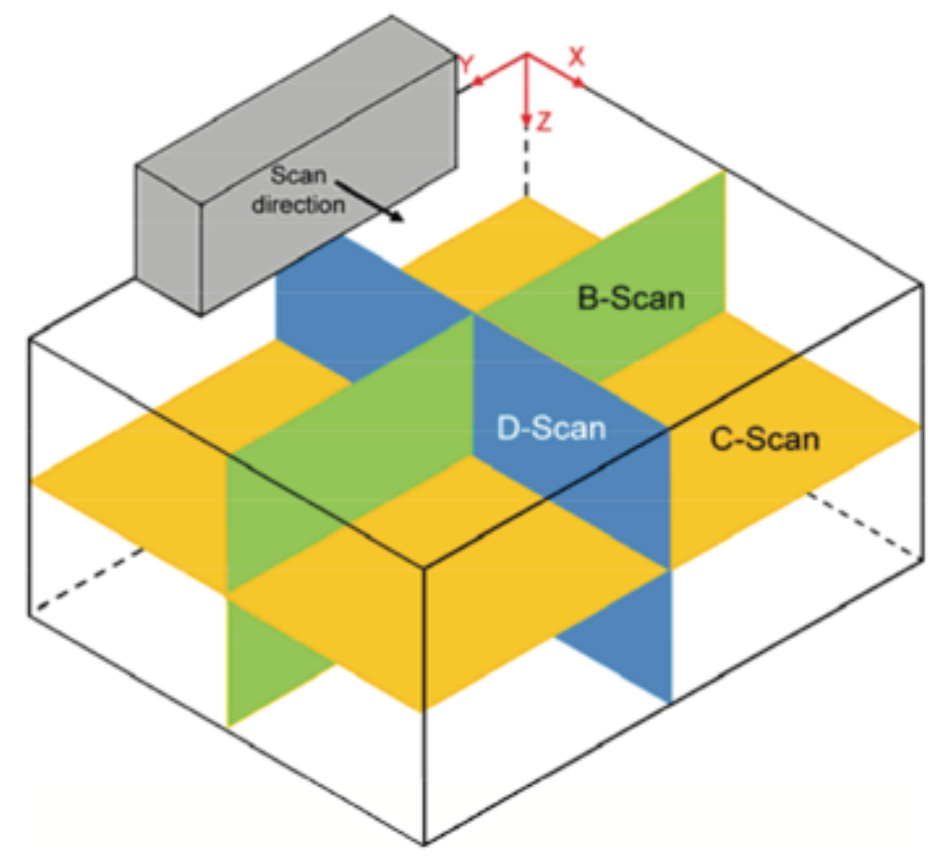

Figure 2.4 - Orthogonal Planes of the MIRA 3D Shear Wave Tomographer (Germann Instruments, 2014)

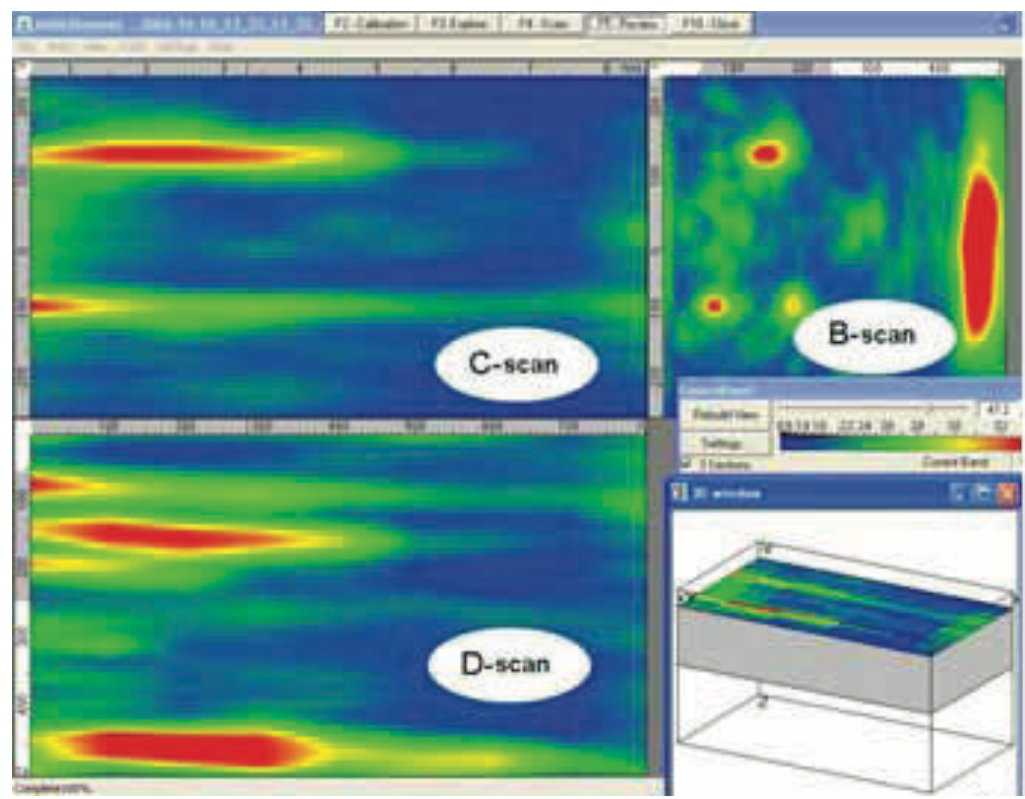

Figure 2.5 - B, C, and D Scan Results of a Typical Scan (Germann Instruments, 2014)

The MIRA 3D shear wave tomographer has been applied successfully to detect various defects. The anomalies will show as different colors based on their density characteristics as shown in Figure 2.6. The reflected image provides information such as:

- Thickness of member

- Detection of voids (cracks, delaminations, etc.) 
- Nature and size of voids

- Crack mapping

- Detection of voids in grouted tendon ducts

- Reinforcement or inclusion location

- Detection of poor-quality bond members

- Presence of clay balls

- Poor consolidation

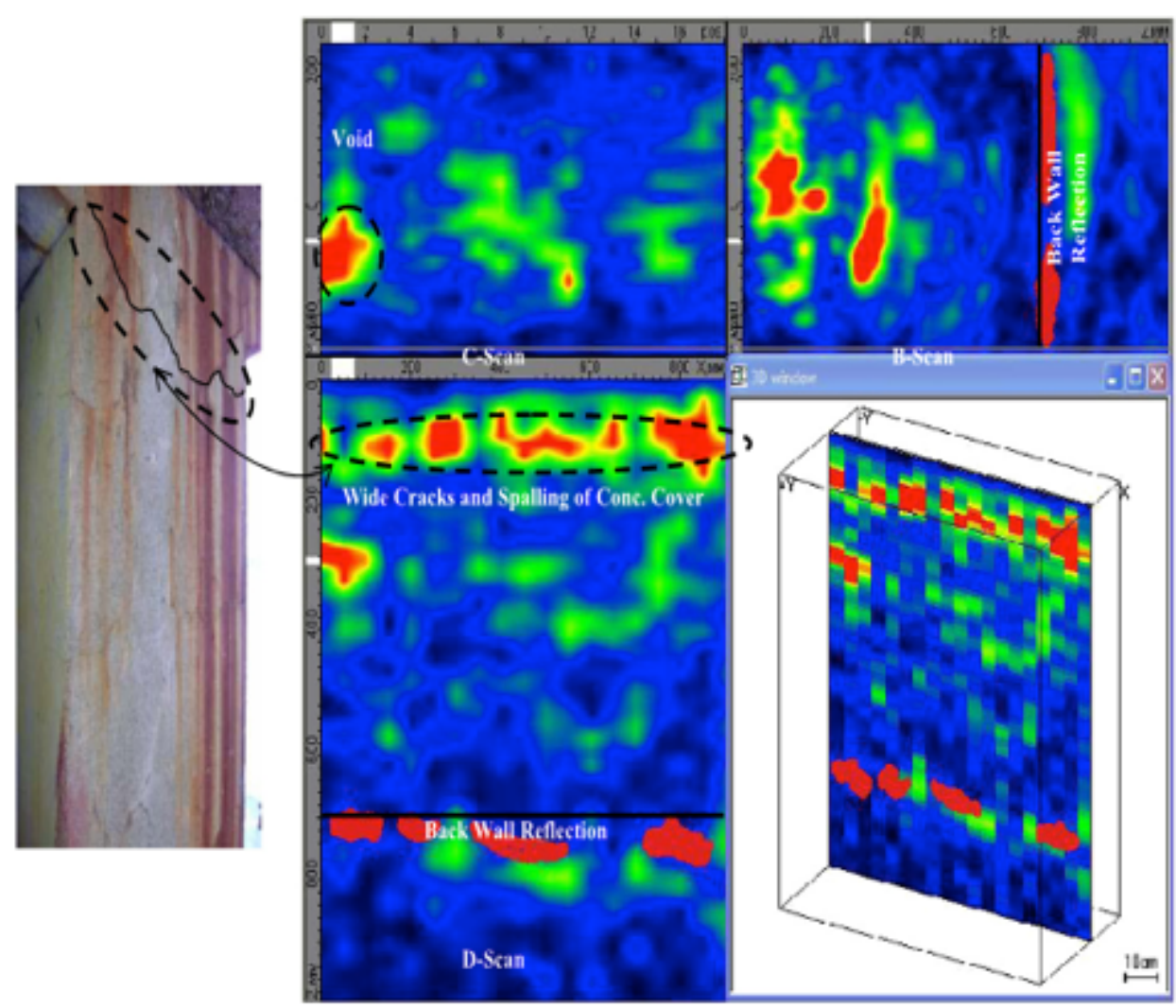

Figure 2.6 - Scan Results Indicating Cracks and Spalling (Dawood and Marzouk, 2011)

\subsection{Impact-Echo Testing}

The impact-echo is another nondestructive testing technique used for concrete and masonry structures. The testing procedure is based on the use of impact-generated stress (sound) waves that propagate through the member which are reflected by internal flaws and external surfaces. The stress pulse is introduced into the test medium via a transducer (pulse-echo) or by mechanical impact (impact-echo). Impact-echo has been utilized successfully in the past to determine the thickness of slabs, location and extent of flaws such as cracks, delamination, voids, 
and debonding in various concrete structures (slabs, columns, etc.)(Sansalone and Streett, 1997). Figure 2.7 illustrates a schematic diagram of the impact-echo method.
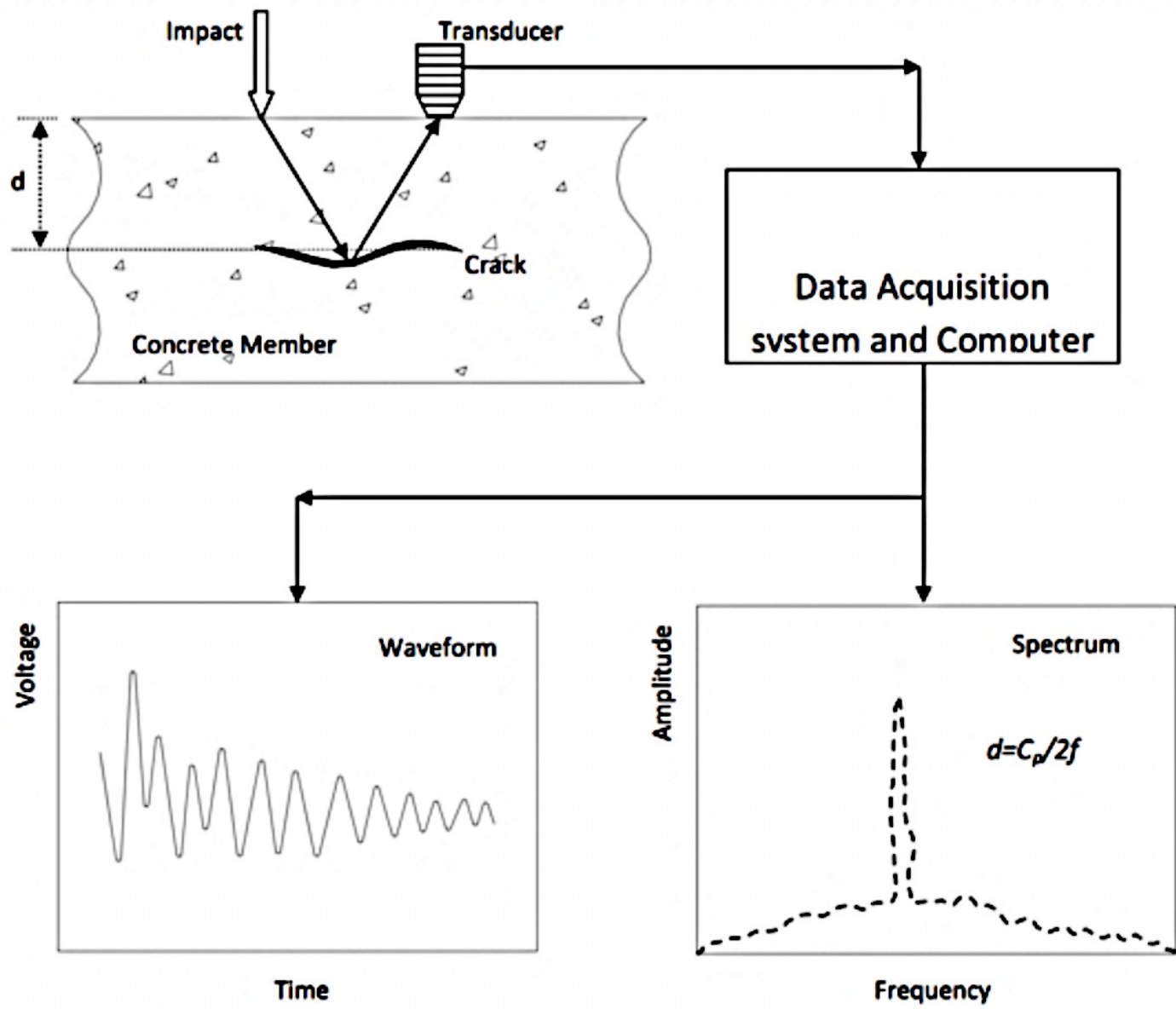

Figure 2.7 - Schematic Diagram of Impact-Echo Method (Sansalone and Streett, 1997)

The impact-echo involves a short-duration mechanical impact, produced by tapping a small steel sphere against the specimen surface. The transducer is located adjacent to the impact, which is used to record the surface displacement caused by reflections of the waves from flaws and/or external surfaces. The relationship between displacements and time signals are transformed into the frequency domain, and the amplitude versus frequency relationship is obtained (Sansalone and Streett, 1997). The integrity of the structure and the location of flaws are determined by using multiple reflections of stress waves between the impact surface, flaws, and other external surfaces to give rise to transient resonances, which can be identified in the spectrum. The patterns of the waveforms and spectra provide information regarding the presence and location of flaws, and the thickness of the tested member. The transient waves introduced into the test medium travel as dilatational Pressure (P) and distortional Shear (S) waves and along 
the surface as a Rayleigh (R) waves (Sansalone and Streett, 1997). The P- and S-waves propagate into the medium along spherical wave fronts, as shown in Figure 2.8. These waves are reflected by internal cracks, voids and external boundaries of the structure.

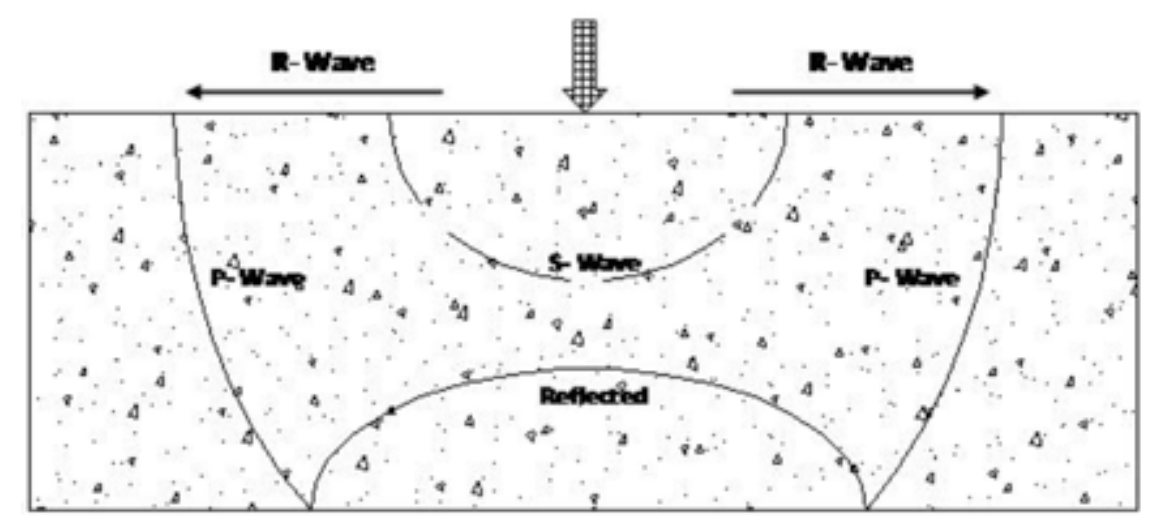

Figure 2.8 - Stress Waves Caused by Impact at a Point on the Surface of a Concrete Plate (Sansalone and Streett, 1997)

The impact-echo testing system consistent of three components:

1. A mechanical impact capable of producing short-duration impacts

2. A high-fidelity receiver to measure the surface response

3. A data acquisition-signal analysis system, that captures the output of the transducer, and stores the waveforms of surface motion, and performs signal processing and analysis (Sansalone and Streett, 1997; Lin and Sansalone, 1992).

A typical impact-echo test system is shown in Figure 2.9. The use of the equipment is dependent on the application, such as surface wave speed measurements, thickness measurements, or detection of flaws. Steel balls are often used as an impact source since the contact time can be changed by changing the diameter of the ball (Goldsmith, 1965). Grease-like material is often used to provide appropriate coupling between the transducer and the testing surface. In addition, the distance between the transducers is important in accurately measuring the flaw depth with the suggested spacing being 0.2 to 0.5 of the flaw depth (Carino and Sansalone, 1986) or less than $40 \%$ of the member depth (Sansalone, 1997). 


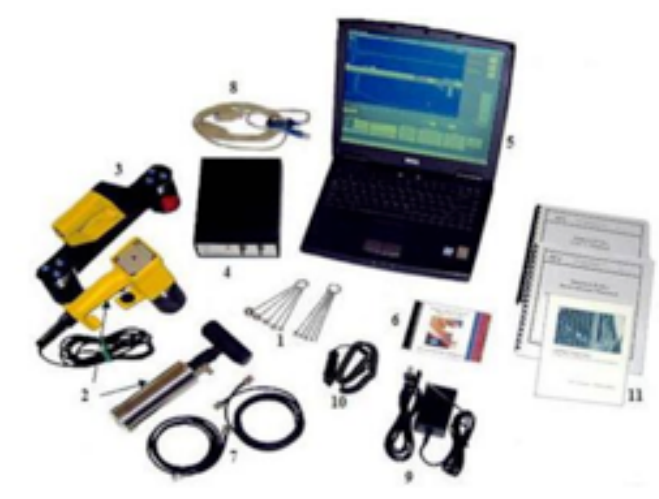

Basic test set-up for a direct $\mathrm{P}$-wave speed measurement

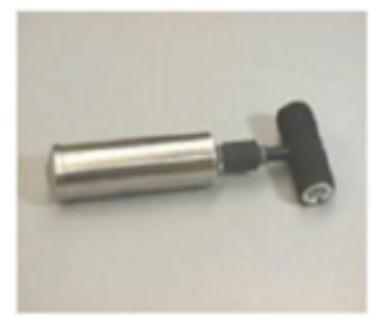

Cylindrical Trarsducer

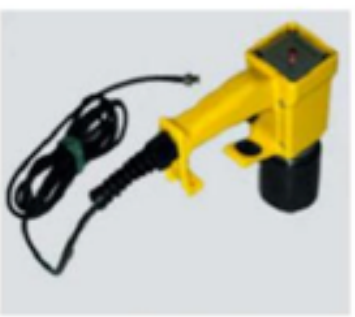

Pistol Grip Transducer

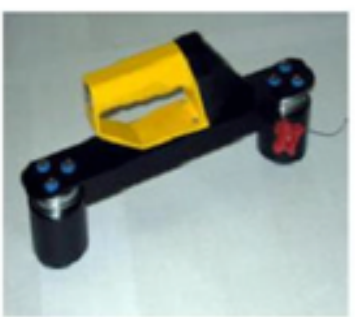

Dual-Head Transducer

Figure 2.9 - A Typical Impact-Echo Test System (Impact-Echo Instruments, 2001)

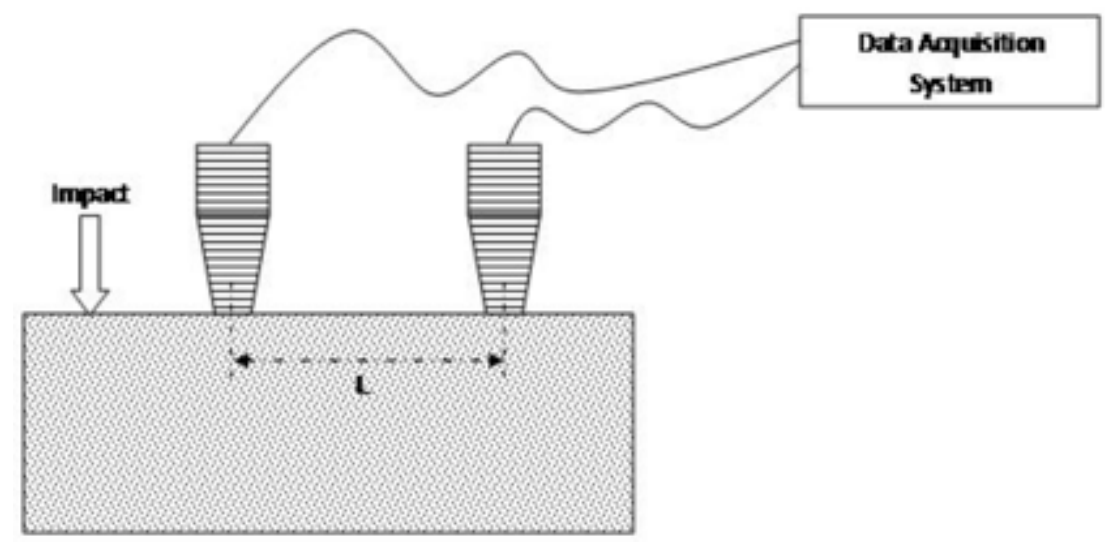

Figure 2.10 - P-Wave Speed Measurement Test Configuration (Sansalone and Streett, 1997)

P-waves play an integral role in impact-echo testing, since the displacements caused by Pwaves are significantly higher than those caused by S-waves near points located close to the impact point. In direct $\mathrm{P}$-wave speed measurement, the wave displacements are recorded by utilizing two adjacent transducers at a known distance apart as shown in Figure 2.10. The wave speed, $\mathrm{C}_{\mathrm{p}}$, is calculated in Equation 2.2, where $\mathrm{L}$ is the distance between the two transducers, and $\Delta \mathrm{t}$ is the time difference between the arrivals of the P-wave at the two transducers.

$$
C_{p}=\frac{L}{\Delta t}
$$


In cases where a solid plate is present, one large amplitude peak exists at a frequency, $\mathrm{f}$, corresponding to the multiple reflections of the P-wave between the top and bottom plate surfaces (Sansalone and Streett, 1997). The depth of the test object, d, and the presence of internal voids or cracks can be obtained by Equation 2.3 where $\mathrm{f}$ is the frequency of the $\mathrm{P}$-wave, and $\mathrm{C}_{\mathrm{p} \text {,plate }}$ is the $\mathrm{P}$-wave speed which is 96 percent of the $\mathrm{P}$-wave speed in an infinite medium $(\mathrm{Cp})($ Sansalone and Streett, 1997). The effects of the geometry of the cross-section on P-wave speed measurement are highlighted in Table 2.1. The impact-echo was utilized to determine the P-wave velocity of the tested specimens to be used in conjunctions with the S-wave velocity to determine the dynamic and static moduli of elasticity, which will be discussed in Chapter 3.

$$
d=\frac{C_{p, p l a t e}}{2 f}
$$

(Equation 2.3)

\begin{tabular}{|llc|}
\hline Element Type & Geometry of the Cross Section & Fundamental Equation \\
& & $\boldsymbol{f}=\boldsymbol{\beta} \frac{\boldsymbol{C}_{\boldsymbol{p}}}{2 \boldsymbol{T}}$ \\
\hline Plate (Slab, Deck, Wall) & Rectangular & $f=0.96 \frac{C_{p}}{2 T}$ \\
\hline Circular Column & Circular & $f=0.92 \frac{C_{p}}{2 T}$ \\
\hline Square Column or Beam & Square & $f=0.87 \frac{C_{p}}{2 T}$ \\
\hline
\end{tabular}

Table 2.1 - Impact-Echo Responses of Solid Structural Elements (Sansalone and Streett, 1997)

\subsection{Ultrasonic Wave Propagation}

Monitoring ultrasonic wave propagations in concrete provides key information, which can be used to determine the performance of the member or specimen. The initial part of signal processing is based on the velocity of the ultrasonic wave, which is proportionate to the density, modulus of elasticity, and Poisson's ratio of the material. Thus, by measuring the velocity of the ultrasonic wave, the density of the material and other essential characteristics can be determined.

The analysis can be carried out using the wave propagation of a one-dimensional longitudinal wave, expressed in Equation 2.4, where $C_{b}$ is the wave speed, $E$ is the modulus of elasticity and $\rho$ is the density of the material.

$$
c_{b}=\sqrt{E / \rho}
$$


The relationship in Equation 2.5 represents the power of the corresponding wave where $\omega$ is the angular frequency, and $\mathrm{A}$ is the amplitude of the wave.

$$
p=\frac{E A^{2} \omega^{2}}{2 c_{b}}
$$

Rearranging Equations 2.4 and 2.5 yields to Equation 2.6, which indicates that the wave amplitude is directly proportional to the modulus of elasticity of the material. The relationship obtained in Equation 2.6 is essential in correlating the wave propagation and the early strength of concrete. As concrete cures, and gains strength, the modulus of elasticity of the material increases rapidly and the amplitude of the wave diminishes.

$$
A=\left(\frac{1}{\omega}\right)\left(\frac{4 p^{2}}{E \rho}\right)^{0.25}
$$

The average CWI-Strain relationship could be analyzed, and used for the development of the desired CWI-crack width model. However, the model is separated into two distinct sections to address the slight variation noticed between the cracked and un-cracked specimen behavior. Based on an experimental investigation of sixteen tested beams, the CWI was calibrated to obtain Equation 2.7 (Hughi and Marzouk, 2014).

$$
\mathrm{CWI}=\sum_{n=0}^{\infty} \sqrt{\frac{\left(A_{f n, 0}-A_{f n, t}\right)^{2}}{\left(A_{f n, 0}\right)^{2}}}
$$

(Equation 2.7)

\subsection{Monitoring Strategy}

A monitoring strategy is a guideline for evaluating a structures performance in order to provide timely and appropriate maintenance. There are various steps in developing a monitoring strategy, which include, data collection, performance management and analysis, and developing assessment models. The strategy development process also includes determining the time increments of site visits, and the requirements of data collection techniques. Preliminary site visits allow engineers to visually inspect the structure to establish where sensors would need to be installed or where testing would need to be done for data collection. Figure 2.11 illustrates a typical structural health monitoring methodology. 


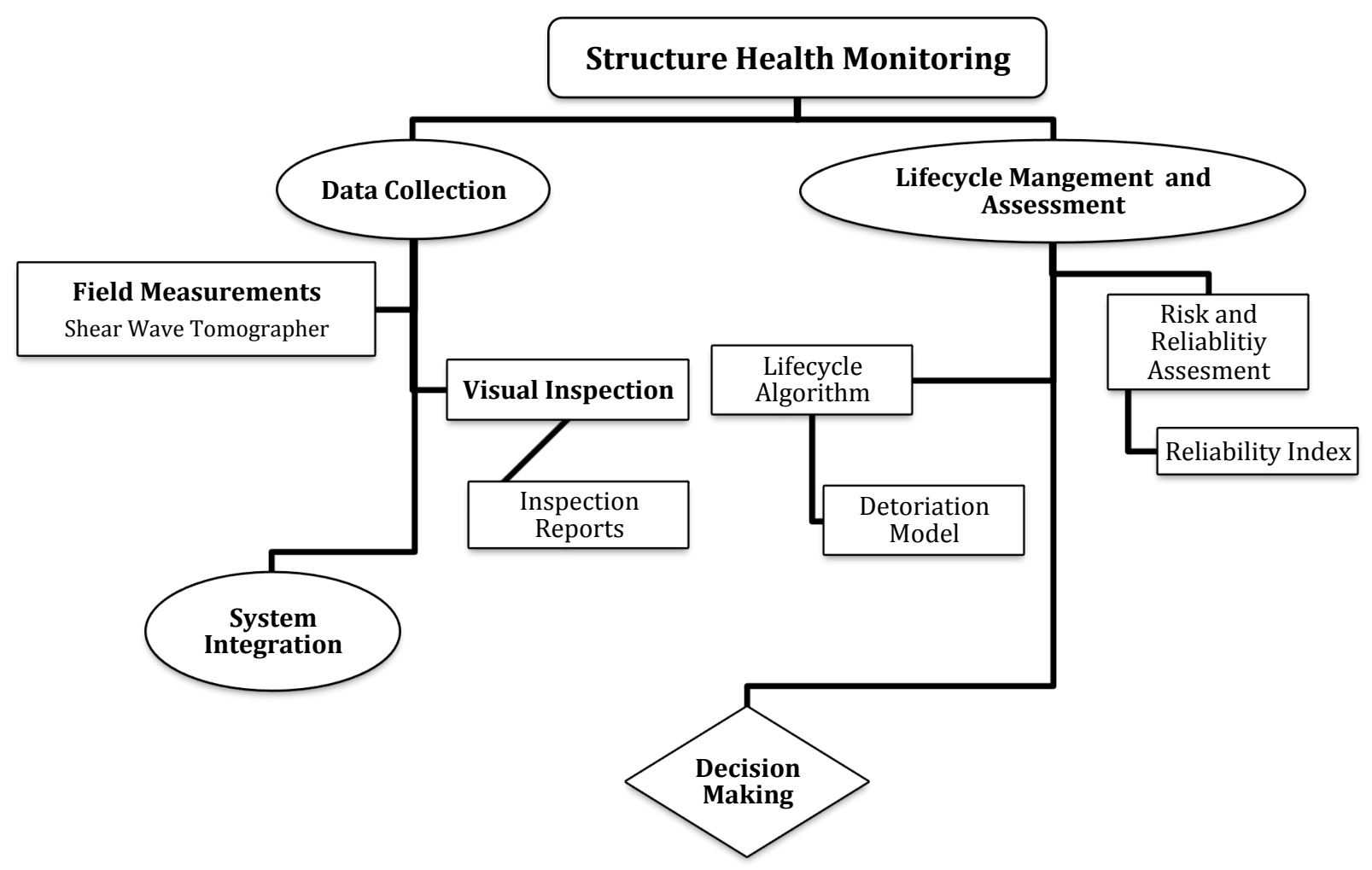

Figure 2.11 - Typical Structural Health Monitoring Methodology

\subsubsection{Data Collection}

SHM is based on the data reflecting changes in the response behavior of the structure due to applied loads. The data collected in this report are from visual inspections and MIRA scans (shear wave tomographer). As discussed previously, the scans will provide useful information and provide an internal map of structural members. The implemented monitoring strategy determined the scan and inspection intervals to be bi-weekly over a 6-month period. Although the behavior of the structure was not expected to change over such a short period of time, multiple scans were used to ensure the data obtained was accurate.

\subsubsection{Performance Management and Analysis}

Performance analysis is required in order to establish analytical models to represent the structures lifetime performance. Deterioration assessment is performed to predict the optimum time for maintenance, and to predict the remaining lifetime of the structure. There are two models 
that allow for this type of assessment, the random variable model and the stochastic model. The deterioration function developed will include factors such as durability, load capacity, serviceability and environmental factors. The developed numerical models will then allow for future predictions of structural behavior.

\subsubsection{Assessment Model}

A system for assessment of any detected damage allows for proper maintenance allocation, thus minimizing the associated cost. In addition, it allows for better engineering decisions by using performance indicators (i.e. mode shapes, damping and vibration intensity) to distinguish between conditions of the monitored structure. The assessment model will be developed by determination of the limit state function. This limit state function $(G)$ is evaluated as $G<0$ (structural element is unsafe), and $G \geq 0$ (structural element is safe). Since the direct calculation of the probability of failure is problematic, it is convenient to measure structural safety in terms of the reliability index $(\beta)$. The reliability index will then rank the structural member as safe, low risk, high risk, and failure. The recommended decision associated with these rankings is whether to provide maintenance, frequent inspection, or complete replacement.

\subsection{Factors Affecting Output Signals in Concrete}

Although the use of ultrasonic waves provides a high range of internal characteristics, it also poses many challenges to overcome; such as the attenuation of transmitted waves caused by the inhomogeneity of concrete. Attenuation is caused by the absorption and scattering of the induced wave. Scattering is a function of the maximum particle diameter, and will decrease as the particle size increases. Attenuation is caused by scattering, and will greatly affect the signal response due to the large reduction in signal strength coupled with an increased spectral response period caused by signal lag.

In concrete specimens, attenuation is primarily caused by the cement and sand in the mix. As the frequency and wavelength increase, small particles affect the transmitted signals more. In comparison, course aggregates aid in the transfer of a signal within the concrete matrix, whereas fine aggregates will absorb and scatter the signal.

The scattering and absorption of waves becomes problematic when trying to determine anomalies deep with the concrete specimen. However, to overcome this, and to obtain an accurate and clear image, a high frequency must be used to provide the smallest details within the tested sample. 


\subsection{Models for Crack Width, Crack Spacing and Dynamic Modulus of Elasticity}

A primary objective in this report is to model the crack width and crack spacing of the piers and abutments of the Rebecca Street Bridge. The obtained values are then checked against code limits to analyze whether they are satisfied. In addition, the shear wave velocities obtained during the scanning phase are utilized to obtain the dynamic modulus of elasticity of the concrete piers and abutments. The in-place elasticity values are then compared to the elasticity values during the time of construction and subsequent rehabilitation values to study the deterioration of these members over time. Chapter 3 discusses the models adopted in this report for modeling the crack width; crack spacing and dynamic modulus of elasticity. 


\section{Chapter 3 Establishing Crack Spacing and Width Limits}

\subsection{Cracking in Reinforced Concrete Structures}

Concrete is strong in compression; however, its low tensile strength is the primary cause of cracking. The crack width and spacing are important parameters to analyze to determine the vulnerability of the member to reinforcement corrosion. Designers often use code prescribed guidelines to control the crack width. Cracking of a reinforced concrete member may also cause a significant increase in deflection. The increase in deflection is due to the reduction in bending stiffness at cracked sections, resulting in diminishing tensile strengths below the neutral axis. However, at successive sections between cracks, some tensile stress is retained in the concrete around steel rebar's due to the bond contributing to the bending stiffness of the member. This phenomenon is known as the tension-stiffening effect.

Crack width models illustrate the relationship between the crack width, spacing and the distance between the reinforcing steel. Therefore, crack control can be achieved by limiting the spacing of the reinforcing steel. Thus, the maximum allowable bar spacing can be determined by limiting the crack width to acceptable limits.

\subsection{Crack Width Model for Thick Reinforced Concrete Members}

Code established serviceability constraints are designed to limit crack widths to avoid aesthetics and durability issues. Extensive research has been done in this field to attempt to study the cracking behavior of flexural reinforced concrete members (Clark, 1956; Frantz and Breen, 1980; Hwan and Jin, 1987; Frosch, 2002). A model for predicting the crack width along the length of the crack was adopted (Dawood and Marzouk, 2011). Therefore, the profile of the cracking opening along the length of the primary cracks can be developed. In addition, the research paper for developing the crack width model (Dawood and Marzouk, 2011) included the effects of the spacing between the longitudinal bars and concrete cover thickness on the crack width for axially loaded reinforced concrete members.

The model was validated by comparing test results with computed values based on the developed model for the crack width, as well as the available code approaches for estimating the value of the crack width (Dawood and Marzouk, 2011). Based on the analytical investigation, the following design equation was adopted to evaluate the crack width $\left(\mathrm{w}_{\mathrm{x}}\right)$ :

$$
w_{x}=0.17 \xi_{x} \alpha \frac{C}{\phi_{1}} S_{b} \varepsilon_{s m}
$$


Where $\mathrm{w}_{\mathrm{x}}$ is the crack width, $\xi_{x}$ is a factor to define the influence of longitudinal reinforcement on the local crack width value, $\alpha$ is the effective height of the concrete to concrete cover, $\mathrm{c}$ is the concrete cover, $\phi_{1}$ is the longitudinal bar diameter, $\mathrm{S}_{\mathrm{b}}$ is the spacing of longitudinal rebar's and $\varepsilon_{s m}$ is the average increase in strain of reinforcement relative to the adjacent concrete. As discussed previously, Equation 3.1 was validated based on data collected during test programs and compared to code prescribed approaches (EC2-2004, CEB-FIP 1990, CSA-S474-04, NS-3437E, and ACI 224R-01). Figure 3.1 shows the cracking response of panel HS-U-20-6-2.5. The concrete cover of this panel is $50 \mathrm{~mm}$, and the spacing between the reinforcing bars is $150 \mathrm{~mm}$. At the serviceability limit (2/3 $f_{y}$ ) (ACI 318R-08), the measured value for the crack width is $0.089 \mathrm{~mm}$, and the corresponding calculated values are $0.096,0.109$, 0.163, 0.214, 0.181, and $0.092 \mathrm{~mm}$, according to CSA-2004, NS-1992, EC2-2004, CEB-FIP 1990, ACI 224R-01, and the proposed model, respectively. Although the code based approaches demonstrate accurate results for panels with normal concrete cover $(\approx 40 \mathrm{~mm})$, they become increasingly sensitive as the concrete cover increases, thus overestimating the crack width. However, the proposed model shows accurate crack width values regardless of the concrete cover. Table 3.1 illustrates the values of average crack width at the serviceability limit $\left(2 / 3 f_{y}\right)$ using different approaches for evaluating the crack width.

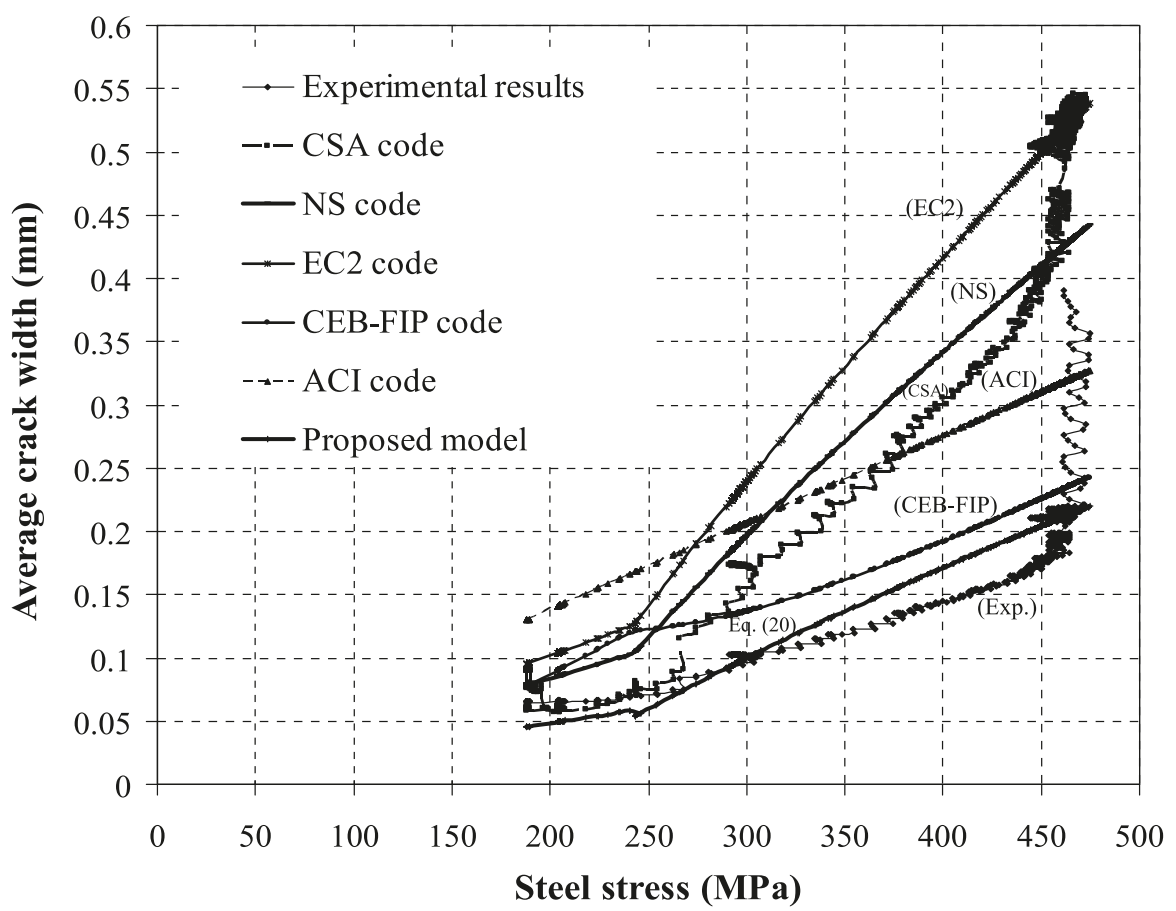

Figure 3.1 - Crack Width for Panel HS-U-20-2.5-6 (Dawood and Marzouk, 2011) 


\begin{tabular}{llllllll}
\hline Specimen & $\begin{array}{l}\text { Crack width } \\
(\mathrm{mm})\end{array}$ & CSA $(\mathrm{mm})$ & NS $(\mathrm{mm})$ & EC2 $(\mathrm{mm})$ & $\begin{array}{l}\text { CEB-FIP } \\
(\mathrm{mm})\end{array}$ & $\begin{array}{l}\text { ACI } \\
(\mathrm{mm})\end{array}$ & $\begin{array}{l}\text { Proposed } \\
\text { model }(\mathrm{mm})\end{array}$ \\
\hline NS-U-15-2.5-6 & 0.212 & 0.183 & 0.157 & 0.185 & 0.093 & 0.157 & 0.179 \\
NS-B-15-2.5-6 & 0.179 & 0.194 & 0.192 & 0.217 & 0.114 & 0.157 & 0.159 \\
HS-U-15-2.5-6 & - & 0.121 & 0.042 & 0.065 & 0.055 & 0.157 & 0.048 \\
HS-B-15-2.5-6 & 0.145 & 0.131 & 0.141 & 0.169 & 0.069 & 0.157 & 0.165 \\
HS-U-20-2.5-6 & 0.089 & 0.096 & 0.109 & 0.173 & 0.124 & 0.181 & 0.092 \\
HS-B-20-2.5-6 & 0.12 & 0.125 & 0.161 & 0.189 & 0.128 & 0.181 & 0.126 \\
HS-U-20-2.5-4 & 0.17 & 0.151 & 0.179 & 0.271 & 0.215 & 0.195 & 0.18 \\
HS-B-20-2.5-4 & 0.215 & 0.219 & 0.252 & 0.361 & 0.211 & 0.195 & 0.225 \\
HS-U-25-2.5-6 & 0.282 & 0.483 & 0.447 & 0.548 & 0.271 & 0.271 & 0.304 \\
HS-B-25-2.5-6 & 0.358 & 0.481 & 0.442 & 0.584 & 0.466 & 0.271 & 0.338 \\
HS-U-25-1.5-6 & 0.233 & 0.244 & 0.194 & 0.254 & 0.253 & 0.197 & 0.232 \\
HS-B-25-1.5-6 & 0.306 & 0.397 & 0.317 & 0.419 & 0.237 & 0.197 & 0.284 \\
HS-U-30-2.5-6 & 0.335 & 0.381 & 0.419 & 0.579 & 0.401 & 0.375 & 0.325 \\
HS-B-30-2.5-6 & 0.394 & 0.541 & 0.535 & 0.689 & 0.417 & 0.375 & 0.371 \\
HS-U-30-1.5-6 & 0.26 & 0.271 & 0.259 & 0.264 & 0.236 & 0.255 & 0.245 \\
Average $w_{\text {cal } / w_{\text {exp }}}$ & & 0.917 & 0.921 & 0.740 & 1.228 & 1.040 & 1.015 \\
Standard deviation $w_{\text {cal }} / w_{\text {exp }}$ & 0.162 & 0.185 & 0.200 & 0.446 & 0.264 & 0.0813 \\
Coefficient of variance & $w_{\text {cal } / w_{\text {exp }} \%}$ & 17.7 & 20.1 & 27.1 & 36.3 & 25.4 & 8.1
\end{tabular}

Table 3.1 - Measured Average Crack Width At service Load (2/3 $\left.f_{y}\right)($ Dawood and Marzouk, 2011)

\subsection{Crack Spacing for Concrete by Using Neural Networks}

Neural network techniques have proven to be successful in predicting the cracking behavior of reinforced concrete members. The procedure was introduced in Tokyo Bay, Japan to assess the damage of thermal power plants. Sensitivity analysis was carried out on a number of variables, such as maximum crack width, area of peeling concrete, and exposure of reinforcement on several damage levels (Yasuda et al., 1993). Crack width estimates under a given load are based on the magnitude of the tensile strain in the reinforcing steel, concrete cover, size of the rebar's, and the distribution of the steel in the tension zone (Carino and Clifton, 1995).

Neural network techniques have also been used to provide preliminary estimates of crack spacing based on regression analysis (Elshafey et al., 2013). A neural network is a mathematical technique used to model complex relationships between inputs and outputs or to find patterns in data (Elshafey et al., 2013). The adopted model (Elshafey et al., 2013) applied two types of neural networks and compared the results with existing equations in international codes. The first type is a radial basis function neural networks (RBFNN) and the second is a feed toward back propagation neural network (FFBPNN). However, the use of these functions can become complicated, therefore the study found a simple and efficient equation for calculating the average cracking spacing. Equation 3.2 considers the reinforcement bar diameter $\left(\mathrm{d}_{\mathrm{b}}\right)$, the spacing between rebar's $\left(\mathrm{S}_{\mathrm{b}}\right)$ and the concrete cover $(\mathrm{C})$; which are most significant parameters that affect crack spacing. 


$$
S_{a v}=1.90 d_{b}^{0.062} S_{b}^{0.514} C^{0.323}
$$

Equation 3.2 was validated based on its comparison to experimental results. Figure 3.2 illustrates the accuracy of the equation due to its similarity to experimental results. In addition, Equation 3.2 proved to be more accurate than other existing equations (CSA-2004, NS-1992, EC2-2004, CEB-FIP-1990, and ACI 224R-01). Figures 3.3 to 3.7 compare the various code prescribed equations to the experimental results.

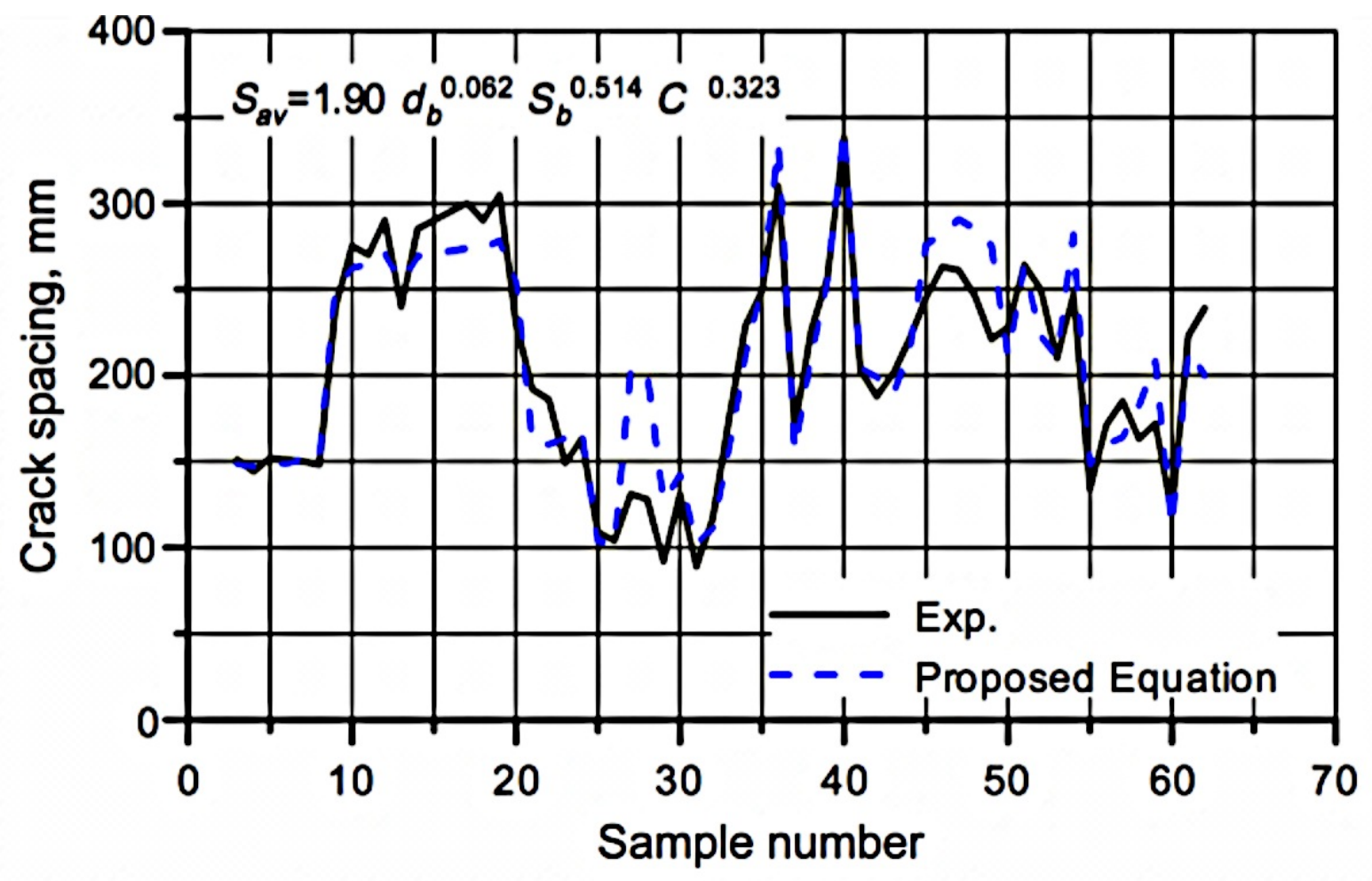

Figure 3.2 - Comparison Between Crack Spacing From Experimental Results and Proposed Equation (Elshafey et al., 2013) 


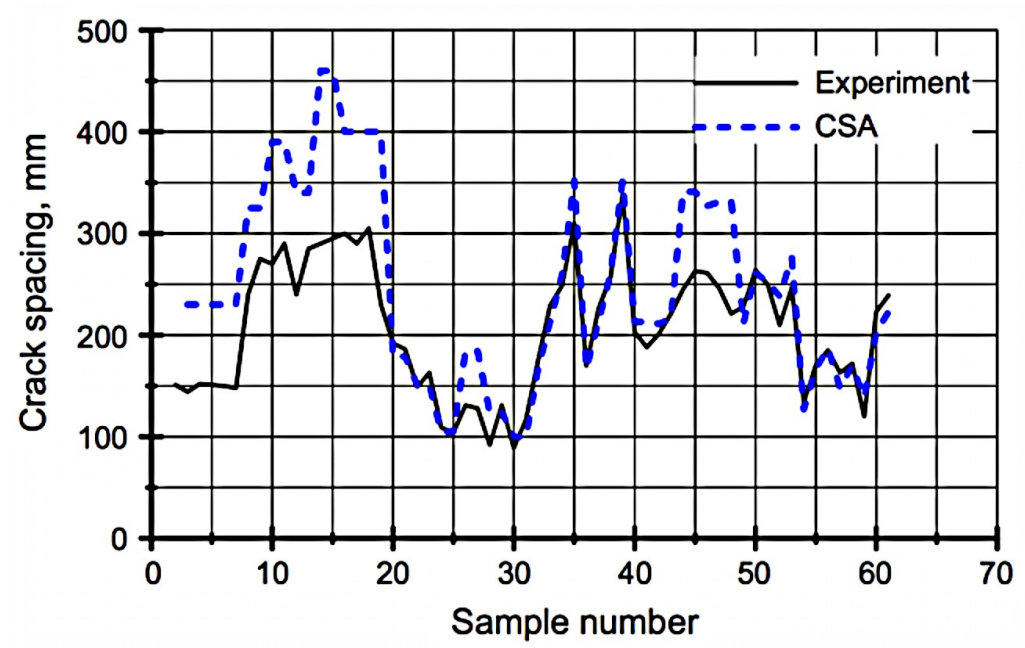

Figure 3.3 - Comparison Between Crack Spacing From Experimental Results CSA-2004 (Elshafey et al., 2013)

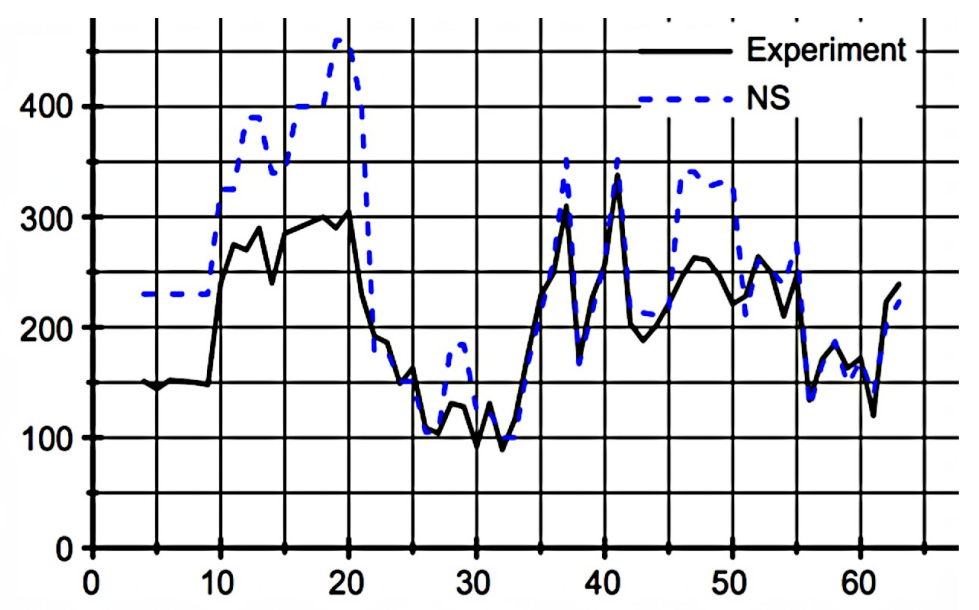

Figure 3.4 -Comparison Between Crack Spacing From Experimental Results and NS-1992 (Elshafey et al., 2013)

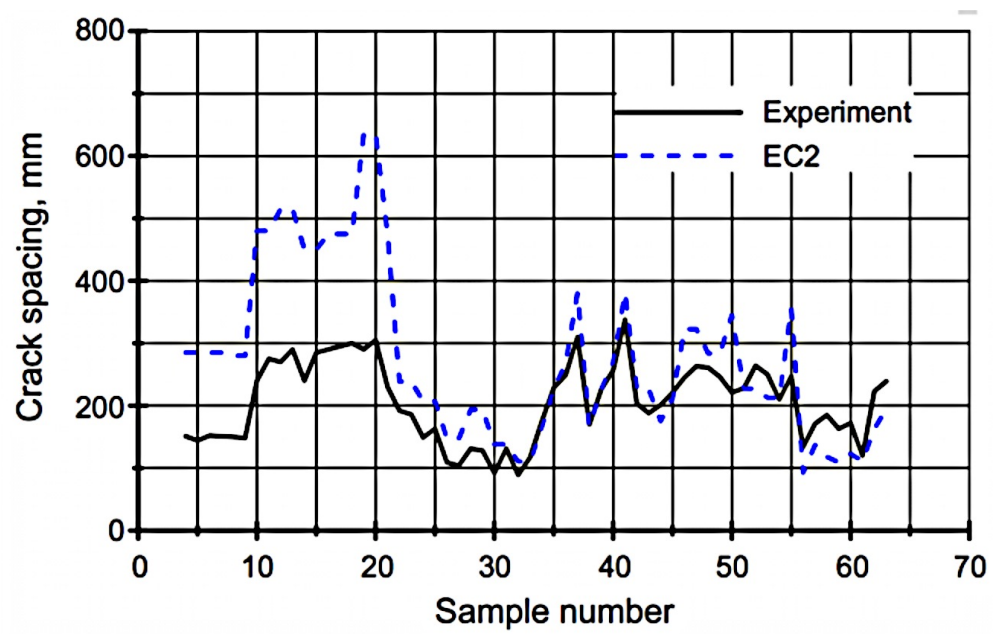

Figure 3.5 - Comparison Between Crack Spacing From Experimental Results and EC22004 (Elshafey et al., 2013) 


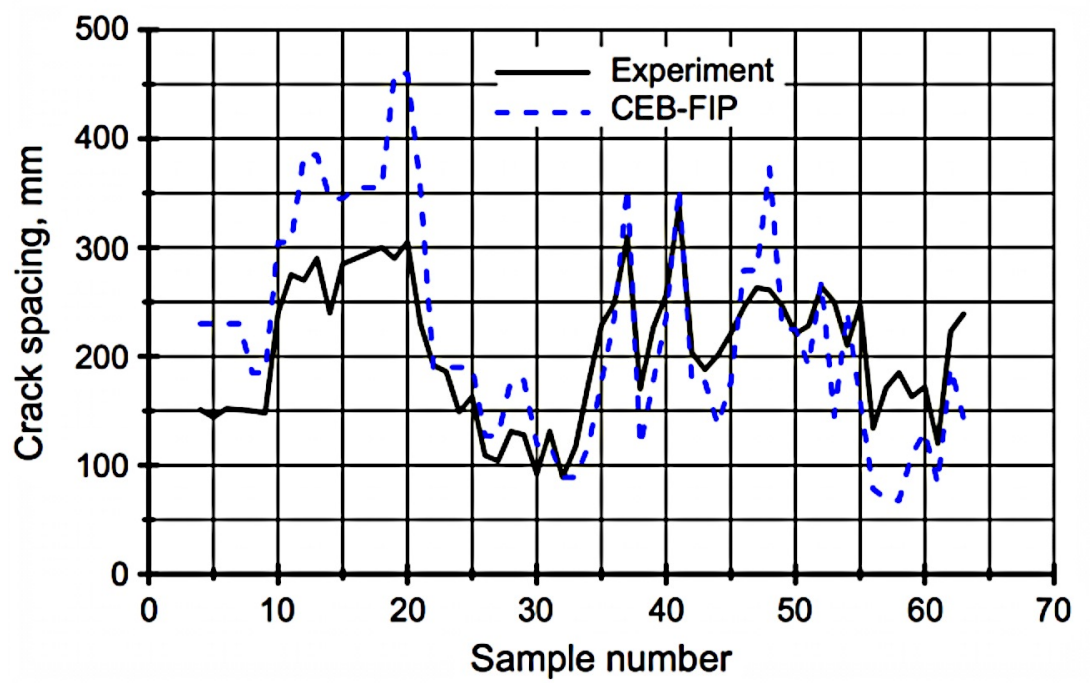

Figure 3.6 - Comparison Between Crack Spacing From Experimental Results and CEB-FIP 1990 (Elshafey et al., 2013)

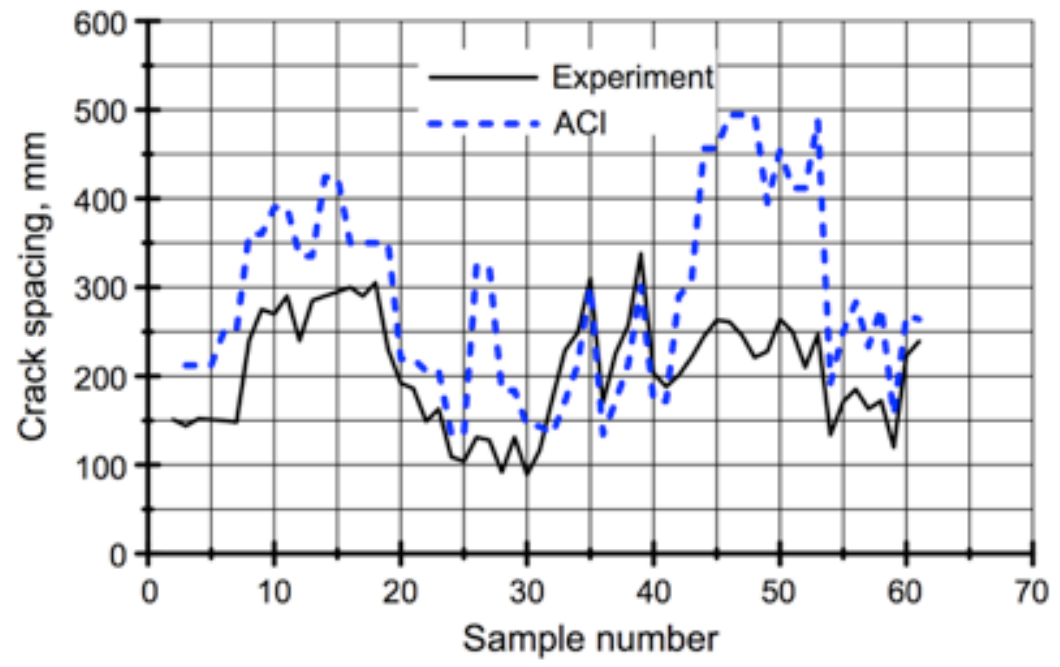

Figure 3.7 - Comparison Between Crack Spacing From Experimental Results and ACI 224R-01 (Elshafey et al., 2013)

\subsection{Static and Dynamic Modulus of Elasticity}

The static Young's modulus (E) is defined as the ratio of the axial stress to axial strain for a material subjected to a uni-axial load (Neville, 1997). In the design stage, the value of $\mathrm{E}$ is important in analyzing the cross-sectional response of a RC beam (Leet and Bernal, 1997). Building specifications require the modulus of elasticity to meet a certain limit in order to limit excessive deformation and sway, especially in tall buildings (Popovics et al., 2008).

Once a structure is erected, it becomes more difficult to determine the elastic properties without damaging the structure. The modulus of elasticity is often determined indirectly through empirical relations with the compressive strengths of concrete cylinders. However, this approach 
has proven to be overly conservative, since concrete with a significantly higher $f_{c}$ is used in order to meet the elastic property requirements, which leads to higher material costs.

Non-destructive methods can be used to estimate the in-place dynamic modulus of elasticity $\left(E_{d}\right)$. However, the dynamic modulus of elasticity is known to be higher than the elasticity obtained from direct static testing of a cylinder drawn from the structure. Thus, it is important to establish an appropriate relationship between the dynamic modulus of elasticity $\left(\mathrm{E}_{\mathrm{d}}\right)$ obtained from NDT result and the static modulus of elasticity $\left(E\right.$ or $\left.E_{\mathrm{s}}\right)$. Quasi-static and dynamic tests on concrete indicate that the relationship between stress and strain is nonlinear, even at infinitesimal values of deformation (Bell, 1984). The nonlinear stress-strain relationship is the reason that $\mathrm{E}_{\mathrm{d}}$ is higher than $\mathrm{E}$, since concrete specimens subjected to dynamic testing undergo significantly smaller strains (Neville, 1997). For both lightweight and normal concrete members, a general relationship between the static and dynamic modulus of elasticity was developed, as shown in Equation 3.3 (Popovics et al., 2008). Where $\mathrm{k}=0.23$ for units of psi and $p$ is the density in $\mathrm{lb} / \mathrm{ft}^{3}$. The relationship between the static and dynamic modulus of elasticity is unaffected by air entrainment, method of curing, or type of cement used (Neville, 1997).

$$
E_{s}=k E_{d}^{1.4} p^{-1}
$$

(Equation 3.3)

The MIRA 3D shear wave tomographer and impact-echo provide the average S-wave and $\mathrm{P}$-wave velocities respectively for each member scanned. Thus, by using the S-wave and P-wave velocities, the dynamic modulus of elasticity can be computed, which then allows the static modulus of elasticity to be computed through Equation 3.3. The adopted model (Birgul, 2009) transforms S-wave and P-wave velocities to obtain the dynamic modulus of elasticity, as shown in Equations 3.4 and 3.5. Thus by back substituting Equation 3.5 into 3.3, the static modulus of elasticity can be obtained.

$$
\begin{gathered}
v=\frac{1-2\left(\frac{V_{s}}{V_{P}}\right)^{2}}{2-2\left(\frac{V_{S}}{V_{p}}\right)^{2}} \\
E_{d}=2 p V_{s}^{2}(1+v)
\end{gathered}
$$

The static modulus of elasticity (E) can then be used as an indicator of the condition of the in-place concrete. The comparison between the initial E during construction and the in-place 
E during subsequent scans provides a basis for how the concrete has deteriorated throughout time. Monitoring the elasticity values provides another benchmark for determining the timing and type of maintenance required. Equations 3.3, 3.4 and 3.5 were used to compute the dynamic and static moduli of elasticity for the bridge pier columns and abutments and are discussed in Chapter 4. 


\section{Chapter 4 Monitoring of the Piers and Abutments}

\subsection{Introduction}

The piers and abutments of the Rebecca Street Bridge were monitored on a bi-weekly schedule over a six-month period. The investigation consisted of both visual inspections and shear wave scans; however the scans were carried out at the lower portions of the bridge piers due to the limited site access. Piers 1 and 4 and the east abutment were not accessible, thus these members were only visually inspected. The scan results were studied in several phases; firstly the obtained wave velocities were transformed into dynamic and static moduli of elasticity to compare with the initial (upon construction) values. Secondly, the MIRA shear wave scan images were studied for visible damage. The internal map provided was used to locate any cracking present, and to determine the size and severity of the crack. The data obtained also sets a benchmark for future investigations by serving as comparative values. The health monitoring strategy implemented on the Rebecca Street Bridge will utilize the obtained dynamic modulus of elasticity and cracking maps to compare future scan values to present maps obtained during this investigation. Thus, the precise deterioration of the bridge members can be assessed throughout its life, which will allow for timely and appropriate maintenance allocation.

\subsection{Velocity Calibration and Wave Frequency Adjustment}

The MIRA shear wave velocity is calibrated to the concrete characteristics of the testing object. The calibration process involves firing waves at various locations on the member to obtain an average calibrated velocity. The calibration process ensures high quality scans, providing a more accurate representation of the member scanned. In addition to the velocity assessment, the wave frequency used significantly changes the results obtained. The wave frequency of the scans is used as an adjustment for the amount of information collected. The higher the frequency, the less information is obtained on regions embedded deep within the tested specimen. The use of high frequencies is utilized in situations where a clearer image is required, indicating major deterioration. Lower frequencies are used to provide high sensitivity to any changes within the specimen. However, low frequencies provide a less accurate representation of real life results. In general, the depth of the specimen and the amount of reinforcement will greatly affect the information gathered by the MIRA. Thus, frequency adjustments are important in obtaining clear and comprehensive shear wave scans. 


\subsection{Evaluation of the West Abutment}

The west abutment was scanned at various locations to determine the overall structural condition. The scans were carried out at a frequency of $50 \mathrm{~Hz}$ and a calibrated wave velocity of 2,487 m/s. Although minor cracks were visually noted, the MIRA shear wave scans indicated no deterioration present. The scan shown in Figure 4.1 suggests the abutment is in good structural condition, and no structural defects are present. Since no deterioration is present at a fairly low frequency of $50 \mathrm{~Hz}$, it can be concluded that the member only has minor aesthetic issues as noted in the visual inspection (Figure 4.2), and has no structural defects.
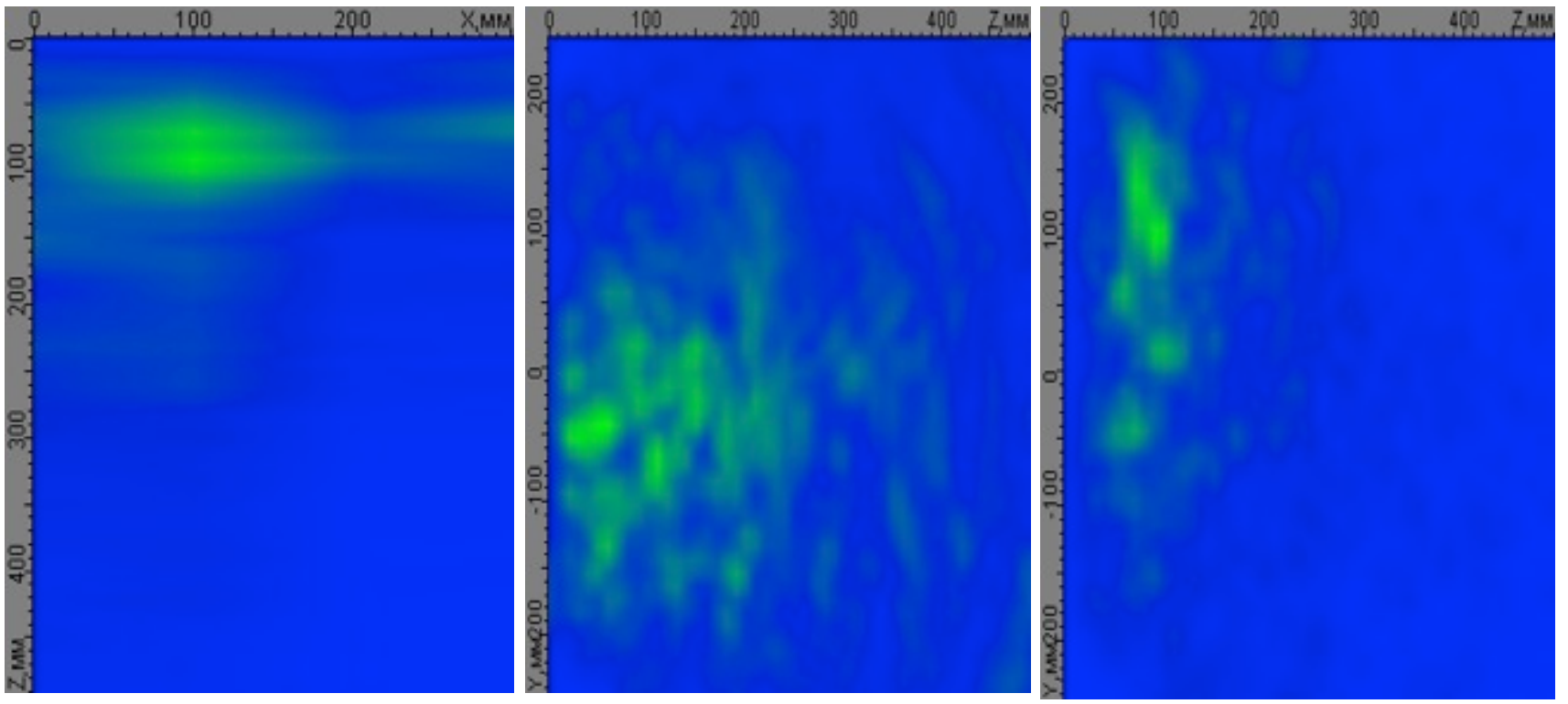

Figure 4.1 - C-Scan (left), B-Scan (middle), and D-Scan (right) of the West Abutment Indicating No Deterioration

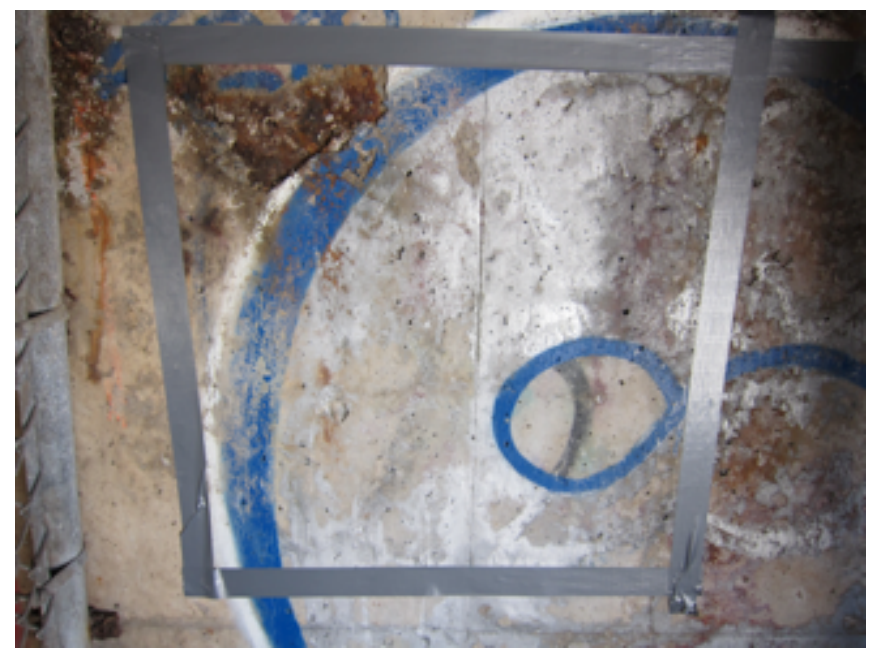

Figure 4.2 - West Abutment Scan Outline 


\subsection{Evaluation of the Bridge Piers}

The aim of this test was to select portions of each pier column that exhibited surface deterioration such as cracks, delamination or honeycombing or portions patched from previous repairs, and further analyze the section via the MIRA 3D shear wave tomographer. In order to achieve meaningful results, a $300 \mathrm{~mm}$ x $300 \mathrm{~mm}$ area was mapped for each scan. Velocity calibrations and frequency adjustments were carried out to provide the clearest image to allow for accurate conclusions to be made. The following section will discuss the findings from the scans of piers $2-7$ inclusively. The pier column numbering is in accordance to the drawings provided by Cole Engineering.

\subsubsection{Pier 2}

Pier 2-1 was scanned on the North-South face (Figure 4.3), with an initial frequency of 50 $\mathrm{Hz}$. The wave velocity was calibrated to $2,449 \mathrm{~m} / \mathrm{s}$ for this pier, which will be utilized in the latter portions of this report to compute the dynamic modulus of elasticity. The shear wave scan was done over a patched portion of the pier, and the resulted 3D image indicated a high presence of inconsistencies (Figure 4.4.). However, to overcome this, the MIRA was adjusted to a frequency of $70 \mathrm{~Hz}$, to provide a clearer image of the member (Figure 4.5). The image indicates the presence of potential voids concentrated at around $100 \mathrm{~mm}-250 \mathrm{~mm}$ from the face of the support. However, to isolate the findings further, an additional scan was carried out at $100 \mathrm{~Hz}$ (Figure 4.6). The high degree of red present in the first two scans is highly due to the MIRA detecting the patched portion of member. However, the higher frequency scan clears up the image, highlighting potential voids present as a result of reinforcement corrosion. This conclusion is evident by the voids present in a line as noted in the B, C, and D-scans. However, the small voids present are not severe at this point, but should be considered in future analysis of pier 2-1. The comparison of the B-scans $(50 \mathrm{~Hz}, 70 \mathrm{~Hz}$, and $100 \mathrm{~Hz})$ is illustrated in Figure 4.7, which illustrates how the frequency adjustment isolates the deterioration. Although the voids noted in the $100 \mathrm{~Hz}$ scan are small in size, to make a conclusive decision, additional scans should be carried out at different elevations over the member to provide insight of the overall structural condition. 


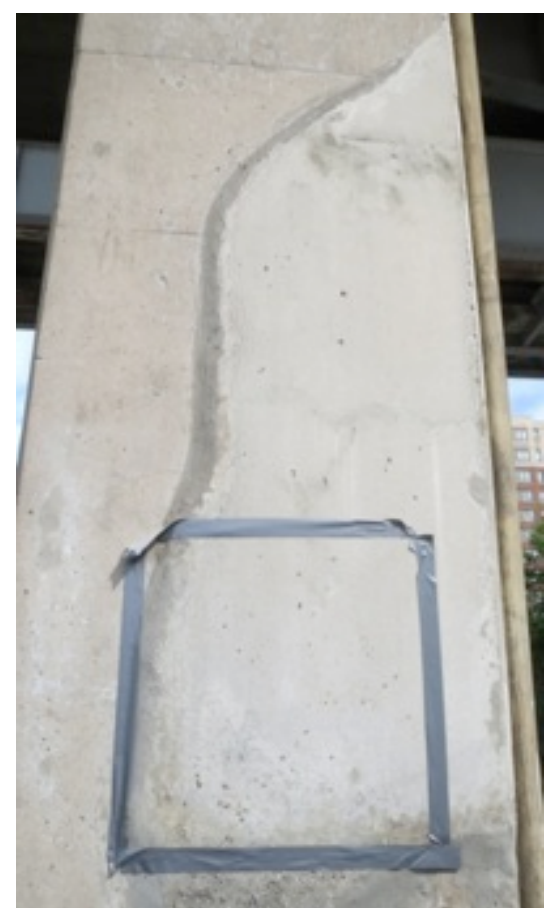

Figure 4.3 - Pier 2-1 Scan Outline

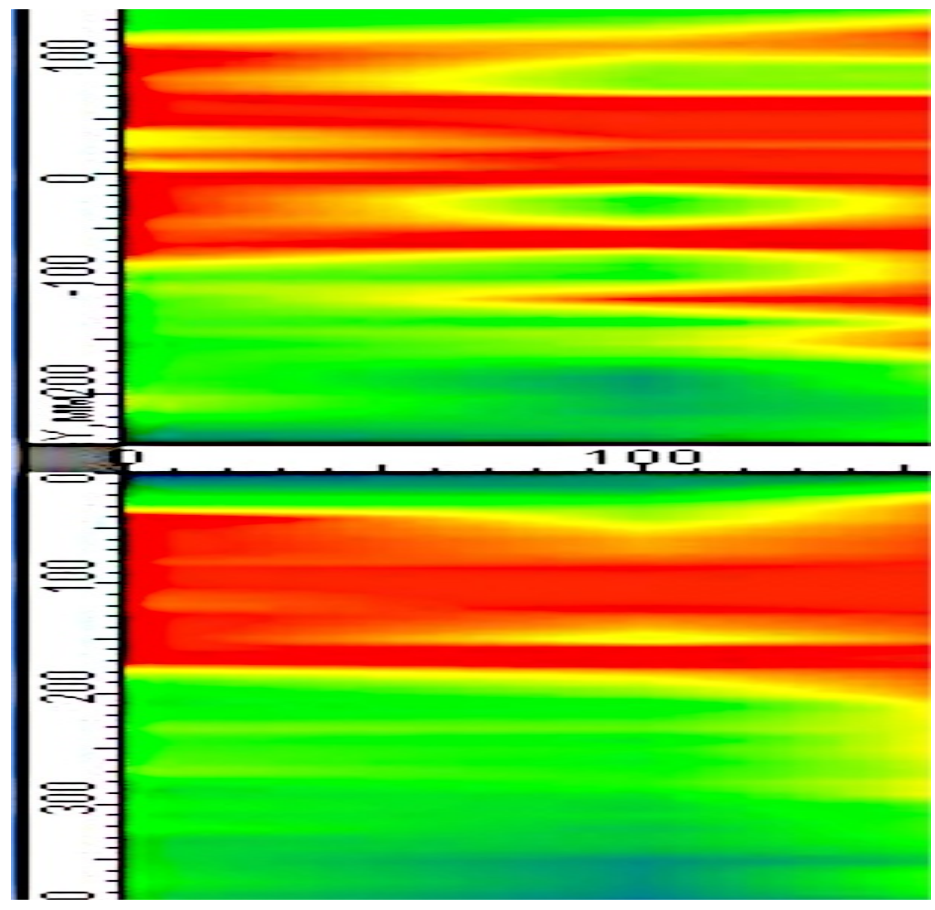

Figure 4.4 - 50 Hz Scan Results from Pier 2-1

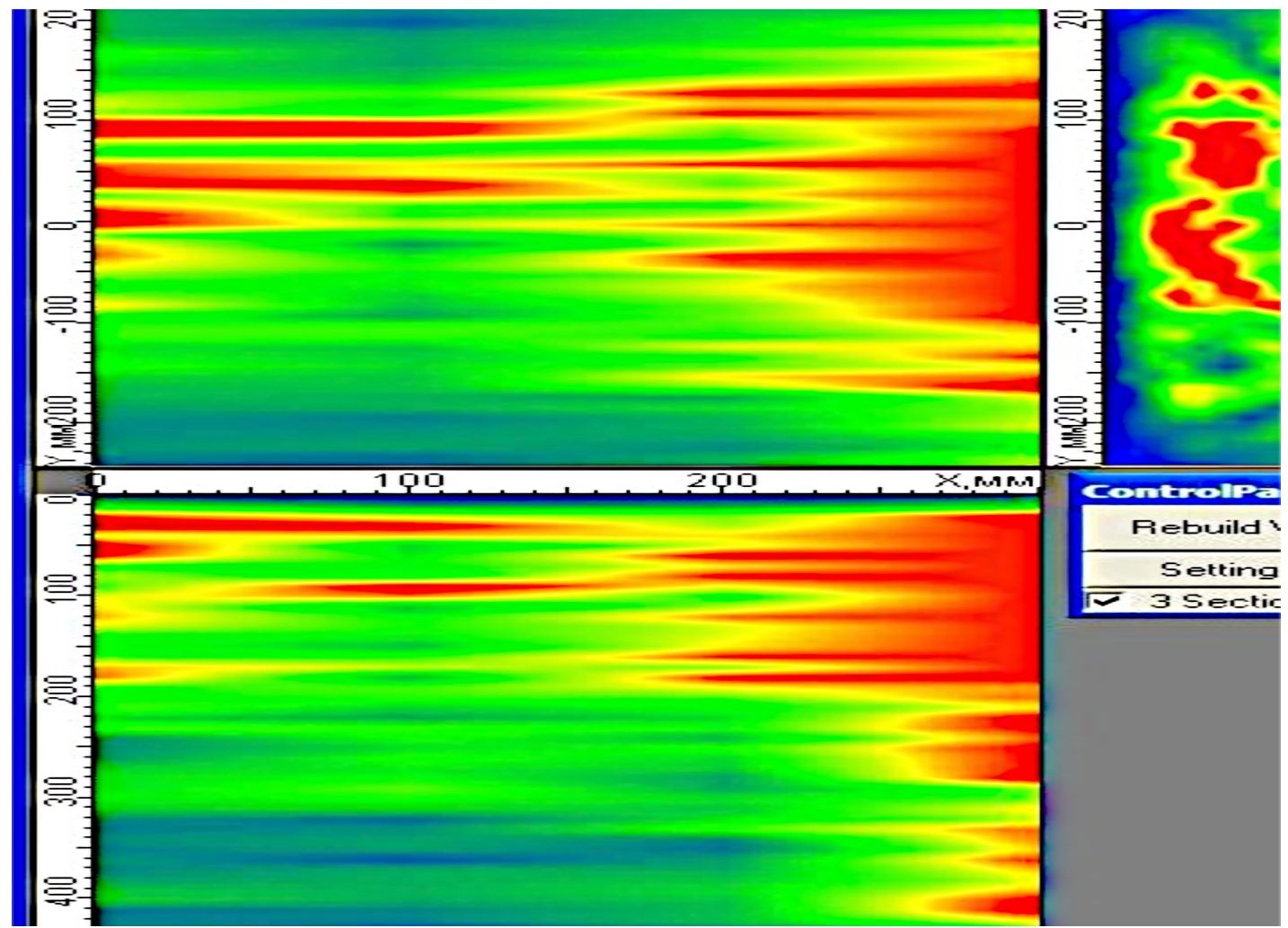

Figure 4.5- 70 Hz Scan Result from Pier 2-1 


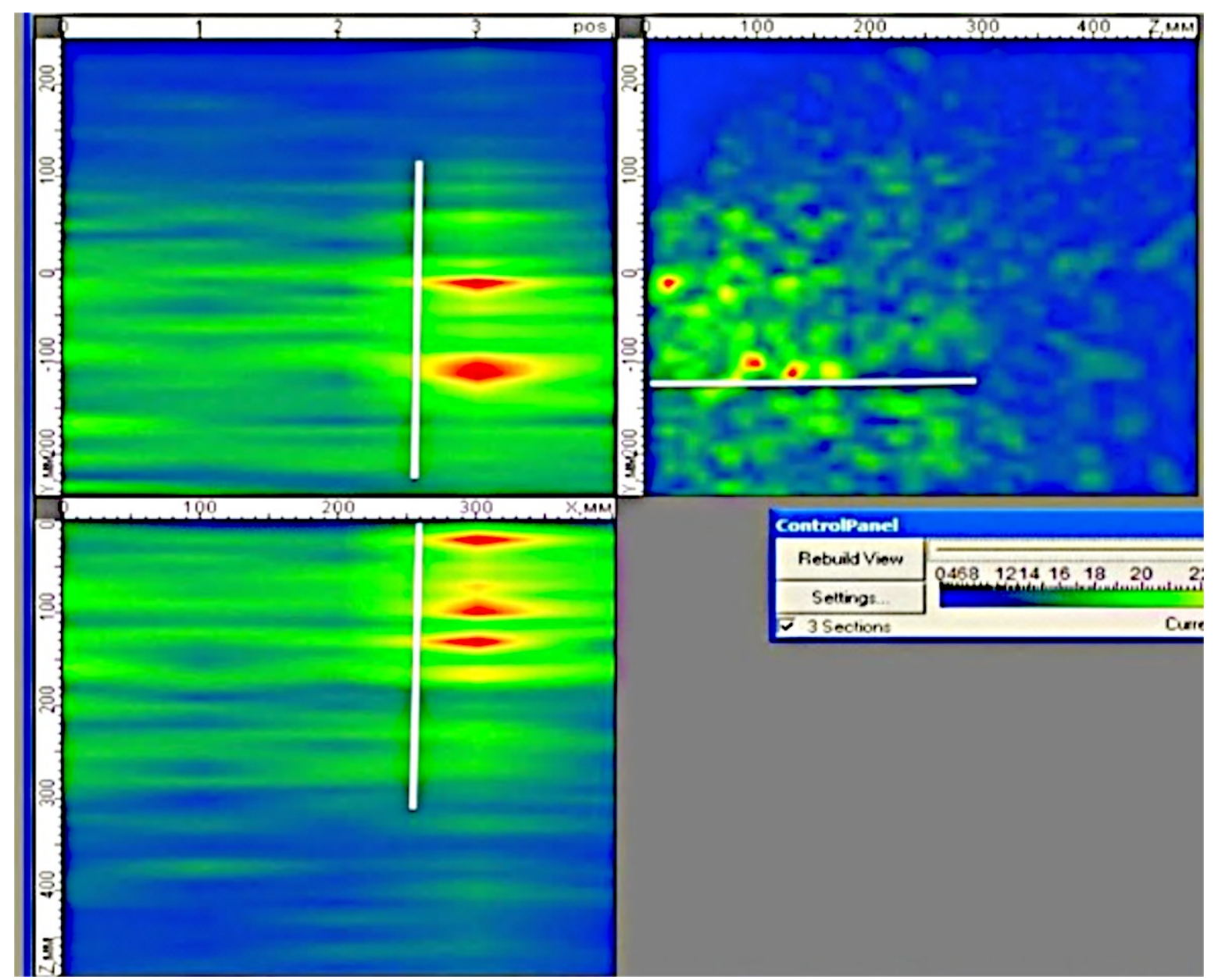

Figure 4.6 - 100 Hz Scan Result from Pier 2-1

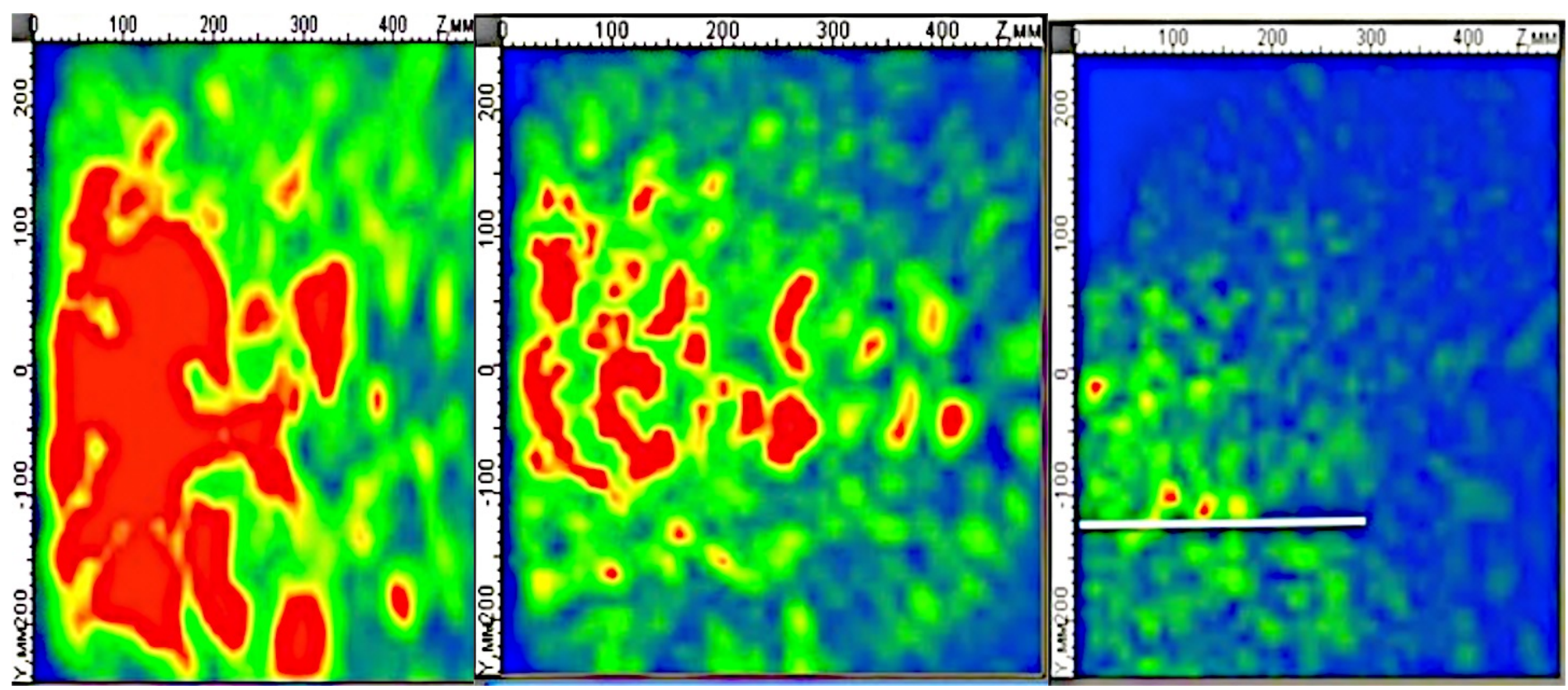

Figure 4.7 - B-Scan Comparison: $50 \mathrm{~Hz}$ (Left), 70 Hz (Middle), $100 \mathrm{~Hz}$ (Right) 
Piers 2-2 and pier 2-3 were both scanned at a frequency of $50 \mathrm{~Hz}$ and a calibrated wave velocity of $2,561 \mathrm{~m} / \mathrm{s}$ and $2,394 \mathrm{~m} / \mathrm{s}$ respectively. Both piers were scanned on the North-South face. Figures 4.8 and 4.9 illustrate the resulting scans, which indicate no void presence. Since no structural defects were noted during visual inspections either, it is assumed that the remaining portions of these members are in good structural condition as well, and no further analysis of these members is required.
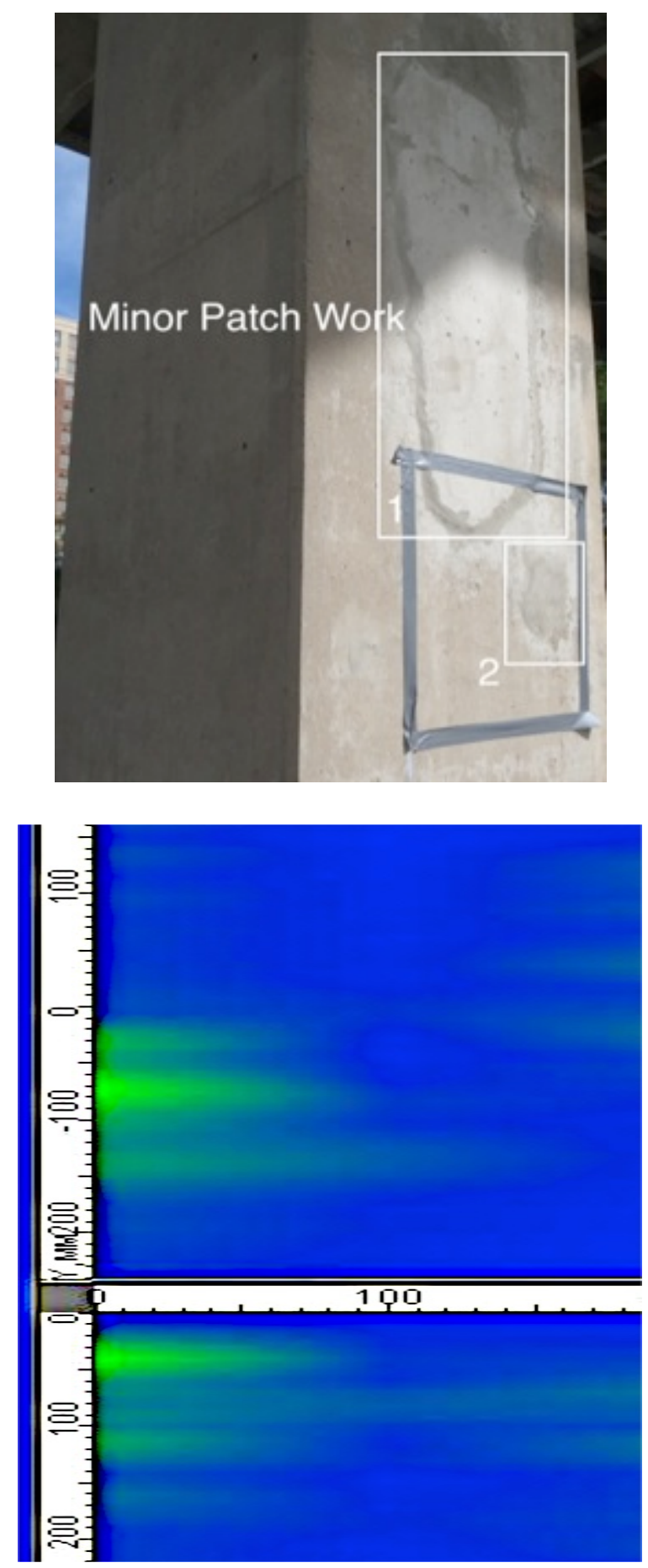

Figure 4.8 - Pier 2-2 Scan Outline and Results 

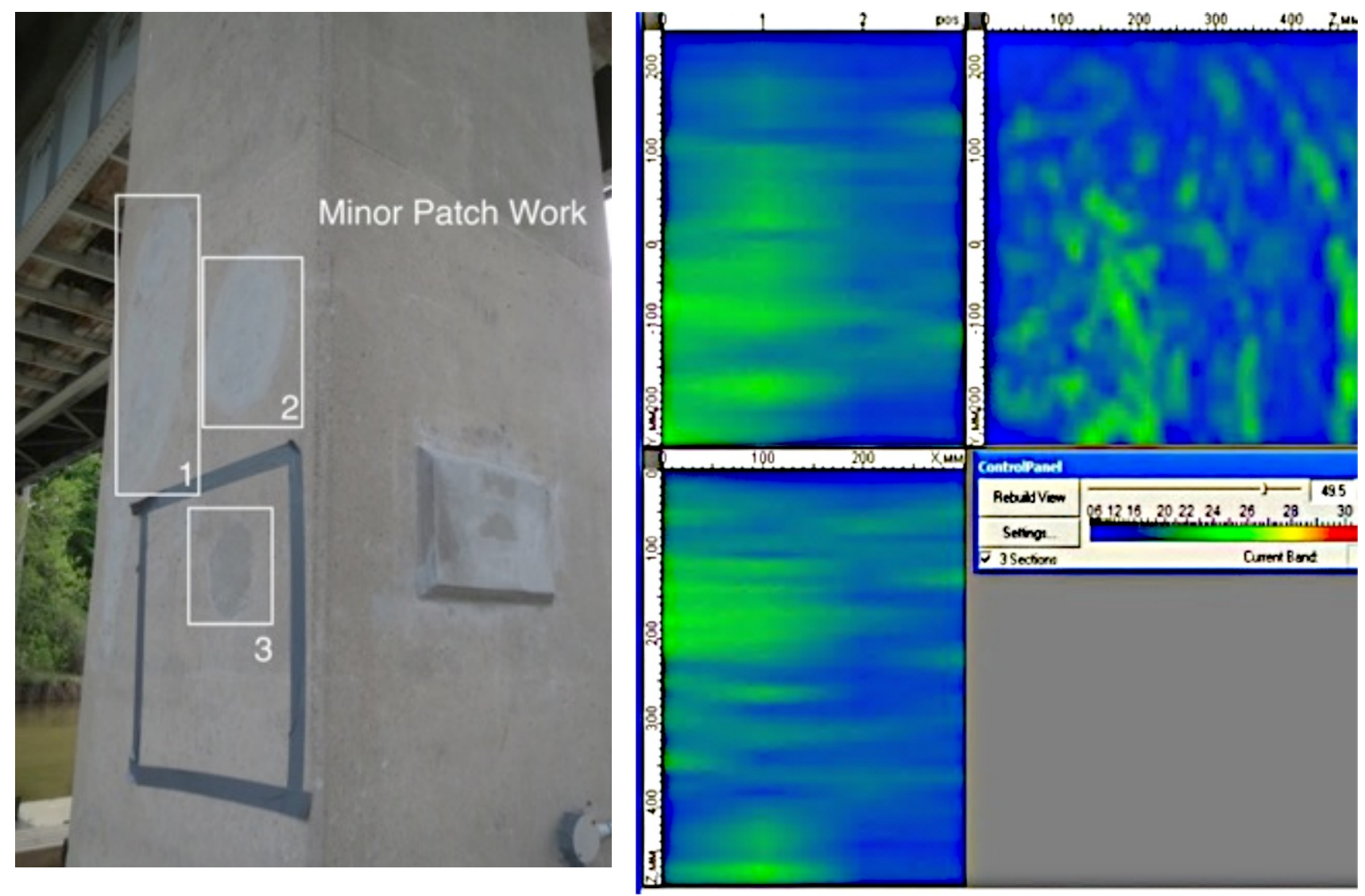

Figure 4.9 - Pier 2-3 Scan Outline and Results

Pier 2-4 was scanned on the South-North face with a frequency of $50 \mathrm{~Hz}$ and a calibrated wave velocity of $2,515 \mathrm{~m} / \mathrm{s}$. Visual inspections of the member indicated a high degree of patching and distinct surface stains as shown in Figure 4.10. The scan shown in Figure 4.11 indicates two voids present at around $85 \mathrm{~mm}$ and $100 \mathrm{~mm}$ from the face of the support (boxed in white). The Cscan indicates that the voids could be due to reinforcement corrosion since they align with other reinforcements present (yellow circle). The voids present in the MIRA shear wave scan line up with the surface stain, which supports the assumption that the voids are due to reinforcement corrosion. Although there are lots of patched portions on this member, the deterioration indicated by the scan is minimal and requires no immediate attention. 


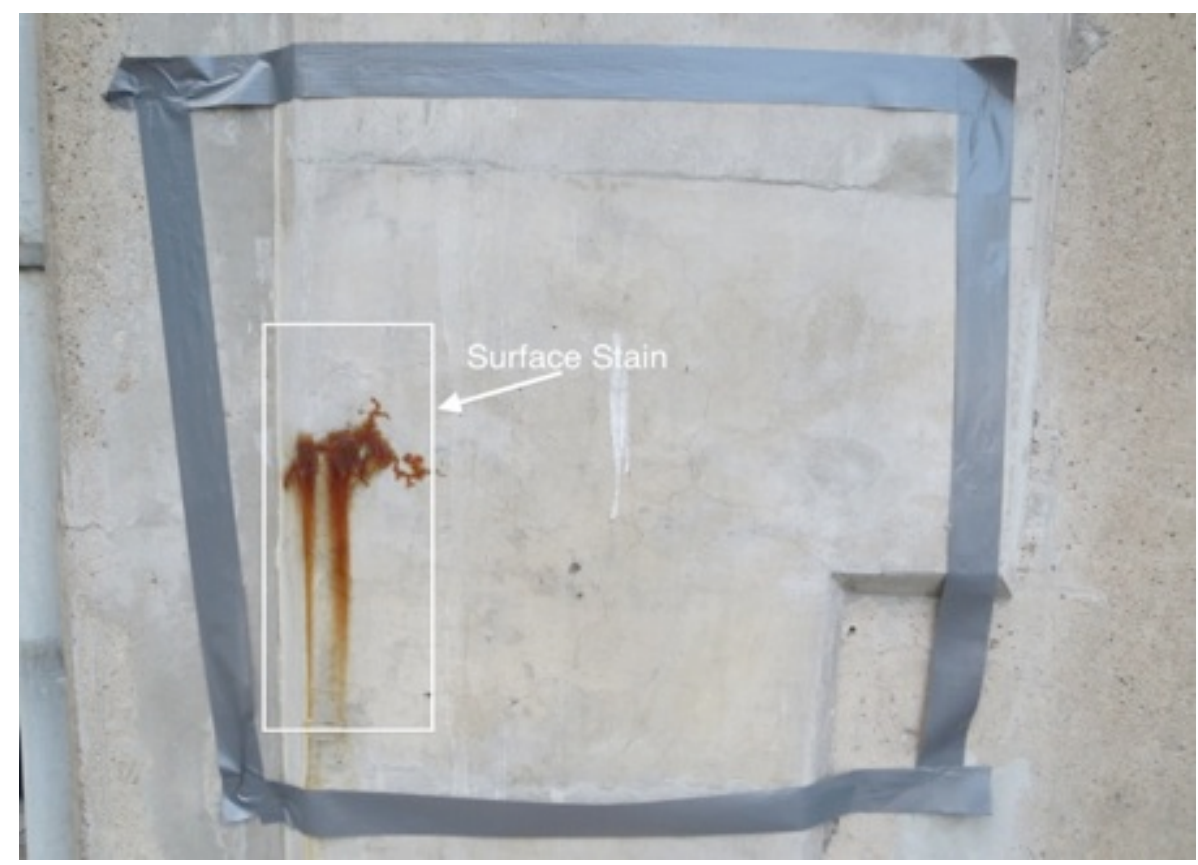

Figure 4.10 - Pier 2-4 Scan Outline Indicating a Small Surface Stain

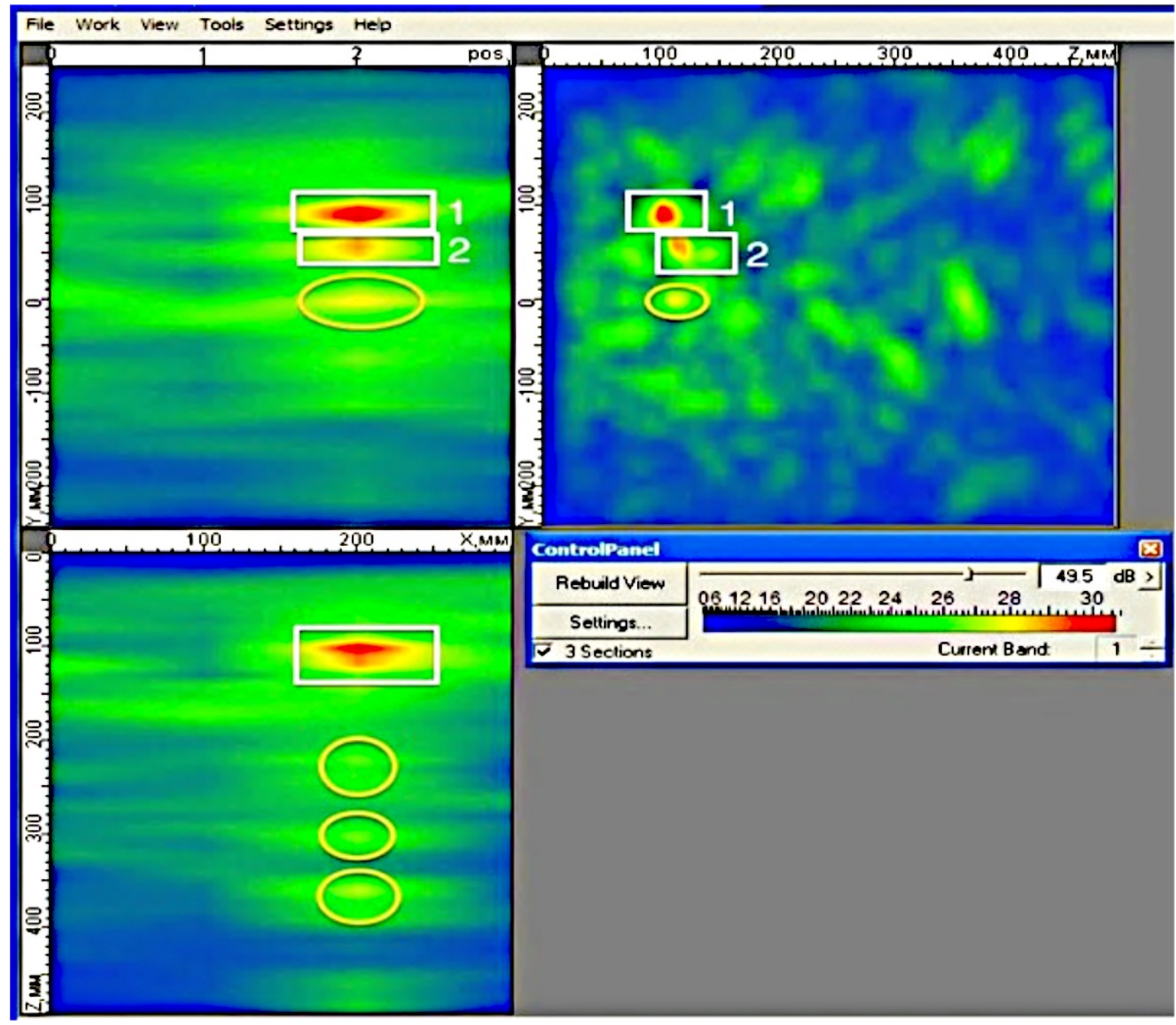

Figure 4.11 - 50 Hz Scan Results from Pier 2-4 


\subsubsection{Pier 3}

Piers 3-1 and 3-2 were fenced off by the rowing storage facility, and thus were not accessible for scanning. Pier 3-3 was scanned at an initial frequency of $50 \mathrm{~Hz}$ and a calibrated wave velocity of $2,435 \mathrm{~m} / \mathrm{s}$. Visual inspections indicated various cracks, as shown in Figure 4.12. The pier was subsequently scanned on the South-North, with the initial results shown in Figure 4.13, which demonstrate inconclusive results. The large presence of inconsistencies is due to the MIRA detecting the patched section, and does not provide any valuable information regarding the member's structural condition. Thus, the frequency was adjusted to $70 \mathrm{~Hz}$ to provide a clearer image as shown in Figure 4.14. From the scan results the presence of voids concentrated between $70 \mathrm{~mm}$ and $200 \mathrm{~mm}$ can be observed. In addition, voids can be observed at around $280 \mathrm{~mm}$ from the face of the support. Although the scan indicates the presence of small voids, there is a section with a cluster of voids. A frequency adjustment was carried out to obtain a scan at $100 \mathrm{~Hz}$, with the results shown in Figure 4.15. The $100 \mathrm{~Hz}$ B-scan shows clear and distinct regions with voids present around the reinforcement level. The B-scan indicates a potential void cluster at around $140 \mathrm{~mm}$ from the face of the support. The high degree of patching at the lower levels of the pier raises some concerns regarding the overall structural condition of this member. Thus, to make a conclusive statement, more scans should be carried out at higher elevations to provide insight of the overall structural condition of this member.
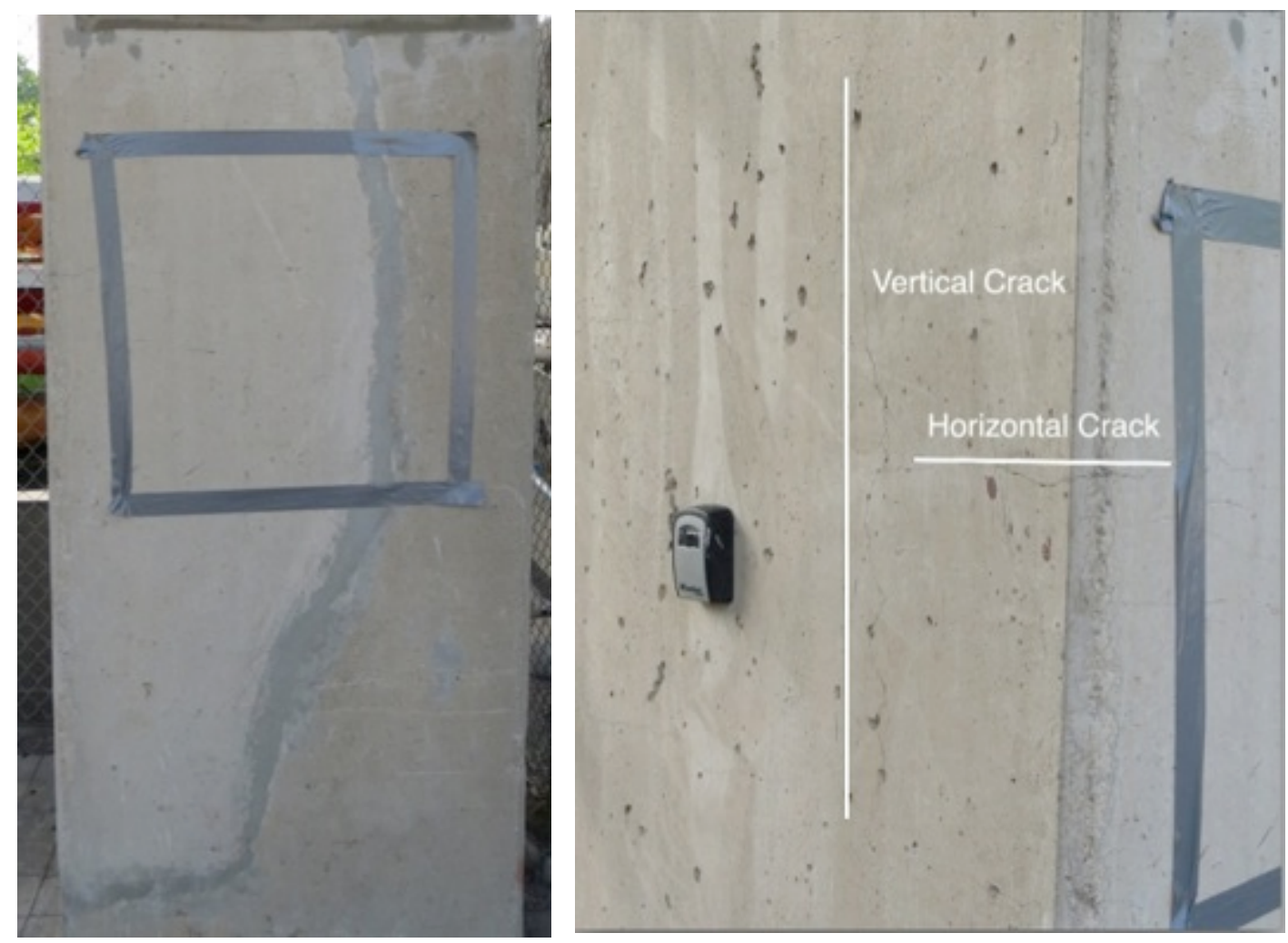

Figure 4.12 - Pier 3-3 Scan Outline 


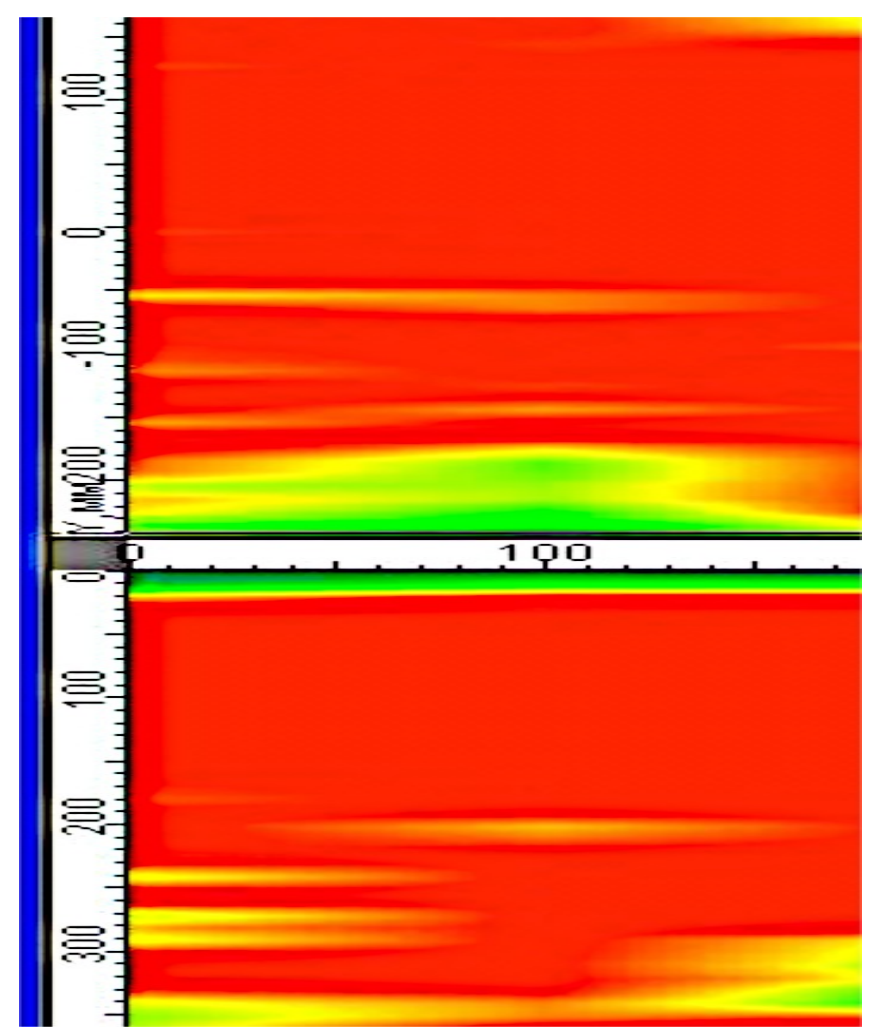

Figure 4.13 - 50 Hz Scan Results from Pier 3-3

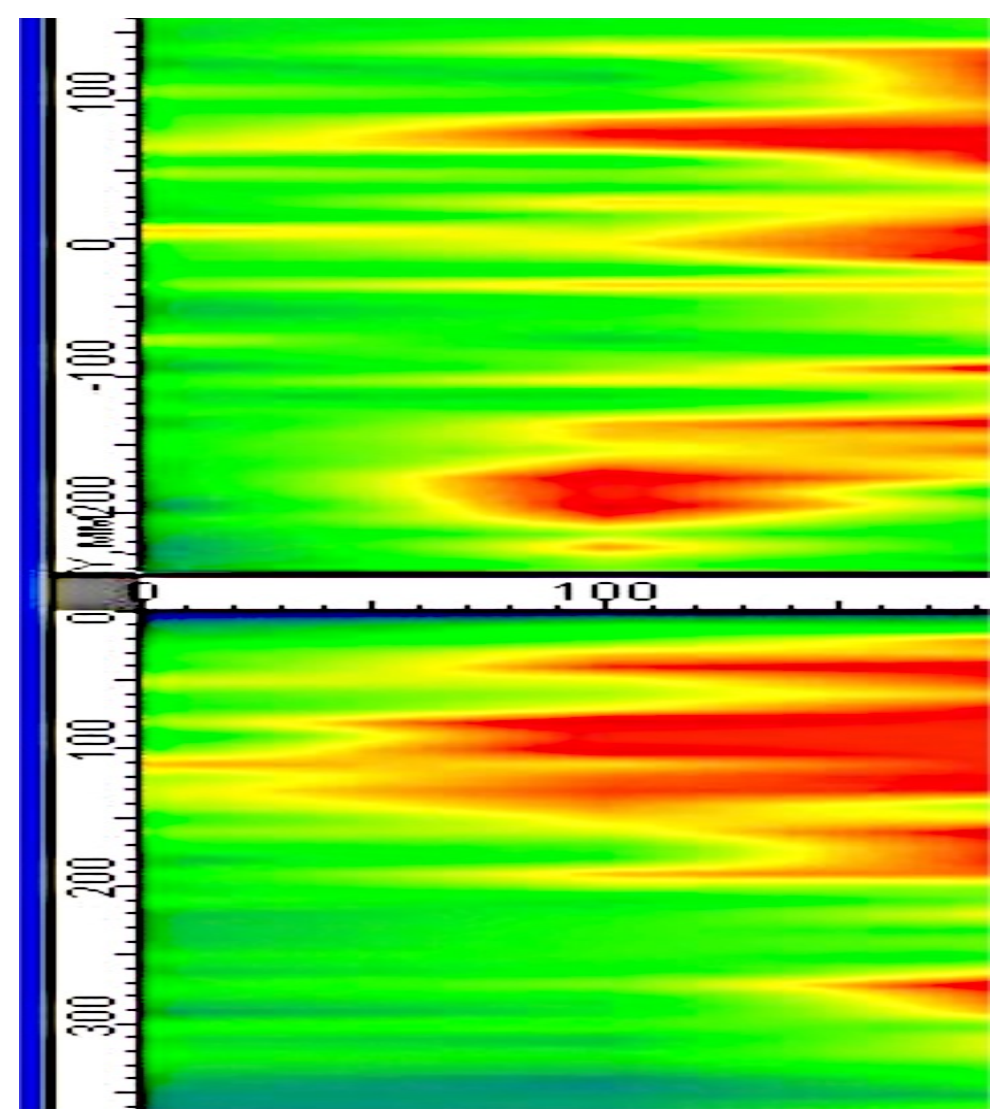

Figure 4.14 - 70 Hz Scan Results from Pier 3-3 


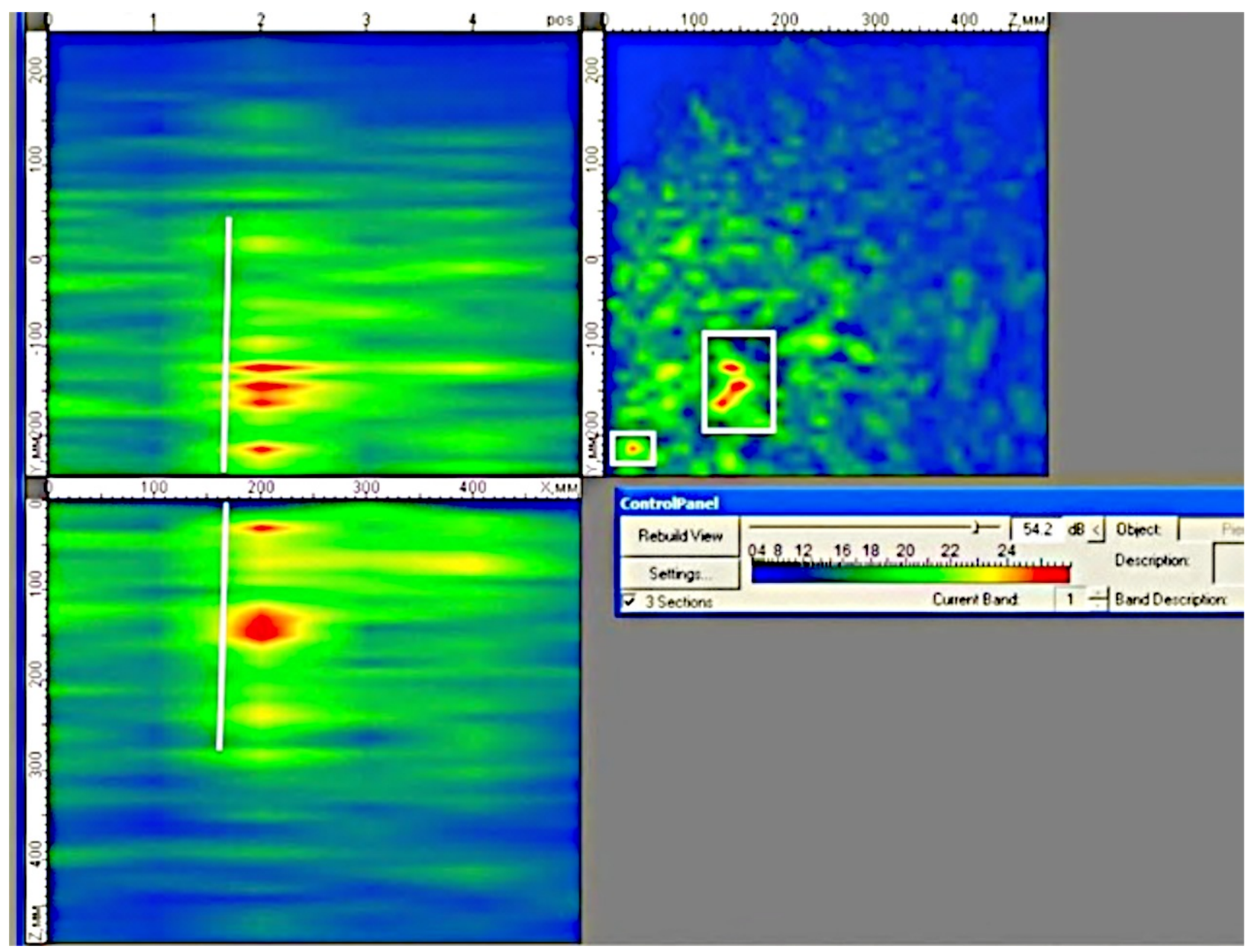

Figure 4.15 - $100 \mathrm{~Hz}$ Scan Results from Pier 3-3

Pier 3-4 was scanned on the South-North (shown in Figure 4.16) face with a frequency of $100 \mathrm{~Hz}$, and a calibrated velocity of 2,483 m/s. The scan indicated minimal signs of deterioration as shown in Figure 4.17 and the visual inspection of the member raised no alarms, thus it is presumed the member is in good structural condition and requires no further attention. 


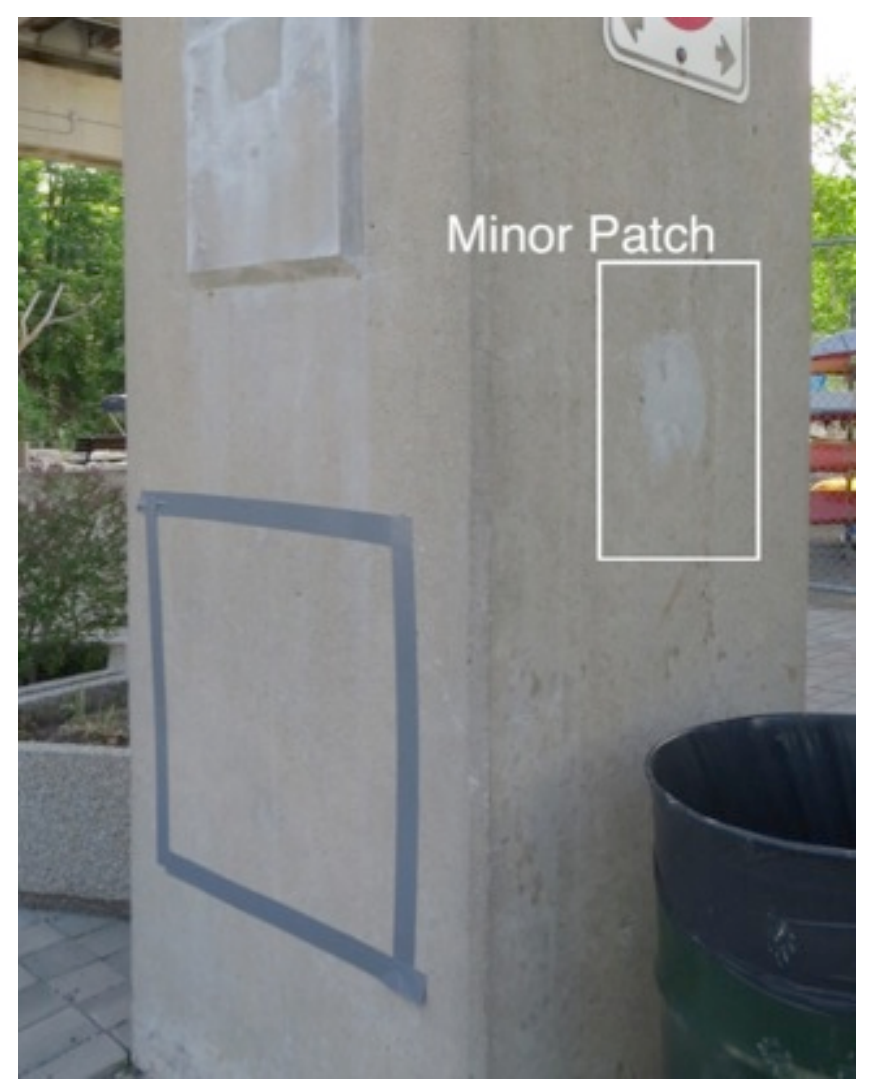

Figure 4.16 - Pier 3-4 Scan Outline

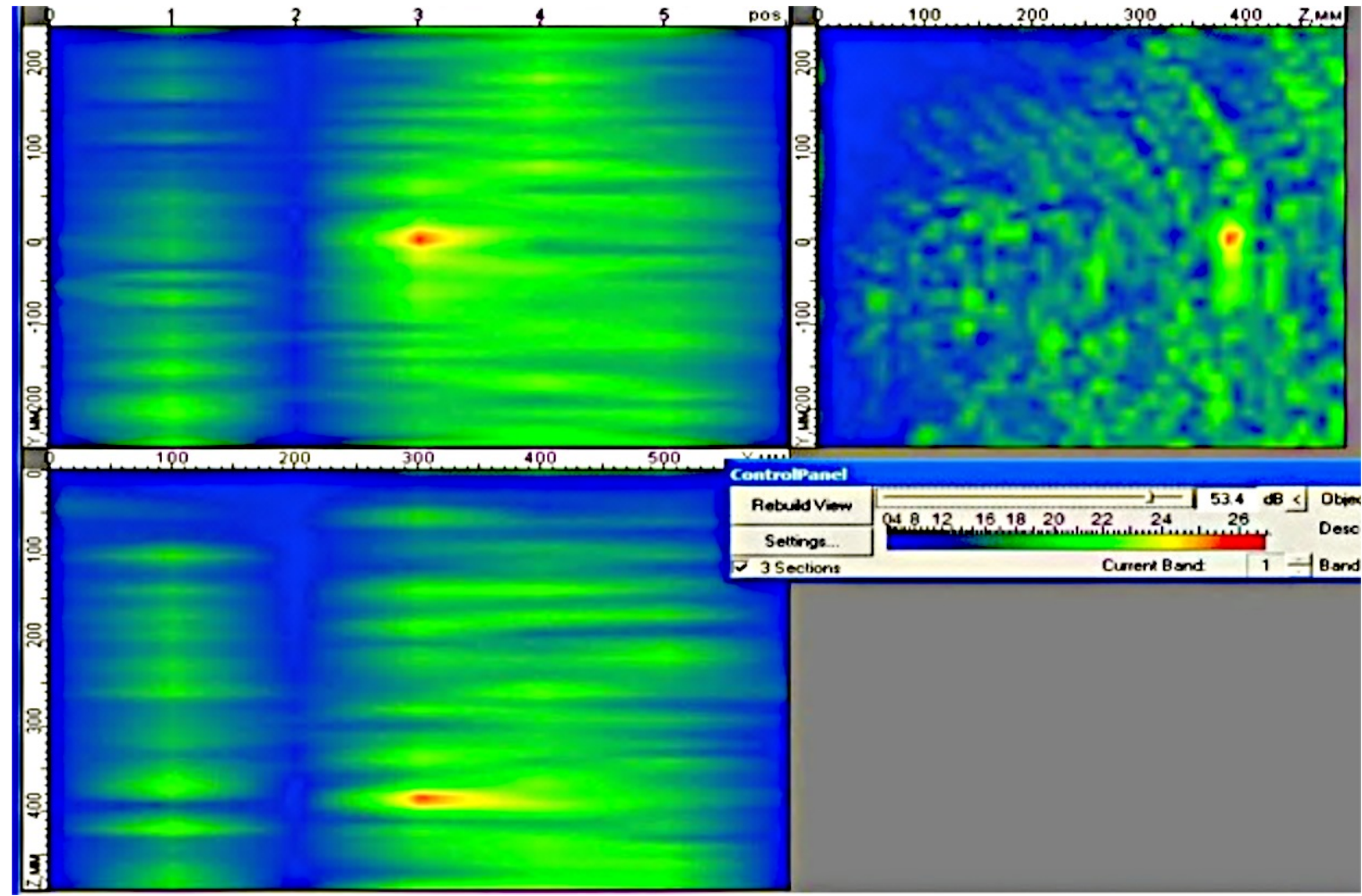

Figure 4.17 - $100 \mathrm{~Hz}$ Scan Results from Pier 3-4 


\subsubsection{Pier 5}

Pier 5-1 was scanned at calibrated wave velocity of $2,397 \mathrm{~m} / \mathrm{s}$ and a frequency of $50 \mathrm{~Hz}$ on the North-South face. Figure 4.18 shows the shear wave scan results, which indicates the presence of voids (boxed). The B-scan for pier 5-1 indicates the presence of 3 distinct voids at 60,75 , and $160 \mathrm{~mm}$ from the face of the support respectively. The D-scan shows reflections of apparent reinforcements, with voids aligned with the reinforcements, indicating potential corrosion and deterioration around the rebar's. Although the visual inspection did not indicate the presence of any deterioration, the shear wave scan indicates voids in close proximity to each other. These voids could grow in size in the future, resulting in large-scale deterioration. Thus, a more detailed evaluation of this member should be undertaken, with scans at higher elevations to provide better insight of the overall structural condition of this pier.

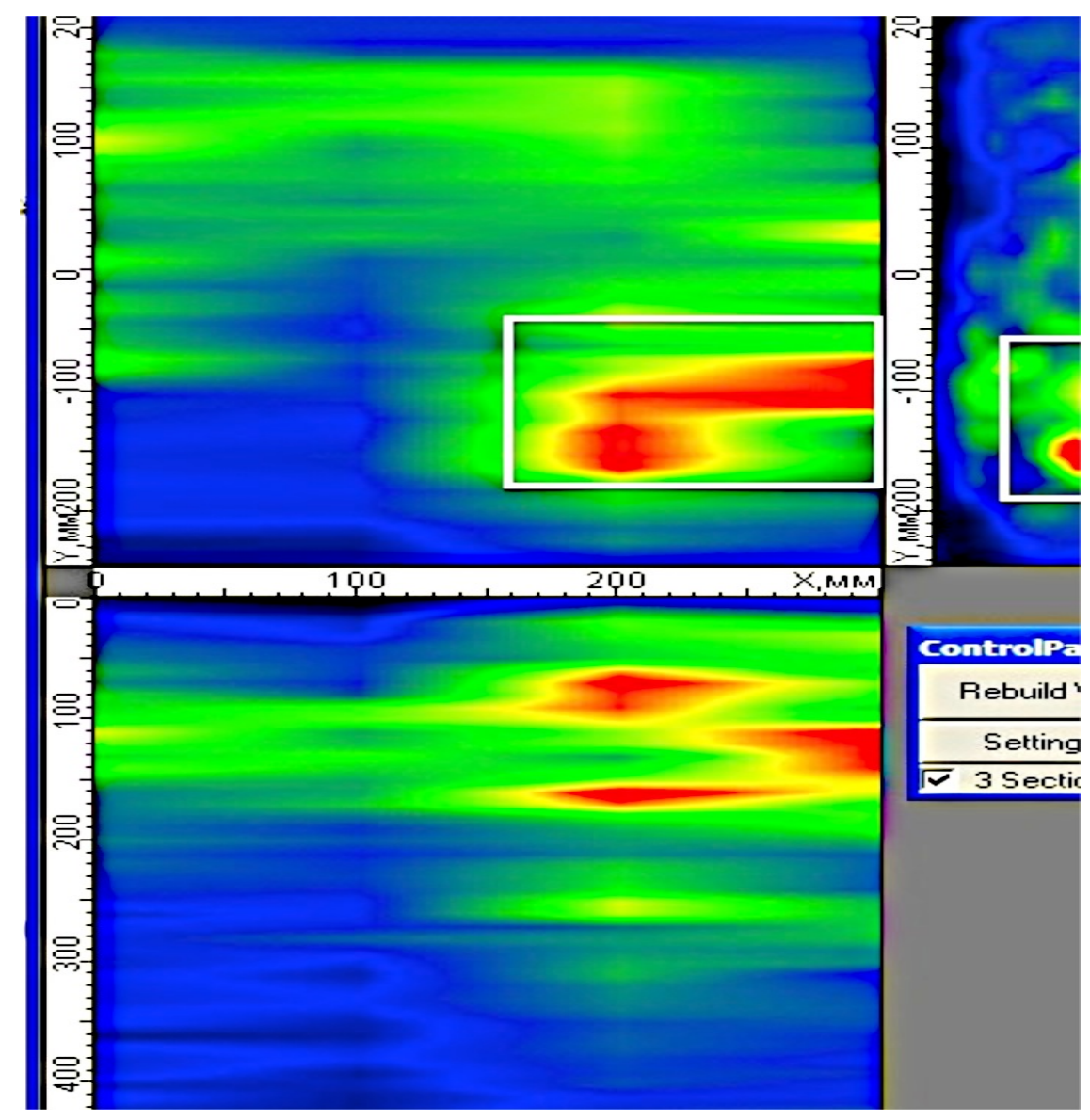

Figure 4.18 - Pier 5-1 Scan Results Indicating Void Presence and Void Formation

Pier 5-2 scans were also carried out at $50 \mathrm{~Hz}$ with a calibrated wave velocity of 2,498 m/s on the South-North face. The shear wave scan results indicate the presence of a large void at around $20 \mathrm{~mm}$ from the surface as shown in Figure 4.19, with smaller voids at around 80-100 
$\mathrm{mm}$ from the face of the pier. The C-scan indicated the presence of reinforcement, with voids aligned with the rebar, indicating potential corrosion and deterioration around the rebar's. The large void present near the surface coupled with the apparent reinforcement corrosion could result in future delamination and cracking and requires immediate attention. In order to provide a proper maintenance plan, the overall structural condition of the member should be studied thoroughly with subsequent scans at higher elevations.

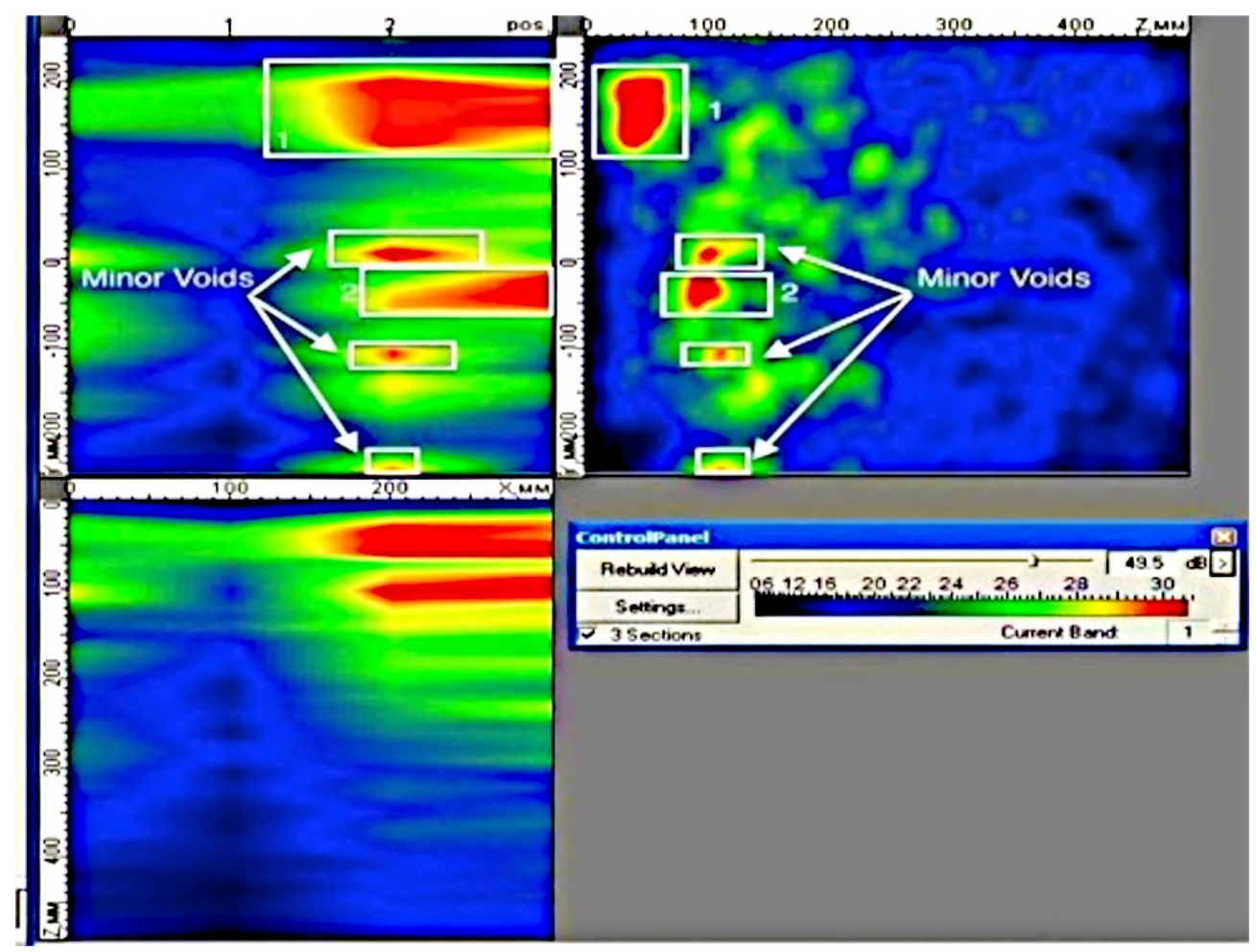

Figure 4.19 - Pier 5-2 Scan Results Indicating Minor and Major Voids Present

Pier 5-3 was scanned at a frequency of $50 \mathrm{~Hz}$ with a calibrated wave velocity of $2,489 \mathrm{~m} / \mathrm{s}$ on the East-West face. Minor vertical cracks were noted during initial visual inspections as shown in Figure 4.20. The shear wave scan results shown in Figure 4.21 indicate large-scale voids present between $70 \mathrm{~mm}$ and $140 \mathrm{~mm}$ from the face of the support, with some surface deterioration at around $30 \mathrm{~mm}$ to $50 \mathrm{~mm}$ from the face of the support. The C-scan and D-scan results indicate the deterioration could be due to reinforcement corrosion as well as concrete deterioration. The clear image in the B-scan and distinct void regions in the $\mathrm{C}$ and $\mathrm{D}$-scans indicate that no frequency adjustment is required. The large-scale voids present should trigger further analysis of the remaining portions of the pier to analyze the overall structural condition of the pier 5-3 in order to allocate appropriate maintenance actions. 


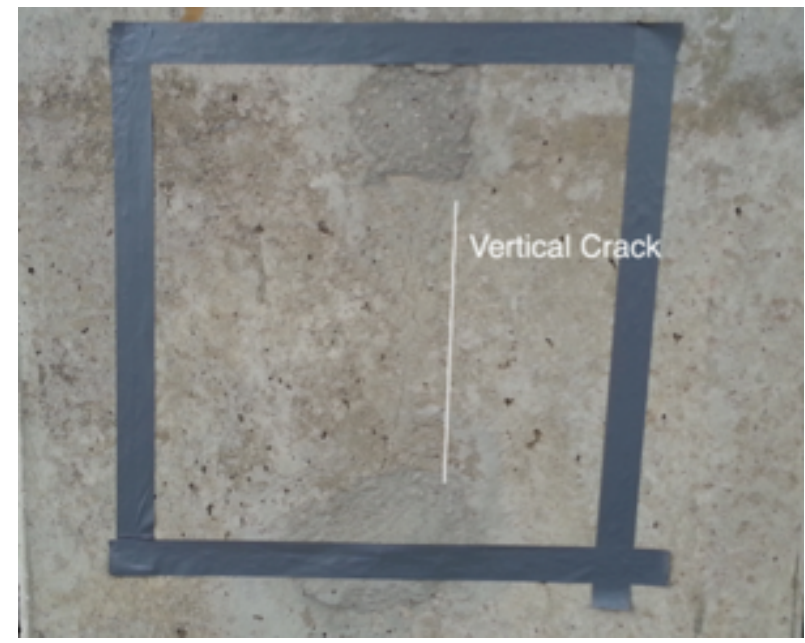

Figure 4.20 - Pier 5-3 Scan Outline and Presence of a Vertical Crack on the Scan Face

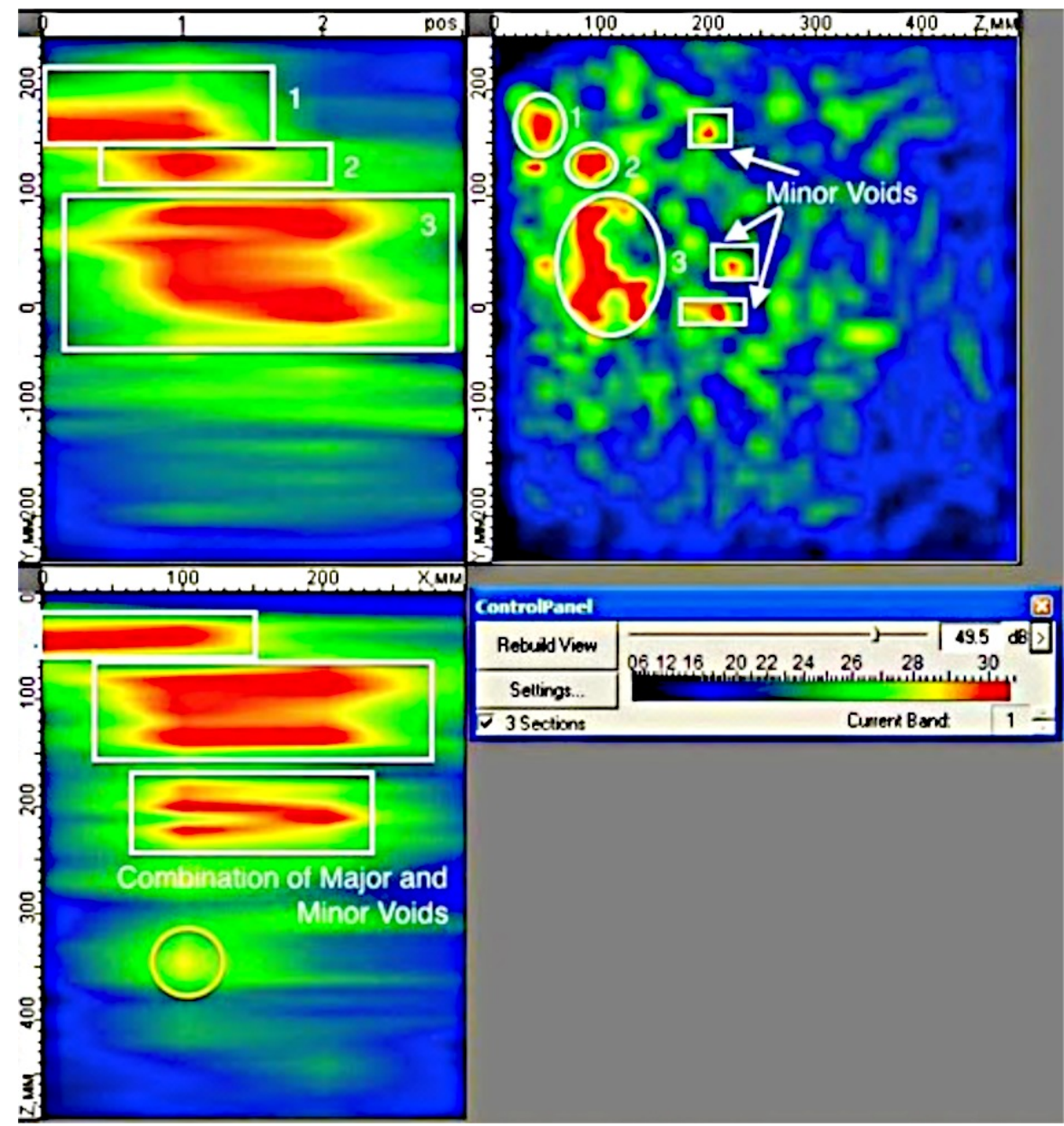

Figure 4.21 - Pier 5-3 Scan Results Indicating Minor and Major Voids Present 
Pier 5-4 was scanned at a frequency of $50 \mathrm{~Hz}$ and a calibrated wave velocity of $2,402 \mathrm{~m} / \mathrm{s}$ on the East-West face as shown in Figure 4.22. The voids (circled) on the B-scan and C-scan indicate minor reinforcement corrosion, which seem to be isolated and small in nature as shown in Figure 4.23. In addition, the reinforcement corrosion appears to be isolated to the surface, with only minor voids detected at deeper levels. Although the voids are minimal in size, they could result in large-scale delamination and cracks as a result of their alignment and proximity to the surface. Although the overall visual inspection and scan results indicate that the member is in good structural condition, the pier should be monitored in more detail to analyze the overall structural condition.

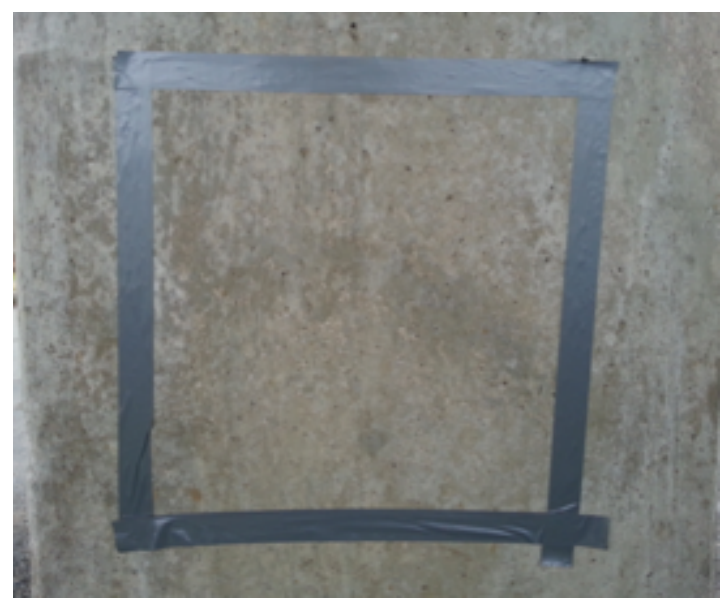

Figure 4.22 - Pier 5-4 Scan Outline

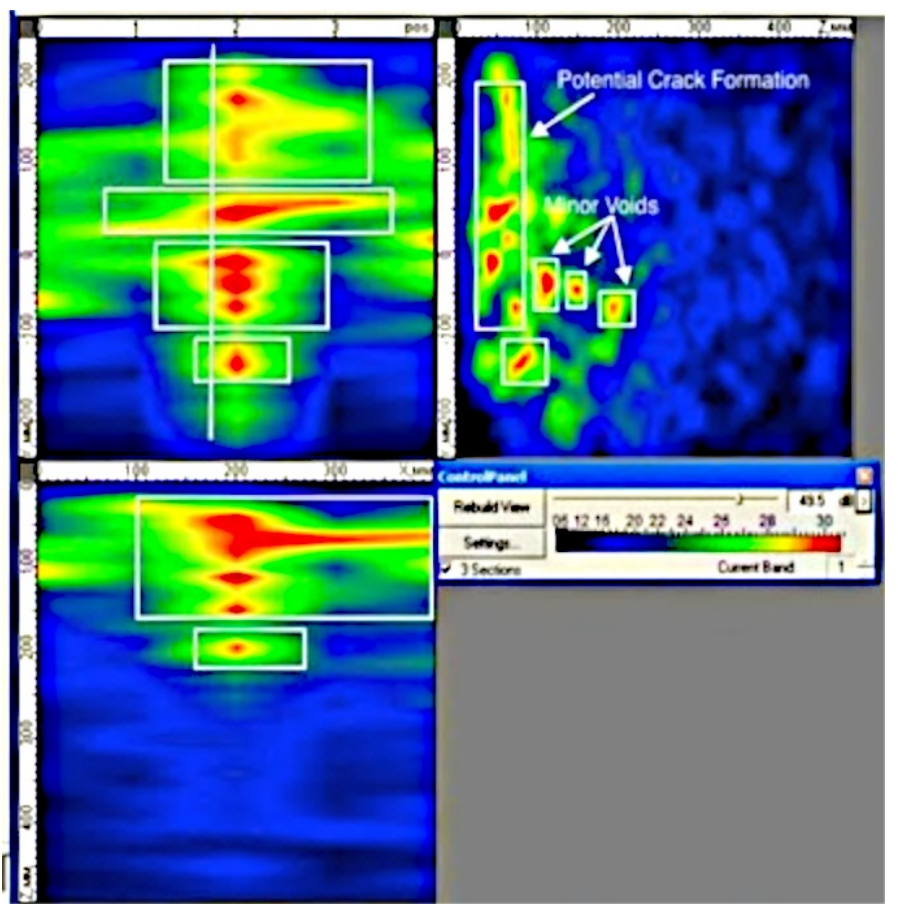

Figure 4.23 - Pier 5-4 Scan Results Indicating Surface Voids and Potential Crack Formation 


\subsubsection{Pier 6}

Pier 6-1 was scanned at a frequency of $100 \mathrm{~Hz}$ and a calibrated wave velocity of 2,494 $\mathrm{m} / \mathrm{s}$ on West-East face. The visual inspection of the member indicated some minor patching, and potential surface stains, thus the shear wave scan was carried out on that face. The shear wave scan results shown in Figure 4.24 indicate some void clusters (boxed) and some minor voids (circled). The overall member indicated extensive patching, with some visible surface cracks present. In addition, the scan results indicate the voids are aligned, potentially forming a crack as a result of reinforcement corrosion. The voids are concentrated at around $100 \mathrm{~mm}$ from the face of the support (west face). Although, additional scans are recommended at higher elevations, the scan results and visual inspection do not raise any alarms regarding the structural adequacy of this member. However, pier 6-1 should be monitored carefully to study the potential development of cracking in order to provide timely maintenance.

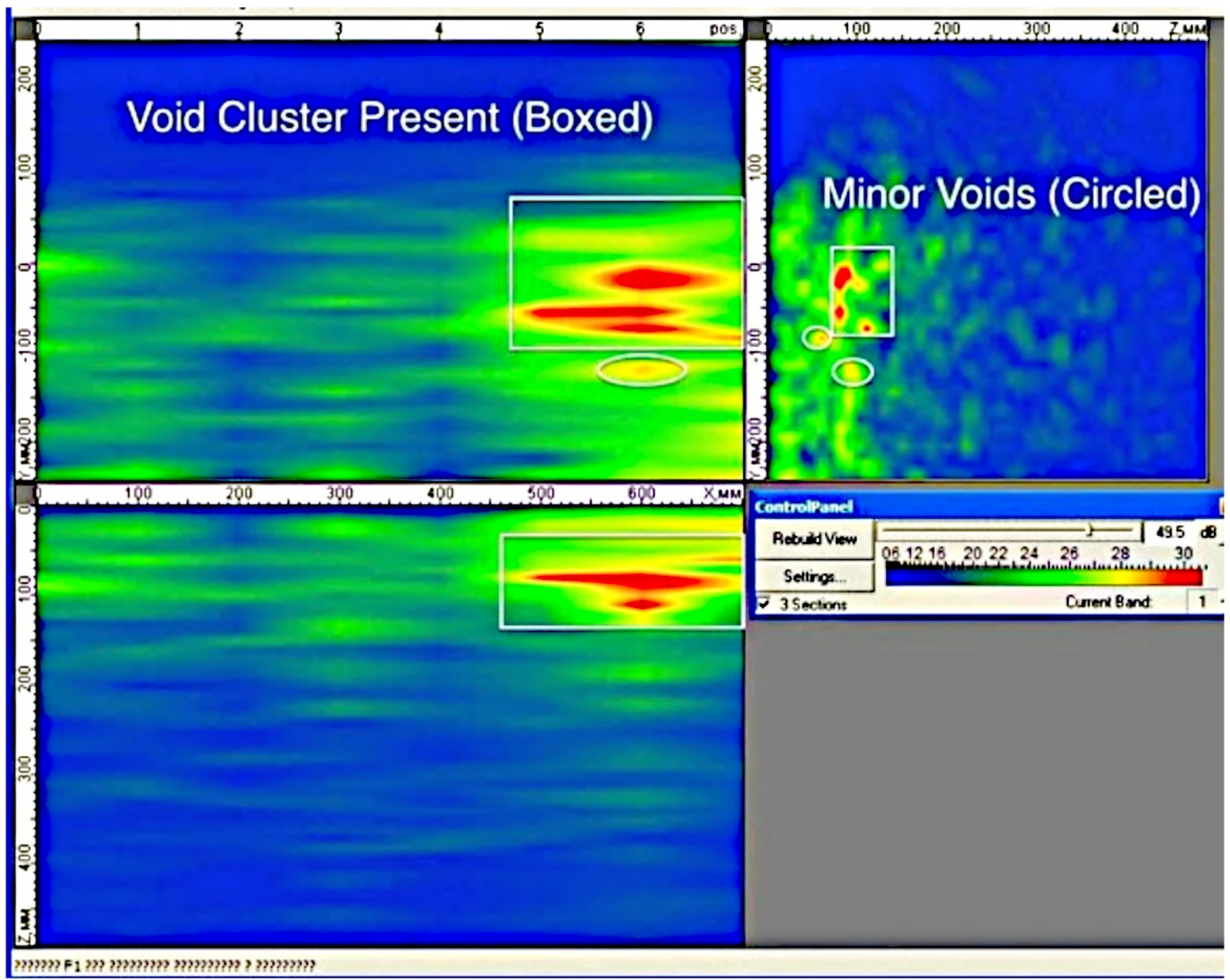

Figure 4.24 - Pier 6-1 Scan Results Indicating Void Clusters and Minor Voids Present 
Pier 6-2 was scanned at a frequency of $100 \mathrm{~Hz}$ and a calibrated wave velocity of 2,539 $\mathrm{m} / \mathrm{s}$ on North-South face. The visual inspection of the member indicated some patched sections along the member, but no surface deterioration was noted. The shear wave scan results shown in Figure 4.25 indicate some minor voids (boxed) at around $60 \mathrm{~mm}$ from the north face of the support. However, the overall scan and visual inspection raised no alarms, and no further analysis of this member is required.

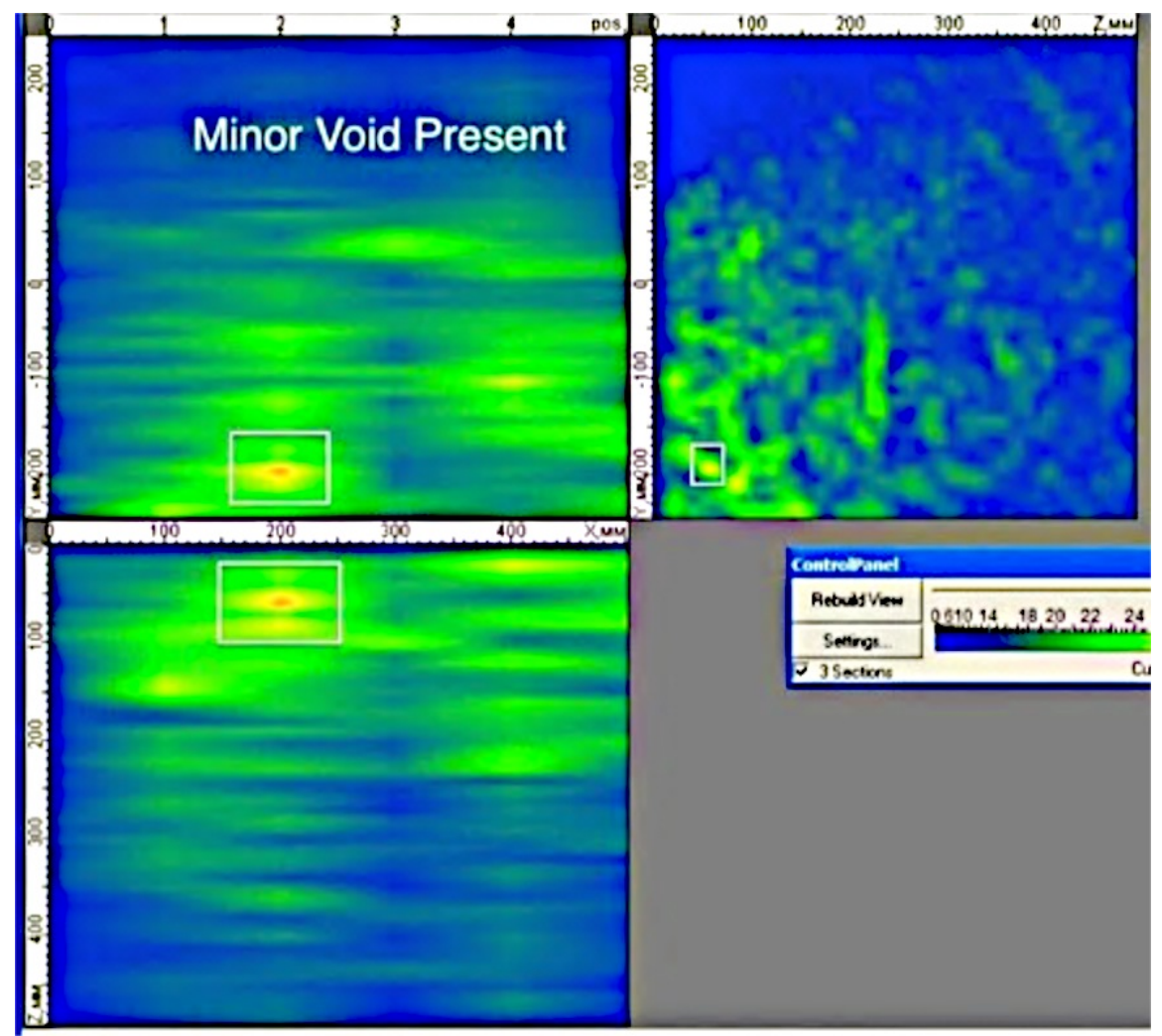

Figure 4.25 - Pier 6-2 Scan Results Indicating Minor Voids Present

Piers 6-3 and 6-4 were scanned at $50 \mathrm{~Hz}$ and a calibrated velocity of 2,470 and 2,474 m/s on the North-South and South-North face respectively. The shear wave scan results are shown in Figure 4.26 and 4.27 indicate no voids present. In addition, the visual inspection of the members did not indicate any deterioration. Thus, piers 6-3 and 6-4 require no further analysis. 


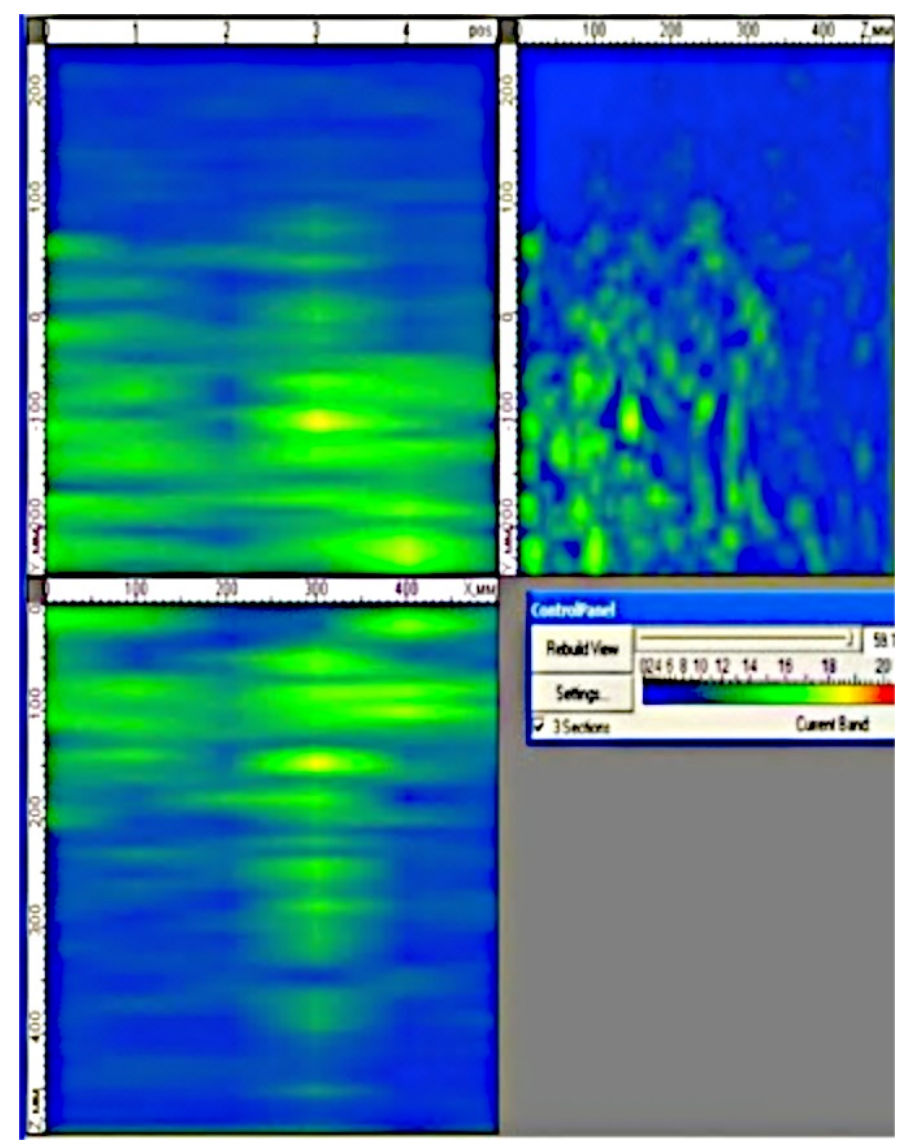

Figure 4.26 - Pier 6-3 Scan Results

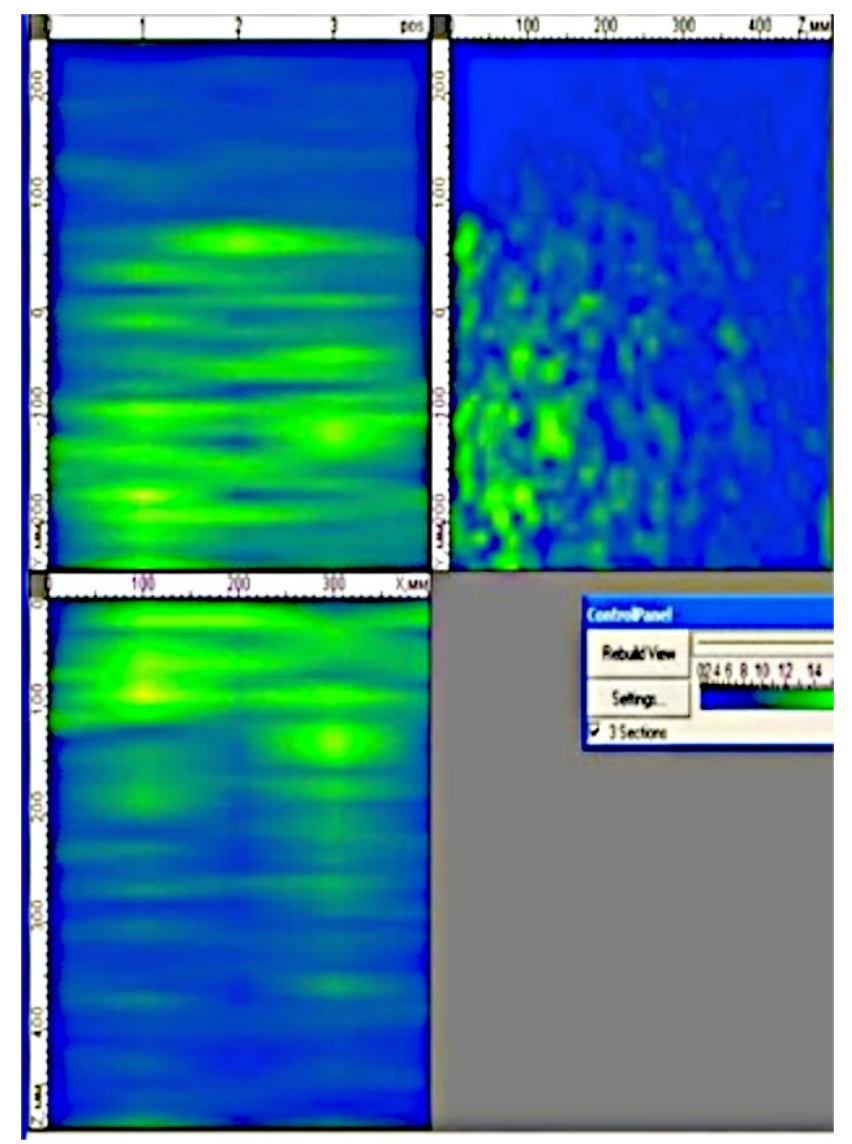

Figure 4.27 - Pier 6-4 Scan Results

\subsubsection{Pier 7}

Pier 7-1 was scanned at a frequency of $50 \mathrm{~Hz}$ and a calibrated wave velocity of 2,444 m/s on the South-North face. Initial visual inspections indicated the presence of surface stains, honeycombing and scaling at various portions of the pier as shown in Figure 4.28. The initial scan shown in Figure 4.29 illustrates the large-scale deterioration in pier 7-1, at around $75 \mathrm{~mm}$ from the south face of the pier. The deterioration could be due to delamination of the concrete or cracking as a result of reinforcement corrosion. The deterioration in the C-scan and D-scan indicate that the deterioration could be along the reinforcements close to the face of the support. The clear scan images suggest that a frequency adjustment is not necessary. The cluster of voids present is bound to cause future problems in this member and appropriate maintenance action should be undertaken as soon as possible. However, prior to undertaking any maintenance actions, the pier should be scanned at higher elevations in order to analyze the overall structural condition of the member. 


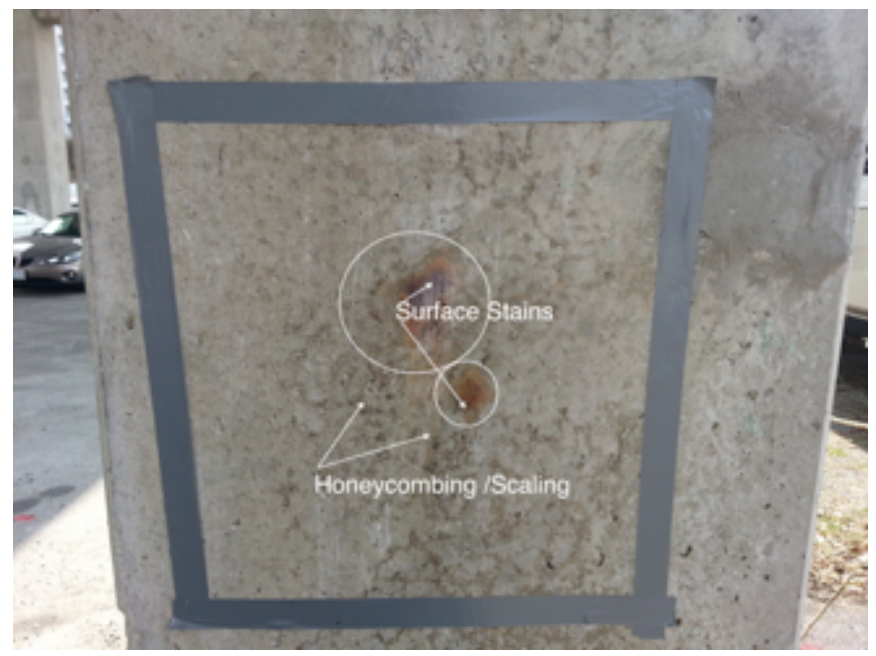

Figure 4.28 - Pier 7-1 Scan Outline with Surface Stains, Honeycombing and Scaling Present

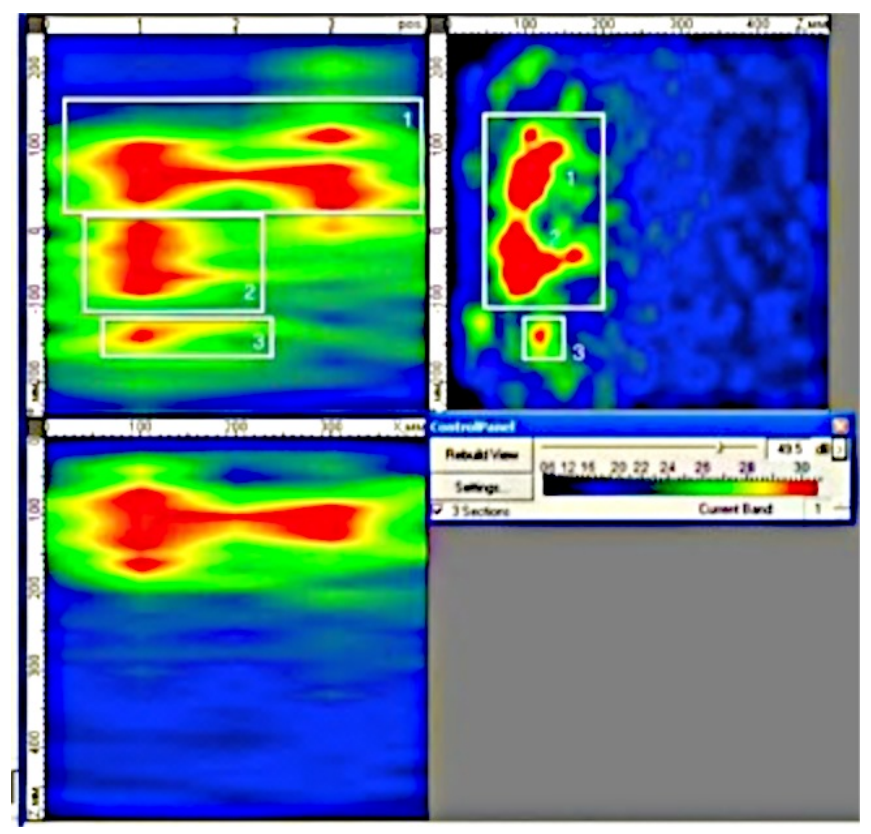

Figure 4.29 - Pier 7-1 Scan Results Indicating Major Void Clusters Present

Piers 7-2 and 7-4 were both scanned at a frequency of $50 \mathrm{~Hz}$ and a calibrated wave velocity of $2,421 \mathrm{~m} / \mathrm{s}$ and $2,403 \mathrm{~m} / \mathrm{s}$ on the East-West face respectively. The shear wave scans shown in Figures 4.31 and 4.33 show minimal signs of deterioration, with only minor voids present. The visual inspection of both members indicated minor vertical and diagonal cracks as shown in Figure 4.30 and 4.32. The small nature of voids noted in the MIRA scans and minor visual anomalies indicate that piers 7-2 and 7-4 are in good structural condition and no immediate action is required. 


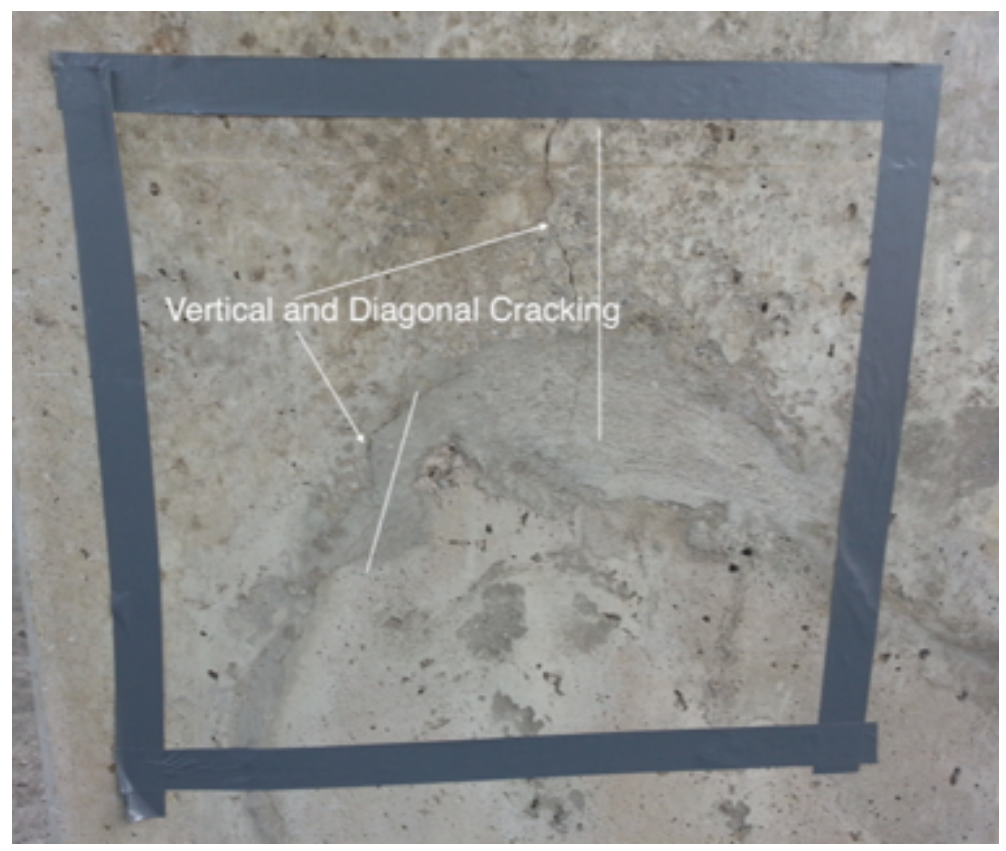

Figure 4.30 - Pier 7-2 Scan Outline with Vertical and Diagonal Cracks Present on the Scan Face

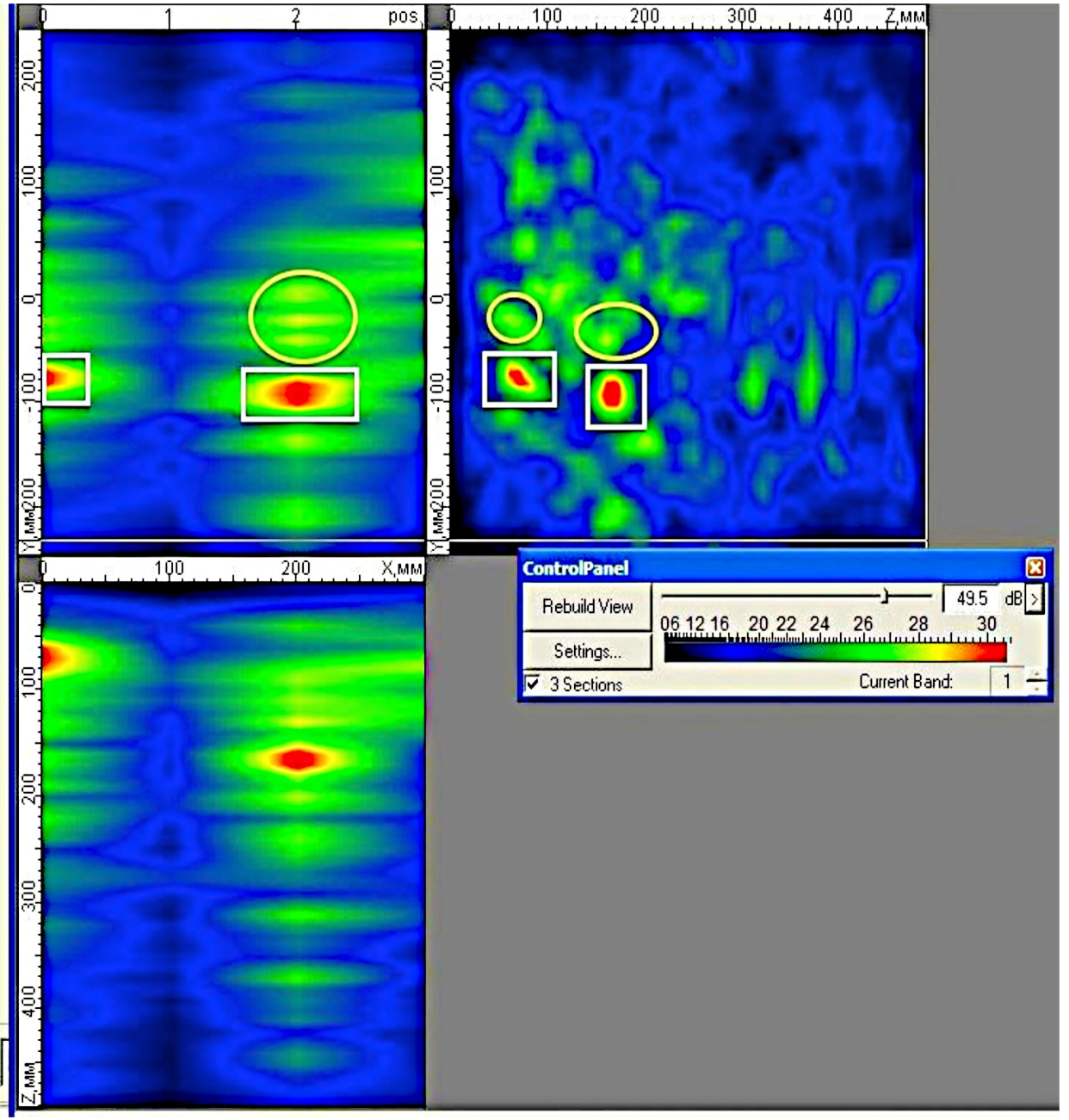

Figure 4.31 - Pier 7-2 Scan Results Indicating Minor Voids Present 


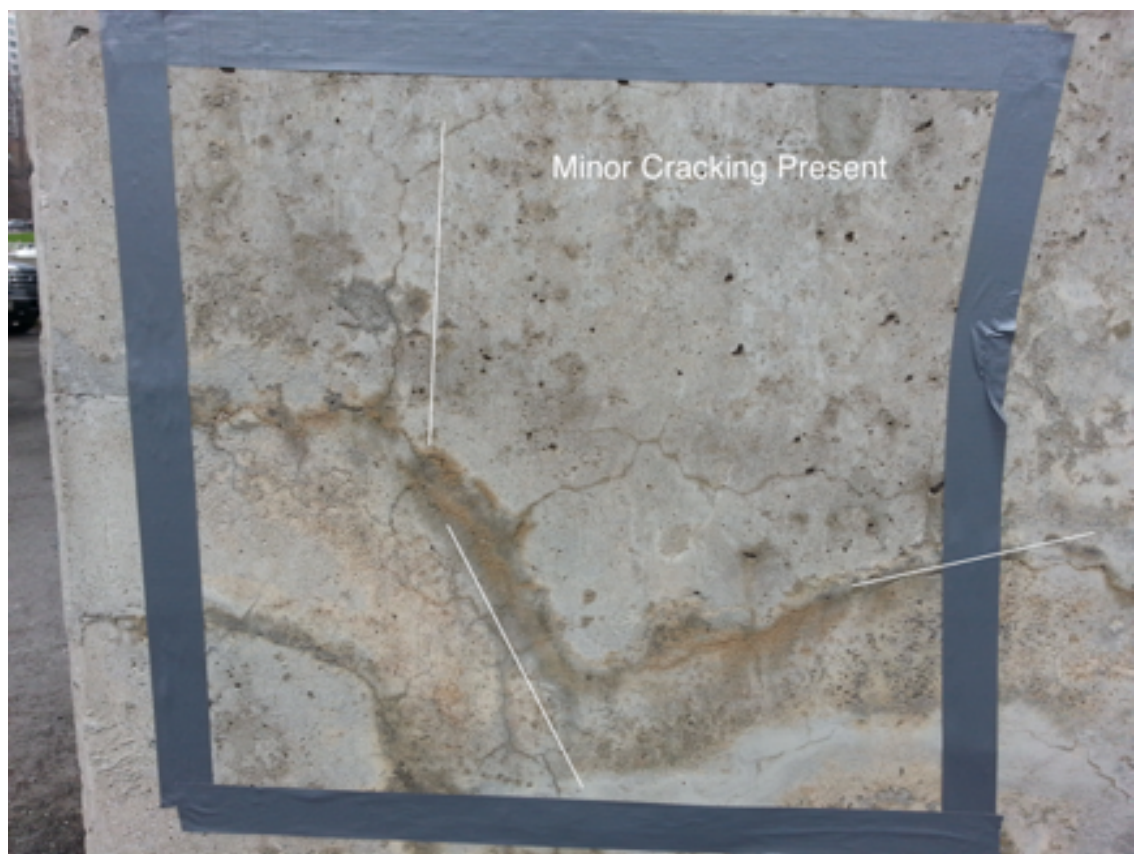

Figure 4.32 - Pier 7-4 Scan Outline with Minor Cracks Noted

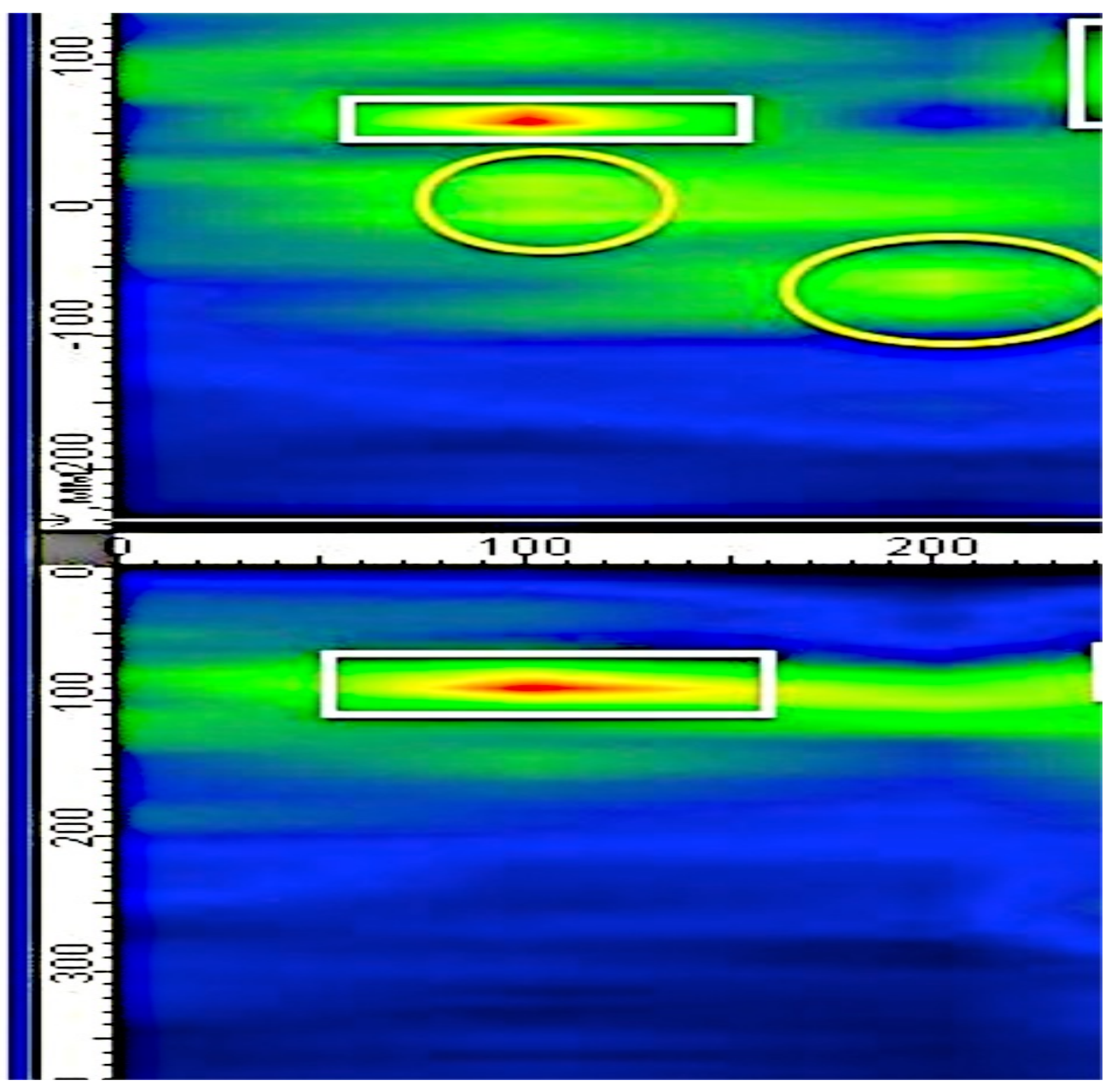

Figure 4.33 - Pier 7-4 Scan Results Indicating Minor Voids Present 
Pier 7-3 was scanned at a frequency of $50 \mathrm{~Hz}$ and a calibrated wave velocity of 2,456 m/s on the South-North face. The shear wave scan results indicate presence of voids at around 100 $\mathrm{mm}$ from the north face of the pier in three distinct zones as shown in Figure 4.34. The void patterning suggests that further deterioration could cause a large-scale crack since the current voids are likely to connect. The $\mathrm{C}$ - and D-Scan indicate that these voids are between reinforcement layers. A subsequent scan was undertaken at a frequency of $100 \mathrm{~Hz}$ to provide a clearer image of the deterioration present. The $100 \mathrm{~Hz}$ scan, shown in Figure 4.35 clearly isolates the void clusters into closely spaced distinct voids (boxed). The close proximity of the voids should be monitored as this could develop into a large cluster and cause extensive cracking or delamination. It should also be noted that the B and D scan have been swapped between scans due to the pier being scanned on a different face. Thus, the void cluster in the B-Scan shown in Figure 4.34 is relative to the D-Scan in Figure 4.35. However, this does not have any effects on the results, as the MIRA provides three-dimensional scans. Although no surface issues were noted in the visual inspection of pier 7-3 (Figure 4.36), the MIRA scans indicated some internal issues. Nonetheless, pier 7-3 does no require immediate attention but should be monitored along with other members noted previously to control the development of cracks or other structural issues.

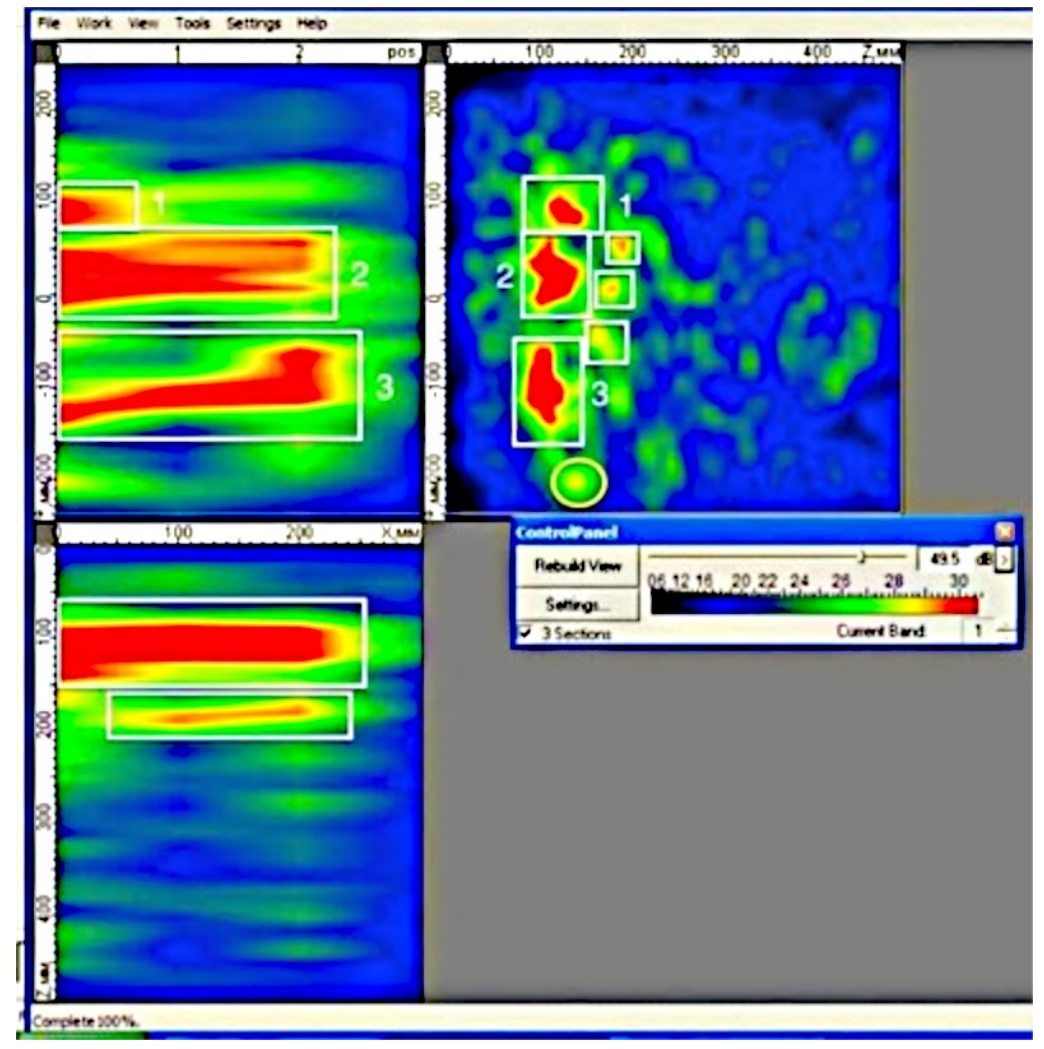

Figure 4.34 - 50 Hz Scan Results from Pier 7-3 Indicating Major Voids Present 


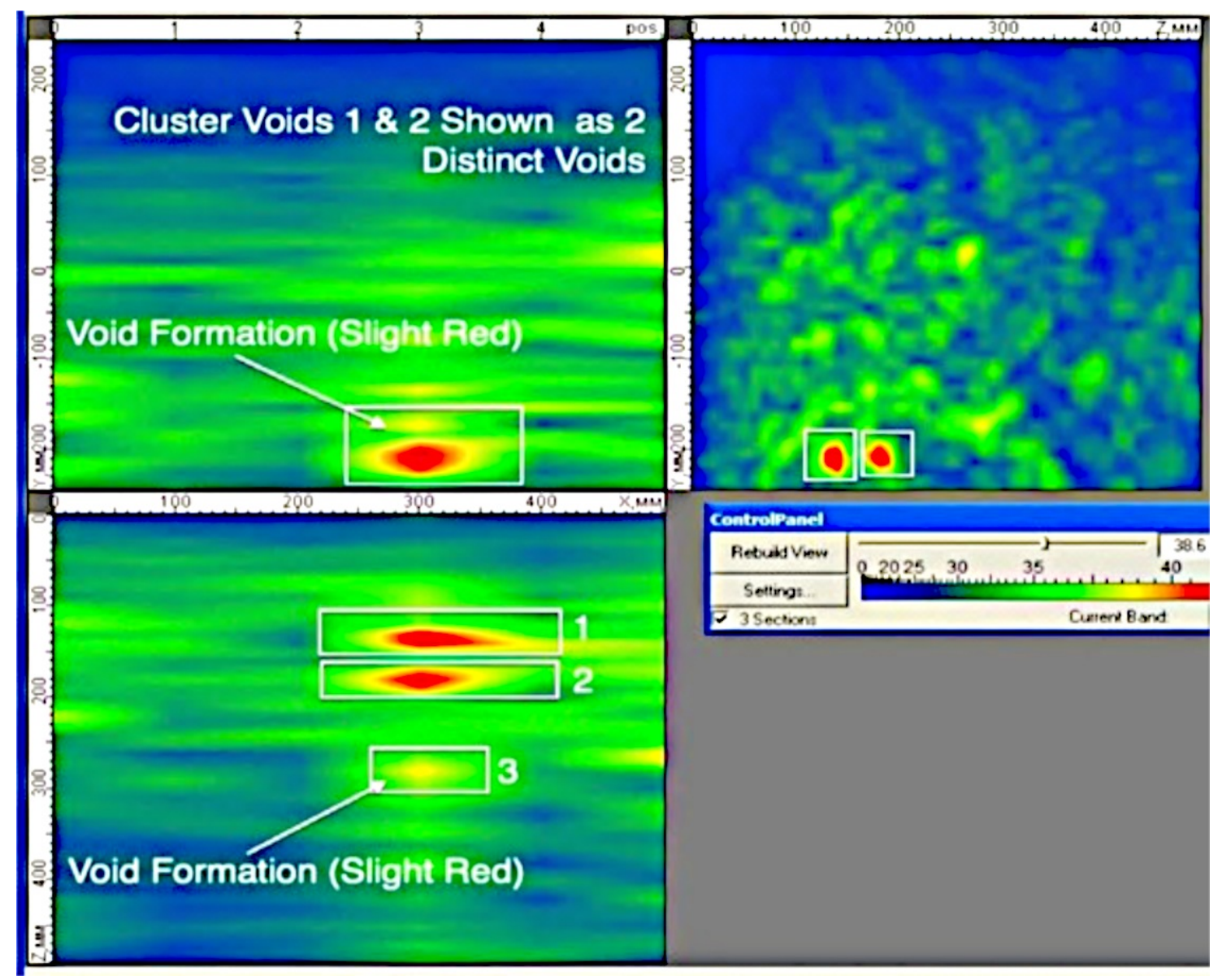

Figure 4.35 - 100 Hz Scan Results Indicating Distinct Voids Closely Spaced and Potential Void Formation from Pier 7-3

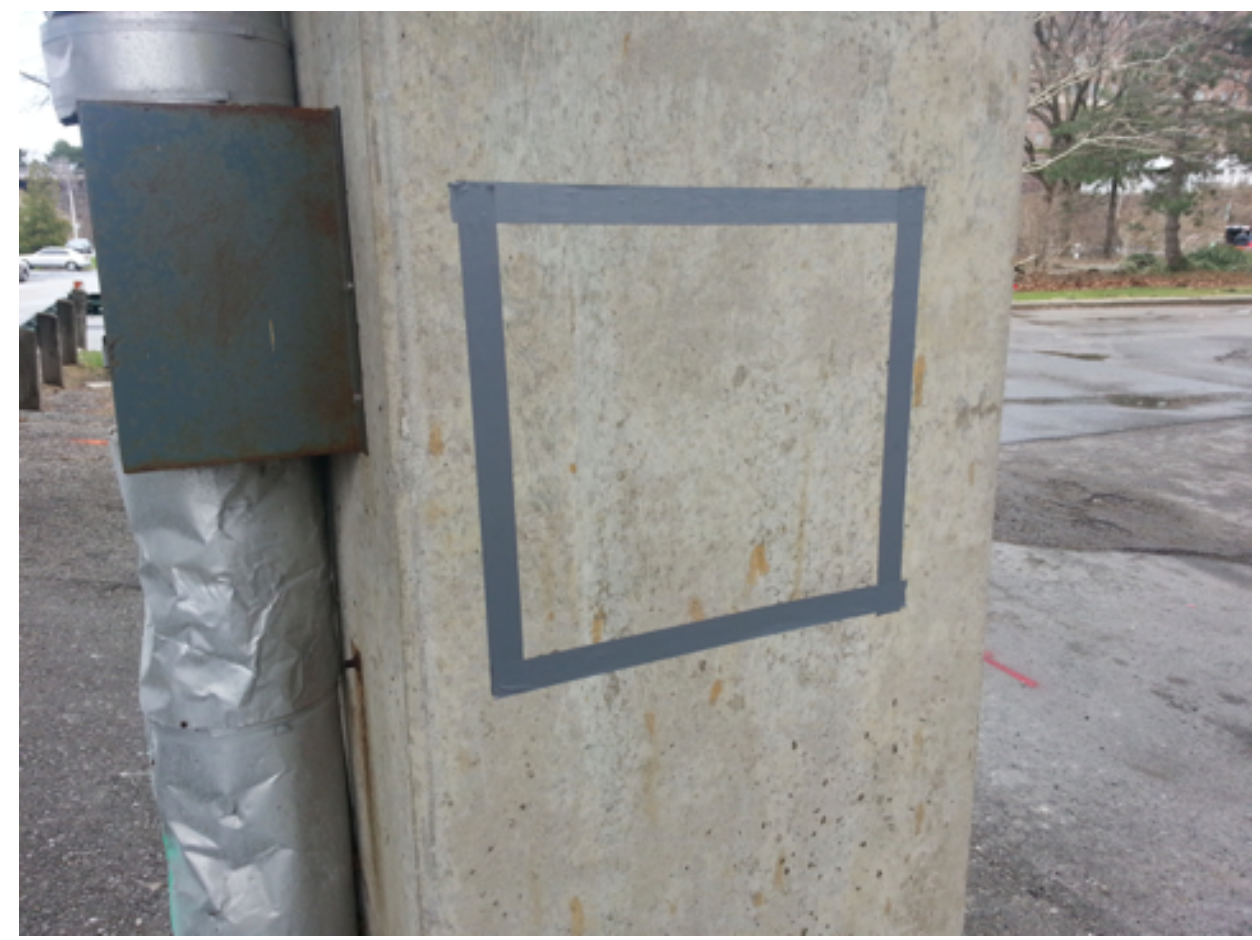

Figure 4.36 - Pier 7-3 Scan Outline 


\subsection{Crack Width, Spacing and Modulus of Elasticity of the Piers and Abutments}

The crack width, spacing and modulus of elasticity of the piers and abutments were calculated using the adopted models (Dawood and Marzouk, 2011; Elshafey et al., 2013; Popovics et al., 2008; Birgul, 2009). The reinforcement detailing provided by the Town of Oakville was used to calculate the crack width and spacing of the pier columns and the obtained $\mathrm{S}$-wave and $\mathrm{P}$-wave velocities from shear wave tomography and impact-echo were used to calculate the in-place modulus of elasticity. The crack width and spacing were calculated based on the area of steel present in the concrete section of $1220 \times 1220 \mathrm{~mm}$ piers. The crack spacing was computed to be $65 \mathrm{~mm}$ while the crack width was calculated to be $0.137 \mathrm{~mm}$. Although the crack spacing is smaller than expected, it is likely due to the close proximity of the reinforcement bars in the pier columns. The in-place static moduli of elasticity of the piers were computed and are shown in Table 4.1. The initial elasticity of the members at the time of construction was not provided by the Town of Oakville; thus a conservative value of $\mathrm{E}=30 \mathrm{GPa}$ was chosen for comparison. The last column of Table 4.1 is the ratio between the in-place modulus of elasticity and the assumed elasticity at the time of construction (30 GPa). In general, a ratio of 0.85 or greater is in the acceptable range, with any values under the threshold requiring a detailed investigation of the members that fell below the threshold. Although some of the ratios in Table 4.1 are greater than 1.0 (meaning an increase in stiffness), it is likely due to errors during scanning or the initial value of the elasticity being different.

\begin{tabular}{|c|c|c|c|c|c|c|c|}
\hline Member & Vs & Vp & V & p & Ed & Es & Es/Es \\
\hline Pier 2-1 & 2,449 & 3,796 & 0.236070 & 2.4 & $35,584,593$ & 29.53521251 & 0.984507084 \\
\hline Pier 2-2 & 2,361 & 3,660 & 0.236070 & 2.4 & $33,073,215$ & 27.45076828 & 0.915025609 \\
\hline Pier 2-3 & 2,394 & 3,711 & 0.236070 & 2.4 & $34,004,213$ & 28.22349689 & 0.94078323 \\
\hline Pier 2-4 & 2,415 & 3,743 & 0.236070 & 2.4 & $34,603,395$ & 28.72081767 & 0.957360589 \\
\hline Pier 3-3 & 2,435 & 3,774 & 0.236070 & 2.4 & $35,178,909$ & 29.19849459 & 0.973283153 \\
\hline Pier 3-4 & 2,441 & 3,784 & 0.236070 & 2.4 & $35,352,489$ & 29.34256589 & 0.97808553 \\
\hline Pier 5-1 & 2,397 & 3,715 & 0.236070 & 2.4 & $34,089,490$ & 28.29427679 & 0.94314256 \\
\hline Pier 5-2 & 2,448 & 3,794 & 0.236070 & 2.4 & $35,555,539$ & 29.51109721 & 0.98370324 \\
\hline Pier 5-3 & 2,419 & 3,749 & 0.236070 & 2.4 & $34,718,118$ & 28.81603788 & 0.960534596 \\
\hline Pier 5-4 & 2,338 & 3,624 & 0.236070 & 2.4 & $32,431,979$ & 26.91854262 & 0.897284754 \\
\hline Pier 6-1 & 2,494 & 3,866 & 0.236070 & 2.4 & $36,904,331$ & 30.63059464 & 1.021019821 \\
\hline Pier 6-2 & 2,539 & 3,935 & 0.236070 & 2.4 & $38,248,098$ & 31.74592102 & 1.058197367 \\
\hline Pier 6-3 & 2,356 & 3,652 & 0.236070 & 2.4 & $32,933,282$ & 27.33462385 & 0.911154128 \\
\hline Pier 6-4 & 2,442 & 3,785 & 0.236070 & 2.4 & $35,381,461$ & 29.36661225 & 0.978887075 \\
\hline Pier 7-1 & 2,444 & 3,788 & 0.236070 & 2.4 & $35,439,439$ & 29.41473451 & 0.98049115 \\
\cline { 1 - 4 }
\end{tabular}




\begin{tabular}{|c|c|c|c|c|c|c|c|}
\hline Pier 7-2 & 2,421 & 3,753 & 0.236070 & 2.4 & $34,775,551$ & 28.86370709 & 0.96212357 \\
\hline Pier 7-3 & 2,456 & 3,807 & 0.236070 & 2.4 & $35,788,308$ & 29.70429537 & 0.990143179 \\
\hline Pier 7-4 & 2,403 & 3,725 & 0.236070 & 2.4 & $34,260,364$ & 28.43610252 & 0.947870084 \\
\hline West Abutment & 2,487 & 3,855 & & & & & \\
& & & 0.236070 & 2.4 & $36,697,460$ & 30.45889195 & 1.015296398 \\
\hline
\end{tabular}

Table 4.1 - Dynamic and Static Modulus of Elasticity Using the Adopted (Popovics et al., 2008; Birgul, 2009) 


\section{Chapter 5 Management Strategy}

\subsection{Introduction}

Ageing structures and limited maintenance budgets require accurate and economic assessment models to address the repair and rehabilitation needs of structures correctly. The condition of bridges is usually assessed through a Bridge Condition Index (BCI), which uses a ranking tool provided by the Ministry of Transportation (MTO, 2014) to schedule maintenance and repair of the bridge. The BCI is not used as an indicator of the bridge safety, but rather, a ranking system used for decision making.

Bridge management strategies are a function of the budget, and the functionality of the structure. Preventive maintenance is a form of bridge management, where the structure is monitored to detect the point of intervention in order to provide timely maintenance or rehabilitation. The methodologies used to monitor the bridge include condition assessment, condition rating, and studying dynamic parameters from structural monitoring procedures. The focus of the study on the Rebecca Street Bridge was to utilize structural health monitoring to analyze the present deterioration and to establish a condition benchmark. Structural health monitoring techniques are often used to analyze the Eigen frequencies, the damping ratio, the vibration intensity and other key performance indicators as shown in Figure 5.1.

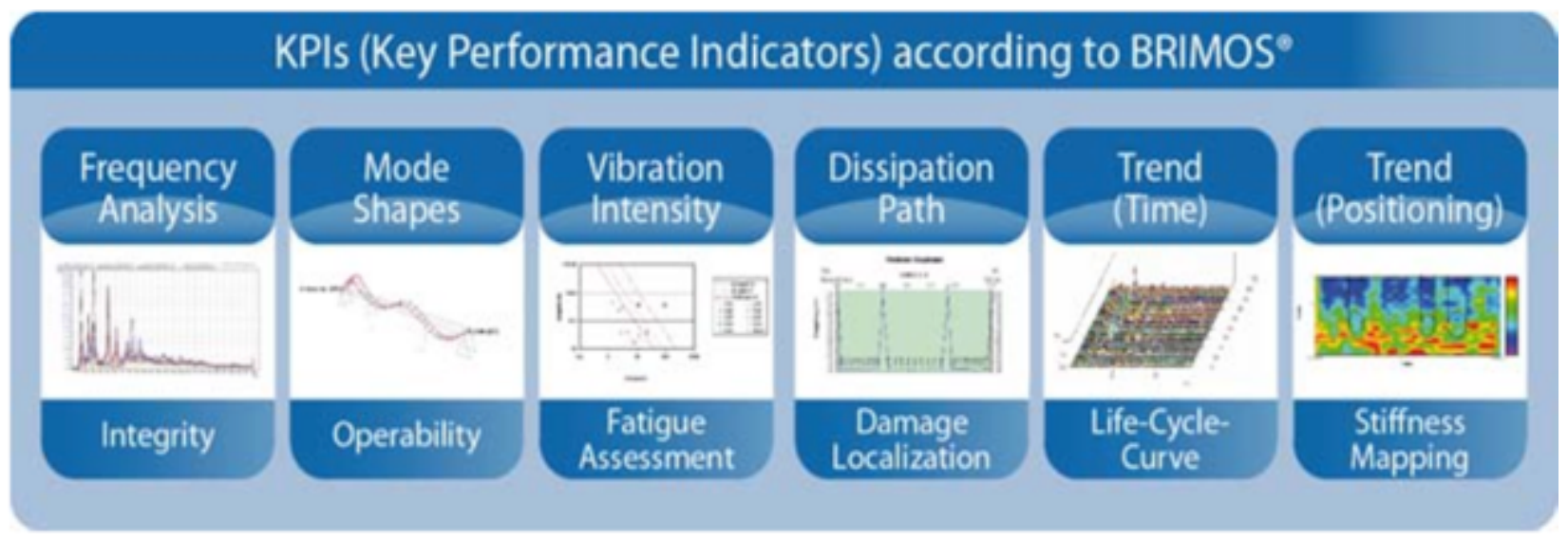

Figure 5.1 - Common Parameters for Structural Health Monitoring (Wenzel, 2010)

\subsection{Life Cycle Assessment}

The basis of any maintenance methodology is the consideration of the entire lifecycle of a structure in order to make appropriate and timely decisions regarding potential retrofit measures 
(Wenzel, 2010). The development of a management strategy is based on some of the following aspects:

- Assumption of a generic degradation model

- A wide range of parameters influencing the condition of the bridge (i.e. stiffness, crack width, crack spacing, settlement, deflection)

- The parameters are grouped such that they are inspected under existing assessment routines (i.e. visual inspection, damage detection methodologies, dynamic monitoring methodologies)

In order to meet the governing requirements regarding the durability, real degradation process and residual lifetime considerations, the following major aspects are to be considered for life cycle modeling (Wenzel, 2010):

- Estimation of the design life of new structures and the estimation of the residual life of existing structures

- Assessment criteria in order to take corrective measure:

- Dynamic bridge monitoring

○ Visual inspections

- Material tests in order to assess the in-place strength (i.e. compressive strength) and durability (i.e. chloride intrusion)

- Maintenance instructions to preserve the original design life and functionality of the bridge

\subsubsection{Estimation of the Design Life and Residual Life of Structures}

The service life of new structures is highly dependent on the initial design, applied design codes, and safety considerations during static calculations. Overdesign of structural members will ultimately lead to a prolonged service life. A sample of the design life of new structures calculated using probability density functions is shown in Figure 5.2. The estimation of the operational lifetime of a structure is based on the following factors:

- Year of construction

- Static system

- Materials

- Cross-Section type 


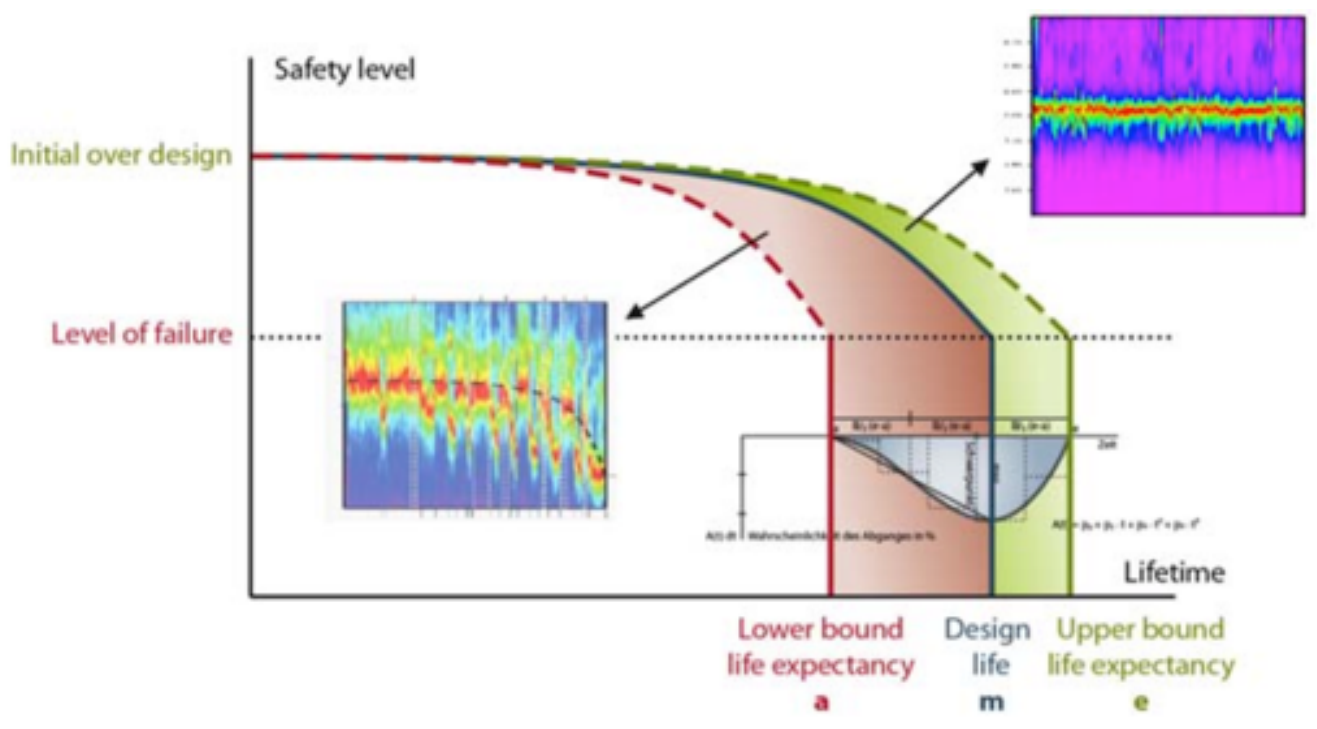

Figure 5.2 - Analytical Lifeline of New Structures (Wenzel, 2010)

The theoretical design life is further assessed and enhanced by considering factors such as the concrete cover, concrete quality, and environmental conditions (i.e. temperature, frost action). In addition, the deterioration process is addressed and includes factors such as freight traffic volume, potential impact, and chemical exposure (i.e. deicing chemicals). The consideration of these major factors ensures that the expected design life is modeled more precisely, and maintenance procedures can be allotted at an appropriate time. In addition, lifelines are also provided for each structural member in order to model the overall structural behavior more accurately.

The lifeline of existing structures is modeled through refining the original design lifeline and supplying additional information such as:

- Bridge inspection reports

- Dynamic monitoring results

- Schedule of performed maintenance and rehabilitation measures

- Loading history

- Material Tests (chloride intrusion / compressive strength, carbonation, etc.)

- Data on the environmental conditions

The additional information is merged though a maintenance condition matrix to determine the updated lifecycle curve. The model relies on parameter updates, after which the life of the structure increases (maintenance/rehabilitation) or decreases (degradation). A typical lifecycle curve is shown in Figure 5.3. 


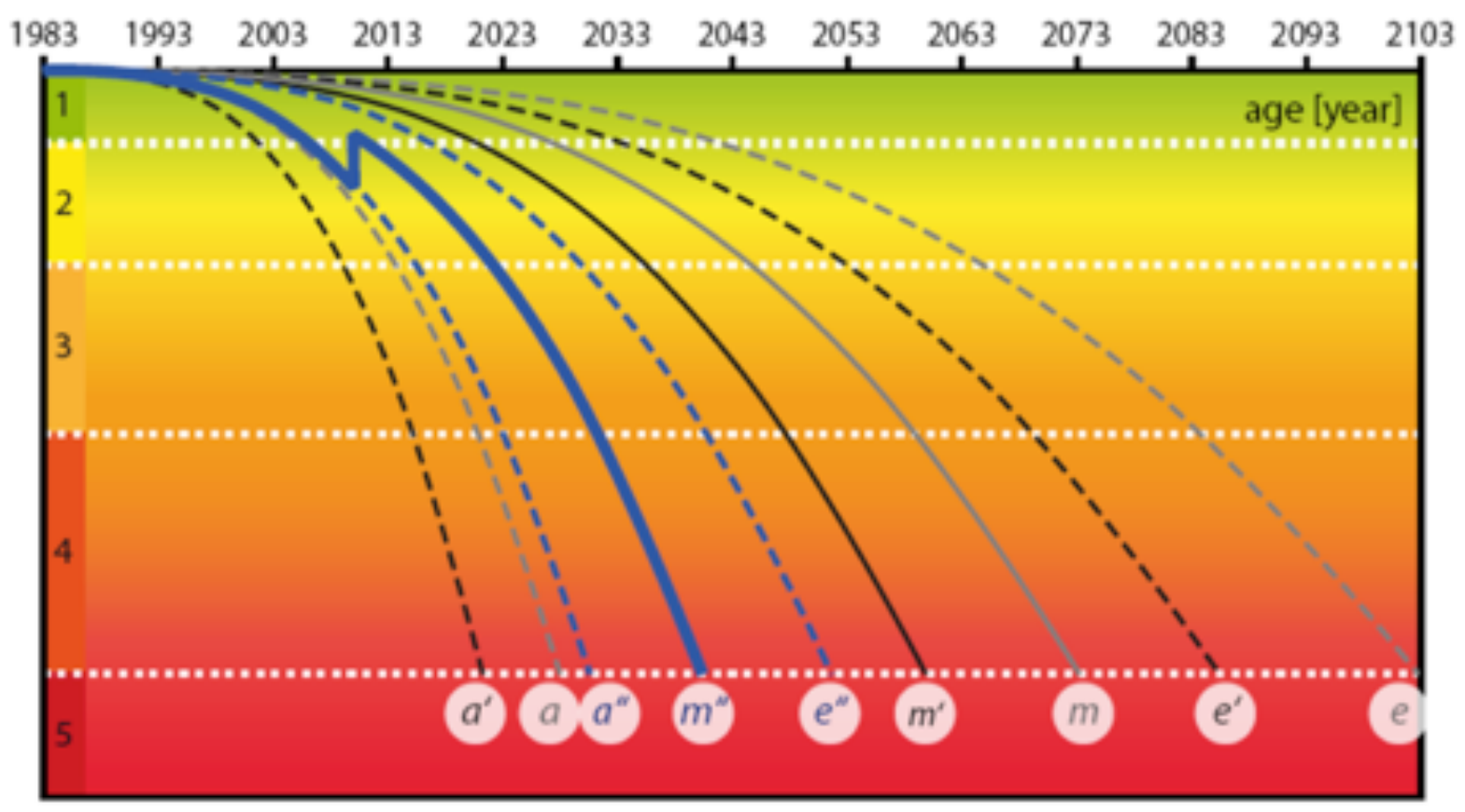

Figure 5.3 - Effects of Maintenance on the Lifeline of Structures (Wenzel, 2010)

Lifecycle curves of existing structures rely heavily on continuous conditions assessment in order to aid with maintenance planning and determining the resultant lifeline curve. The ageing speed of the structure is gauged through comparison of the expected and measured structural integrity over time. The engineer in charge of bridge inspections is often obligated to provide appropriate maintenance instructions to guarantee the original design life of the structure is fulfilled. The determination of the lifecycle curve for the Rebecca Street Bridge was beyond the scope of this report, and will not be computed.

\subsubsection{Assessment Procedure}

The assessment procedure is a multi-level procedure that involves investigations to obtain the input, weighting the inputs and comparing maintenance and repair options and their effects on the residual life of the structure. The investigation findings are often predetermined parameters to input into the lifecycle matrix. The confidence level in determining the service life increases as the input accuracy increases. A confidence level of 0.95 (95\%) is applied to the analysis under normal circumstances. Figure 5.4 illustrates the assessment procedure using visual inspections and structural health monitoring. 


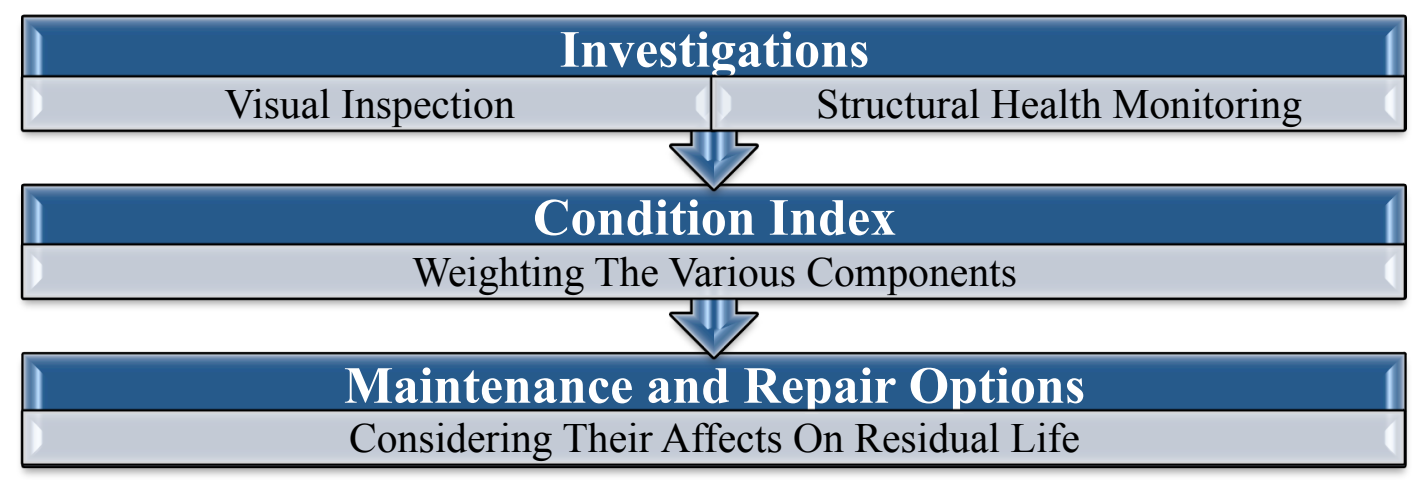

Figure 5.4 - Assessment Procedure Using Visual Inspections and SHM

\subsection{Moment Curvature for Crack Modeling}

The curvature of loaded structures is used in health monitoring to detect structural damage based on changes in the stiffness of the structural members. The bending stiffness of a structural member, such as the bridge piers can be measured from the moment-curvature relationship to evaluate the performance of the bridge under service loads. Monitoring the stiffness factor is a key factor in SHM, as an increase in damage is correlated to a decrease in the stiffness of the structure. A typical moment-curvature is shown in Figure 5.5 for reinforced concrete members. The curve is composed of three portions (I, II and II), which constitute to the cracking moment $\left(\mathrm{M}_{\mathrm{cr}}\right)$, the plastic moment $\left(\mathrm{M}_{\mathrm{p}}\right)$ and the ultimate moment $\left(\mathrm{M}_{\mathrm{u}}\right)$ respectively.

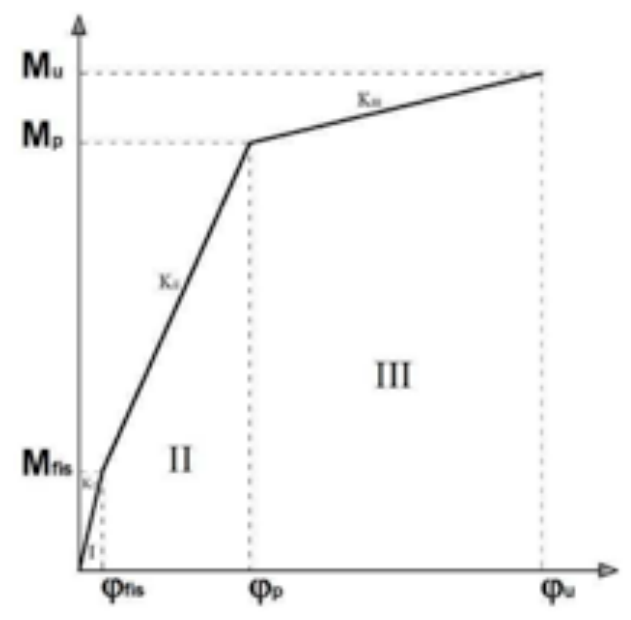

Figure 5.5 - A Typical Moment-Curvature Plot

In general the moment curvature relationship of reinforced concrete members is controlled by flexural stresses. A trilinear moment curvature relationship can be used to denote the transitions between the initial cracking, yielding and ultimate moment stages. The moment- 
curvature relationship for a given member can be established by first dividing the member into a number of concrete and steel fibres. The process involves iterative procedures in determining the moment $(\mathrm{M})$ and curvature $(\phi)$ at various strain levels. Once the moment-curvature points are obtained, the curve is idealized with linear and non-linear segments. The computed moment curvature of the Rebecca Street Bridge piers is shown in Figure 5.6. The plot labels indicate the points of initial cracking, yielding, and additional points until the ultimate failure. At the first stage (prior to cracking), the tensile portion of the concrete member does not experience any cracking since the applied loads are too small. The cracking point $(\mathrm{M}=24,851 \mathrm{kN} . \mathrm{m})$ is reached when normal service loads are applied and flexural cracks in the tensile portion of the concrete begin to develop. However, flexural cracks are inevitable in reinforced concrete, since concrete is weak in tension. The additional points include strains of $0.0015,0.0025,0.004,0.006$ and 0.009 . The moment continues to increase until the yielding point is reached $(168,164.9 \mathrm{kN}$.m). The final stage is characterized by a rapid increase in strains until the ultimate point is reached $(M=243,287$ kN.m).

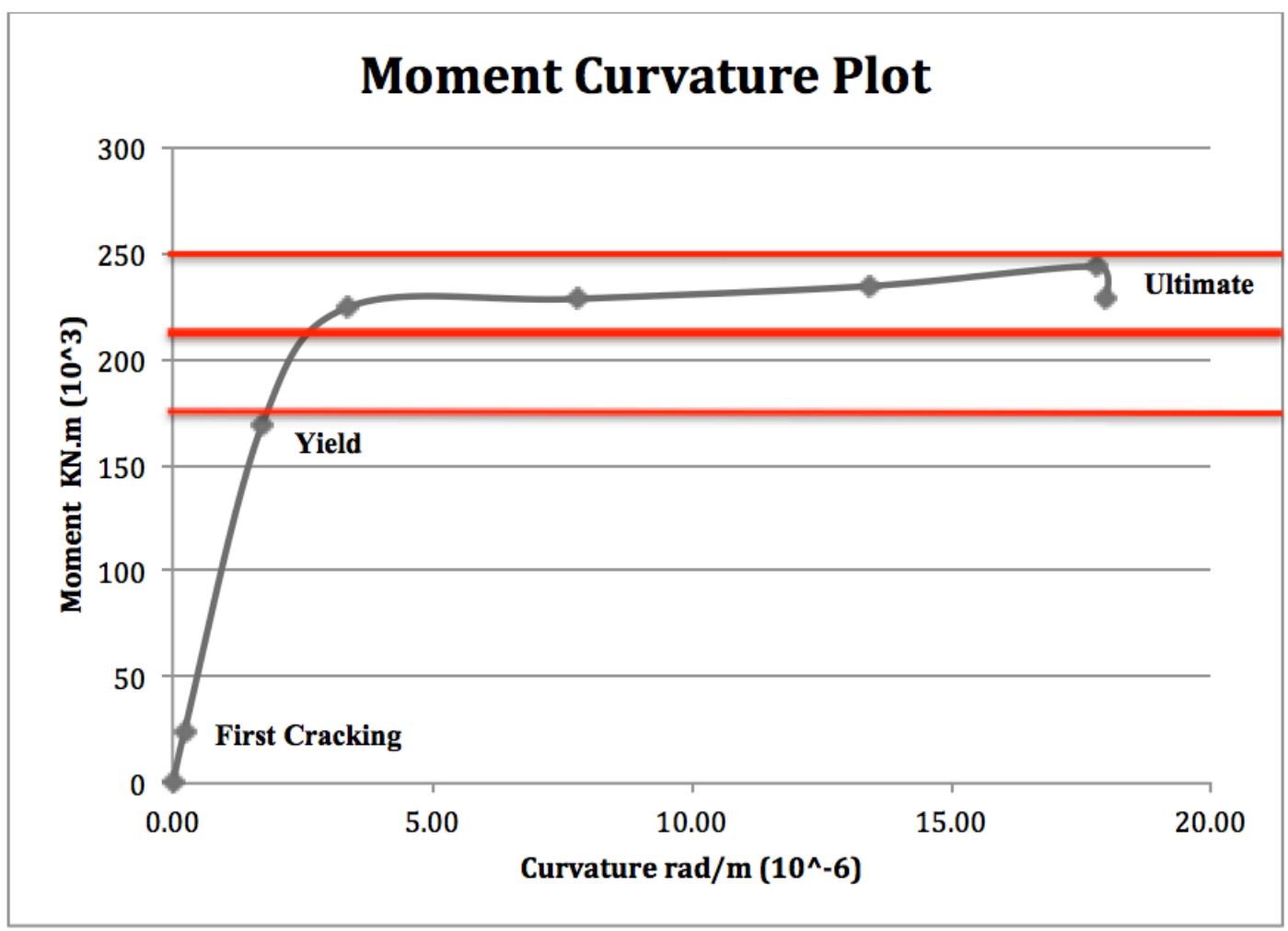

Figure 5.6 - Moment-Curvature Plot of the Rebecca Street Bridge Pier Columns

The chart shown in Figure 5.6 also indicates three red lines, at the yield point, at the ultimate point, and an intermediate point at 40\% ( $\mathrm{M}=198,213 \mathrm{kN} . \mathrm{m})$ between the yield and ultimate point. The intermediate point is used as a warning level, triggering emergency repair or 
rehabilitation procedures when the strains surpass the established threshold. Although the bridge will not be continuously monitored, periodic dynamic assessments such as the shear wave tomographer can be used to calculate the strains and stiffness of the bridge piers or abutments. Fiber optics sensors have also been successfully used to monitor the moment-curvature. The sensors are installed at a level above the neutral axis (compressive zone), and below the neutral axis (tensile zone). The sensors provide real time data, measuring the strains and computing inplace moment curvatures. The type of sensor (short-gauge or long gauge) is dependent on the type of material being monitored (i.e. steel or concrete). Figure 5.7 shows a general guideline for selecting the type of sensor. Although fiber optics sensors are usually installed at the time of construction, they could also be implemented during major rehabilitation where the concrete is chipped past the reinforcement level.

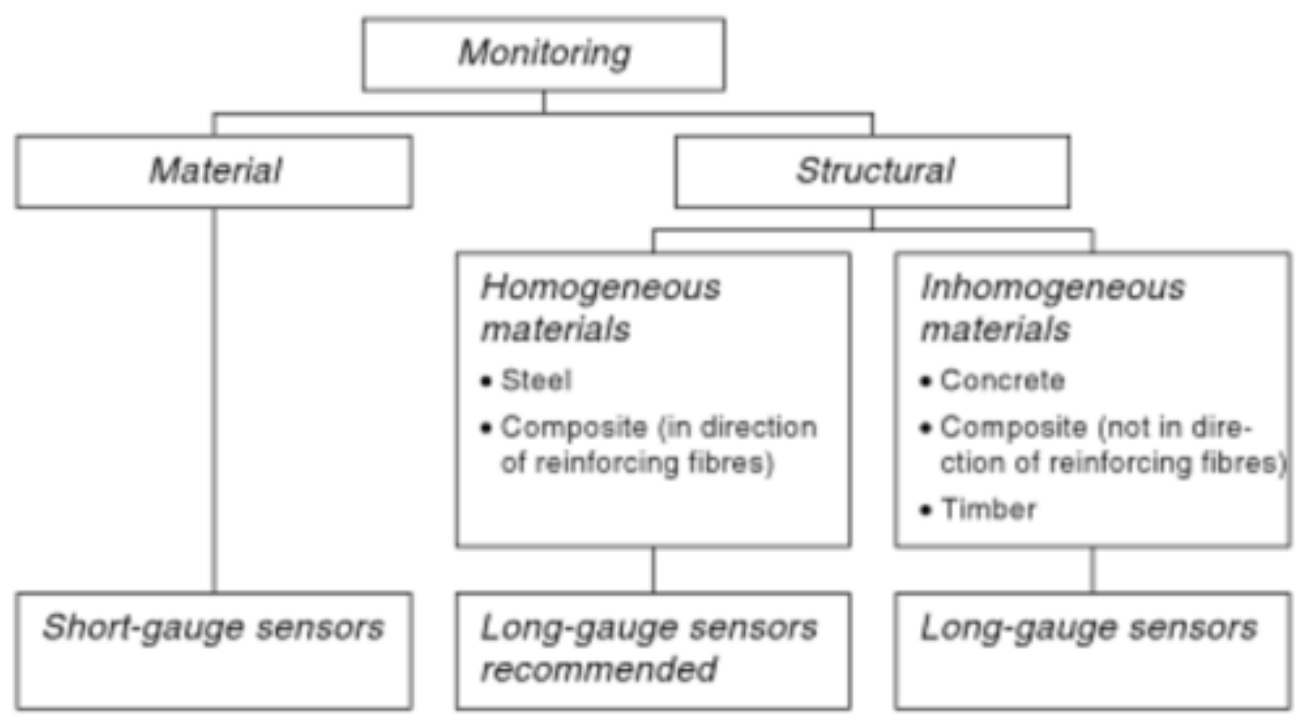

Figure 5.7 - General Principle of Gauge Length Selection Based on Purpose (Glisic and Inaudi, 2007)

\subsection{Management Strategy for the Rebecca Street Bridge}

\subsubsection{Structural Information}

The Rebecca Street Bridge (William Anderson Bridge) was constructed in 1961 over the Sixteen Mile Creek in the Town of Oakville. The bridge is composed of a four-lane steel girder with a composite concrete deck and concrete piers and abutments, supported by eleven simply supported spans (10@16.5 m and $1 @ 39.5 \mathrm{~m}$ ). The overall length of the bridge deck is $204 \mathrm{~m}$ with an asphalt-wearing surface of $14 \mathrm{~m}$ in width and a $2 \mathrm{~m}$ wide sidewalk cantilevered on both sides. The bridge also has a utility corridor (600 mm water main, $1000 \mathrm{~mm}$ sewer line and 170 
mm gas main) provided below the bridge deck. Figures 5.8 and 5.9 show the plan and elevation drawings of the bridge respectively.

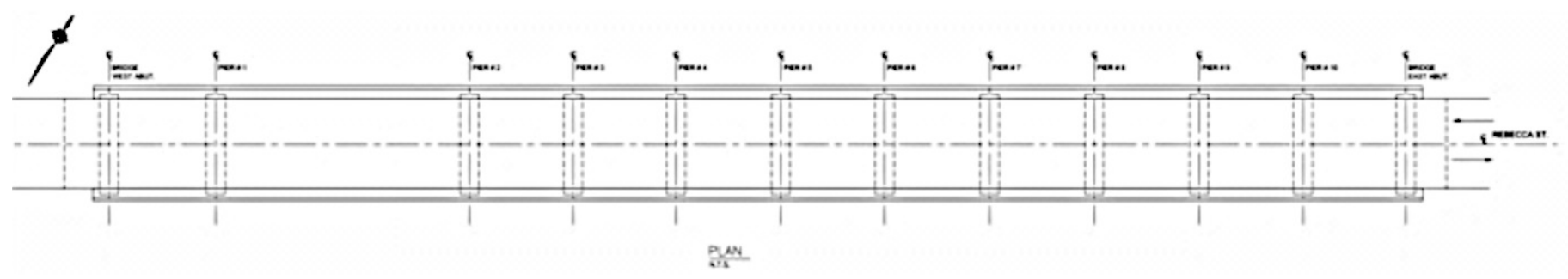

Figure 5.8 - Rebecca Street Bridge Plan View Drawing (Cole Engineering, 2013)

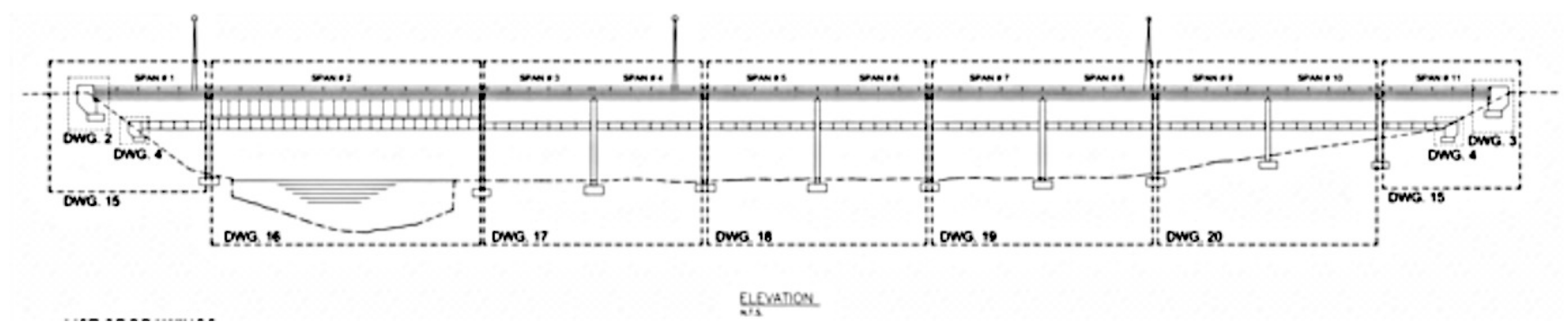

Figure 5.9 - Rebecca Street Bridge Elevation View Drawing (Cole Engineering, 2013)

\subsubsection{Visual Inspection Indicator}

The safety and maintenance requirements of provincial bridges is outlined in the Government of Ontario (2008) Public Transportation and High Improvement Act, which requires that all provincial and municipal bridges be visually inspected every two years under the direction of a professional engineer using the Ministry of Ontario Structure Inspection Manual. The act instructs the engineer to provide a detailed visual assessment of each bridge element, noting any material defects, performance deficiencies, and maintenance/rehabilitation needs. The Ministry of Transportation of Ontario (MTO) inspects provincial bridges, whereas municipal bridges, such as the Rebecca Street Bridge in the Town of Oakville are the responsibility of the municipality (Town of Oakville).

Visual inspections are used to ensure bridge safety, and to identify members in need of maintenance/replacement. The inspector may also ask for detailed investigations such as a deck condition survey or fatigue investigation. The bridge inspections are supplied into a Ministry database, known as the Bridge Management System (BMS), which contains physical and historical information about the bridge, the bridge length, number of spans, area of each bridge element, the results from each inspection, and the condition each element is to be assessed is in from poor to excellent. Using this information, the system calculates a single value known as the 
Bridge Condition Index (BCI), which is a measure of the bridge's overall structural condition, and its remaining economic value (0 to 100). Table 5.1 highlights the correlation between the $\mathrm{BCI}$ and the recommended action in Ontario.

\begin{tabular}{|ccl|}
\hline BCI Range & $\begin{array}{c}\text { Condition } \\
\text { Good } \mathbf{1 0 0}\end{array}$ & $\begin{array}{l}\text { Recommended Action } \\
\text { Maintenance work is usually not required within the next } \\
\text { five years. }\end{array}$ \\
\hline $\mathbf{6 0}-\mathbf{7 0}$ & Fair & $\begin{array}{l}\text { Maintenance work is usually scheduled within the next five } \\
\text { year. This is the ideal time to schedule major bridge repairs } \\
\text { from an economic perspective. }\end{array}$ \\
\hline Less than 60 & Poor & $\begin{array}{l}\text { Maintenance work is usually scheduled within one year from } \\
\text { inspection date. }\end{array}$ \\
\hline
\end{tabular}

Table 5.1 - BCI Ratings Used by MTO (MTO, 2014)

In order to provide an economic and timely maintenance schedule, it is recommended that once the BCI of the Rebecca Street Bridge falls below 65, a detailed investigation of the bridge be undertaken. As suggested by provincial guidelines for bridge inspection, a BCI ranged from 60-70 would be the correct time to begin scheduling for major rehabilitation. Thus, a conservative value of 65 was chosen to allow for additional visual inspections and detailed dynamic monitoring in order to optimize the maintenance procedure.

\subsubsection{Dynamic Monitoring Indicator}

The dynamic monitoring procedure for the Rebecca Street Bridge can be decomposed into the monitoring of each bridge element. The superstructure (Steel Girders) should be monitored via the Random Decrement (RD) with Fiber Brag Grating. The instrumentation will be mounted on the main W760 x 173 steel girders in order to monitor the strains and the dynamic signature of the girder. The RD is a relative approach, comparing future response curves to an initial curve to monitor the frequency, damping and other parameters. A loss of stiffness in the girders due to deterioration (i.e. corrosion) will result in a new curve. Thus, monitoring the response curve will allow for timely maintenance strategies. The detailed SHM program for the steel Girder is out of the scope of this investigation. The substructure (piers and abutments) should be monitored via the MIRA 3D shear wave tomographer. Shear wave scans provide:

- Detection of damage (i.e. cracking, delamination, etc.)

- Location of the damage

- Identification of the type of damage

- Quantification of the severity of the damage 
The shear wave scans provide a better estimate of the amount of concrete that needs to be removed on each of the piers and abutments and provides a more economical repair approach. In addition, the scans provide the shear wave speed, which can be used to calculate the in-place dynamic and static moduli of elasticity using the adopted models (Popovics et al., 2008; Birgul, 2009). The elasticity can then be used to determine the in-place concrete strength and compared to the original concrete elasticity and strength at the time of construction and subsequent shear wave scan results. The bridge deck can be assessed using a variety of methods such as:

- Impact Echo (IE)

- Ultrasonic Pulse Echo (UPE)

- Half-Cell Potential

- Impulse Response (IR)

- Ultrasonic Surface Waves (USW)

- Ground Penetrating Radar (GPR)

- Chain Drag/ Hammer Sounding

- $\quad$ Electrical Resistivity (ER)

- Infrared Thermography

- Galvanostatic Pulse Measurement (GPM)

A Belgian study (Gucunski and Nazarian, 2010) compared various NDT instruments for identifying bridge deck damage and ranked them according to accuracy, precision, speed, ease of use, and cost. The analysis utilized the instruments to identify concrete delamination, cracking, degradation and reinforcement corrosion. The study used a weighted approach placing significant importance on accurate, precision, speed, ability to detect concrete delamination and ability to detect reinforcement corrosion. Table's 5.2 and 5.3 summarize the weighted factors used and the result of the tests respectively.

\begin{tabular}{|l|c|l|c|}
\hline \multicolumn{1}{|c}{$\begin{array}{c}\text { Performance } \\
\text { Measure }\end{array}$} & \multicolumn{1}{c|}{ Weight Factor } & Deterioration Type & Weight Factor \\
\hline Accuracy & 0.25 & Delamination & 0.42 \\
\hline Precision & 0.30 & Corrosion & 0.35 \\
\hline Speed & 0.25 & Cracking & 0.10 \\
\hline Ease of Use & 0.10 & Concrete Degradation & 0.13 \\
\hline Cost & 0.10 & \multicolumn{2}{c}{} \\
\cline { 1 - 2 } & &
\end{tabular}

Table 5.2 - Performance Measure and Deterioration Type Vs. Weight Factor (Gucunski and Nazarian, 2010) 


\begin{tabular}{|l|c|c|c|c|c|}
\hline \multicolumn{2}{|c|}{ Deterioration Type Delamination } & Corrosion & Cracking $\begin{array}{c}\text { Concrete } \\
\text { Deterioration }\end{array}$ & $\begin{array}{c}\text { Overall } \\
\text { Value }\end{array}$ \\
\hline Impact Echo & 4.7 & 1.0 & 2.5 & 3.1 & 3.0 \\
\hline Ultrasonic Pulse Echo & 3.6 & 1.0 & 2.6 & 3.4 & 2.6 \\
\hline Half-Cell Potential & 1.0 & 4.9 & 0.0 & 1.0 & 2.3 \\
\hline Impulse Response & 3.6 & 1.0 & 0.0 & 2.6 & 2.2 \\
\hline Ultrasonic Surface Waves & 2.5 & 1.0 & 3.0 & 3.4 & 2.2 \\
\hline Ground Penetrating Radar & 3.0 & 1.0 & 1.0 & 3.1 & 2.1 \\
\hline $\begin{array}{l}\text { Chain Drag/ Hammer } \\
\text { Sounding }\end{array}$ & 3.7 & 1.0 & 0.0 & 1.0 & 2.1 \\
\hline Electrical Resistivity & 1.0 & 3.9 & 0.0 & 1.0 & 1.9 \\
\hline Infrared Thermography & 3.2 & 1.0 & 0.0 & 1.0 & 1.8 \\
\hline $\begin{array}{l}\text { Galvanostatic Pulse } \\
\text { Measurement }\end{array}$ & 1.0 & 3.0 & 0.0 & 1.0 & 1.6 \\
\hline
\end{tabular}

Table 5.3 - Ranking of NDT for Determining Bridge Deck Deterioration (Gucunski and Nazarian, 2010)

\subsubsection{Monitoring Prognosis Model}

The monitoring prognosis model is based on the periodic visual inspections, which provide the Town of Oakville with a Bridge Condition Index (BCI) value and recommended maintenance and repair procedures. As discussed previously, a BCI value ranged from 60-70 corresponds to maintenance planning over the next 5 years. In this investigation, a BCI value of 65 was chosen to be the determining factor, a value above means no immediate maintenance is required, a value below means that an in depth analysis of the main bridge members is required. The detailed investigation should analyze the condition of the deck, piers, pier caps, abutments and main steel girders. A preliminary inspection of these members will define whether they are in "good" or "poor" condition. Members that are deemed to be in "poor" condition should be assessed via dynamic monitoring to determine the type, extent and location of the damage. The Town of Oakville should then determine a budget for maintenance and review maintenance and repair options (discussed in Appendix D). Figure 5.10 illustrates a flow chart illustrating a basic monitoring prognosis model for the Rebecca Street Bridge. 


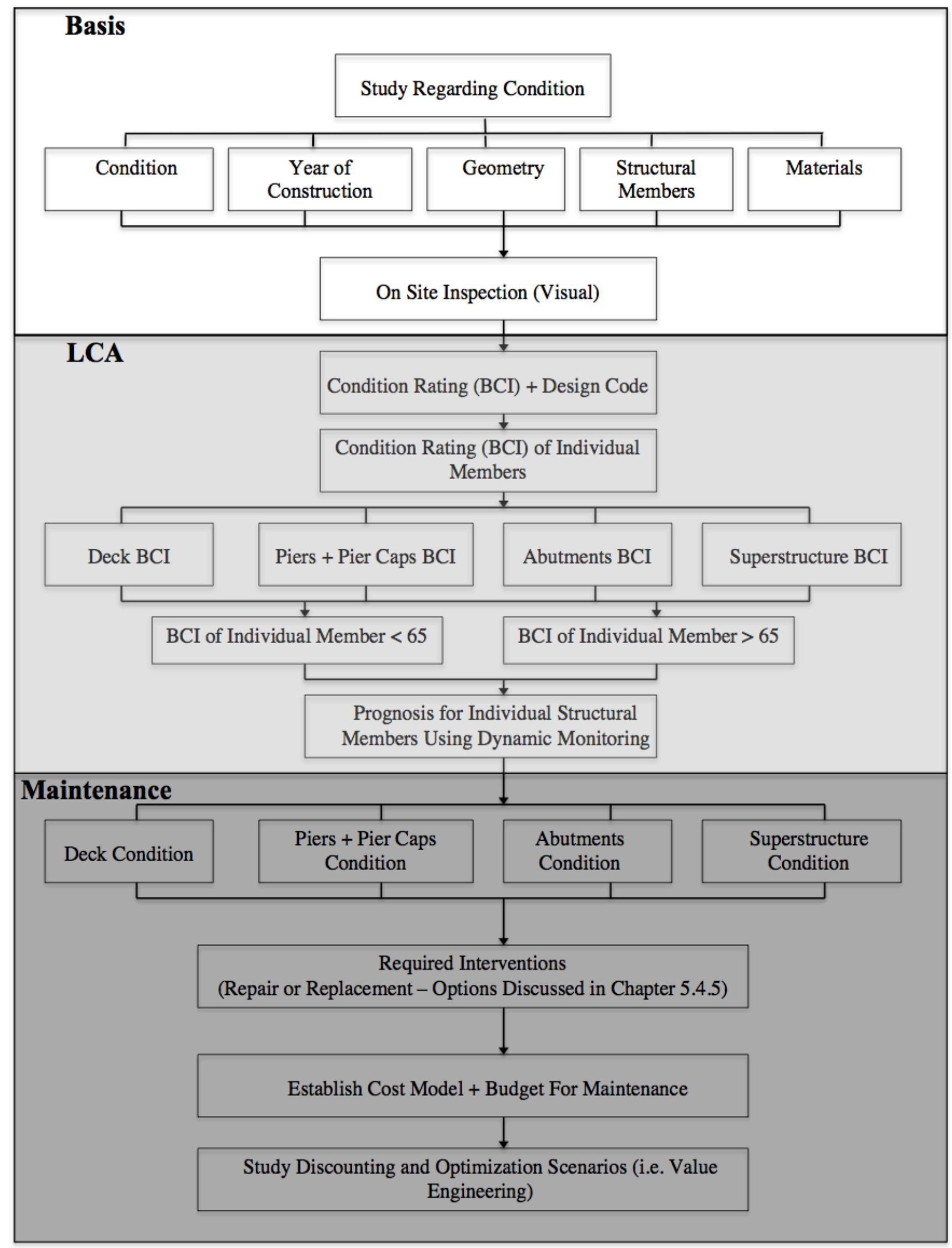

Figure 5.10 - Rebecca Street Bridge Prognosis Model 


\section{Chapter 6 Conclusion}

The scope of this study was to employ a structural health monitoring strategy for the Rebecca Street Bridge (William Anderson Bridge) to provide accurate information regarding the structural behavior and performance during regular operation.

This research investigation used nondestructive testing to detect the presence and location of any damage in the concrete piers and abutments. Structural health monitoring techniques detect presence, location, type and extent of any damage based on changes in the structural and modal parameters. Damage identification is an important step in structural health monitoring, as it provides a warning trigger for the level of structural damage, which is useful in determining the level of maintenance and rehabilitation appropriately. In addition, the data obtained during structural health monitoring studies can be used to model the remaining life of the structure and to analyze how different maintenance strategies affect the structural service life of the bridge. The nondestructive equipment used in this study included the MIRA 3D shear wave tomographer to obtain shear wave scans and shear wave velocities, and Impact-Echo to obtain pressure wave velocities. The shear wave scans were studied to provide:

- Detection of the existence and size of damage

- Location of the damage

- Identification of the type of damage

- Quantification of the severity of the damage

The shear wave scans were used to determine the presence of any anomalies such as cracks, which then trigger further investigations to determine the width/spacing of the crack present and compare them with the allowable limits. In general, it is desirable to limit cracks widths/spacing under serviceability limitations to avoid aesthetics and durability issues. The validity of code prescribed crack width and spacing computations has been studied extensively, and it has been found that code based computations can be modified for thick structural members, like the piers of the Rebecca Street Bridge. Thus, the Crack Width Model (Dawood and Marzouk, 2011) and Neural Analysis (Elshafey et al., 2013) were utilized to compute the crack width and spacing respectively.

The visual inspections and shear wave scan results provided a solid foundation for analyzing the current state of the structural members of the Rebecca Street Bridge. As initially expected, the overall structural condition of the bridge is good and no major deterioration was noted. However, the results obtained during this investigation did raise some concern in piers 2-1, 
3-1, 3-2, 5-1, 5-2, 5-3,5-4, 6-1, 7-1 and 7-3. Although most of the voids detected during the shear wave scans were small in nature, the potential formation of void clusters could result in cracking and delamination in these members. Thus, it is recommended that a more in depth analysis of these members be undertaken, with subsequent scans suggested at higher elevations. In addition, the results obtained during this investigation provide a benchmark for future analysis, where future crack maps can be compared to those obtained during this investigation.

The wave velocities obtained during the scanning phase were utilized to obtain the dynamic modulus of elasticity using the adopted models (Popovics et al., 2008; Birgul, 2009). The in-place dynamic modulus of elasticity value is important, as it is compared to the modulus of elasticity at the time of construction or subsequent rehabilitation procedures. However, since the elasticity value at the time of construction was unknown, an arbitrary value was assumed in order to complete the analysis. The comparison between the values is a helpful tool to study the deterioration of the different members over time. In general, a member with an in-place dynamic modulus of elasticity that is within $85 \%$ of the original value is assumed to be in good structural condition. The values obtained for the tested members were all within the $85 \%$ threshold, denoting them to be in good structural condition.

A monitoring strategy was developed based on the crack width and moment curvature of the concrete cross section using reliability analytical models that would allow for lifetime monitoring. The prediction models used the Bridge Condition Index (BCI) to evaluate the structural condition of the bridge. The bridge moment-curvature plot was obtained in order to establish allowable limits, with the limits established at $40 \%$ between the yielding of the steel reinforcement and ultimate load. The established allowable limit was computed to be $\mathrm{M}=$ 198,213 kN.m.

A tailored prognosis was developed for the Rebecca Street Bridge in order to address the various deteriorating members (i.e. abutments, piers, steel girders, deck, etc.). The prognosis model includes both a general model for the overall structural condition of the bridge, as well as models for the deck, piers, abutments and steel girders. The prognosis model is based on the Bridge Condition Index (BCI) guide provided by the Ministry of Transportation of Ontario (MTO). According to the guidelines established by MTO, the Town of Oakville is responsible for visually inspecting municipal bridges every 2 years and to report a BCI value to the ministry. A BCI value ranged from 60-70 is a good benchmark for the Town of Oakville to consider major rehabilitation of the bridge in the next 5 years. Based on this guideline, a BCI value of 65 was chosen as the benchmark for the prognosis model for the Rebecca Street Bridge. In addition, 
suggested maintenance procedures for the various bridge members were discussed in an effort to help guide the Town of Oakville in selecting the appropriate maintenance plan for the various deteriorating bridge members.

Prolonging the life span of the Rebecca Street Bridge is primarily dependent on undertaking appropriate and timely maintenance procedures. The prognosis model developed in this report provides the Town of Oakville with a guideline for maintaining the structural condition of the bridge. In addition, the crack maps obtained during the shear wave scans and the obtained dynamic modulus of elasticity serve as a benchmark for future analysis in order to monitor the bridge deterioration over time. Utilizing appropriate NDT technique's such as the shear wave tomographer for scanning the concrete piers and abutments, and the random decrement for scanning the steel girders allow the bridge to be diagnosed properly, allowing the Town of Oakville to allocate appropriate maintenance plans.

Future investigations of the Rebecca Street Bridge should include shear wave scans at all elevations of the piers and pier caps. The limited site access during this investigation posed as a limiting factor, with all the data obtained at the lower portions of the piers. In addition, the short duration of the project did not allow for the obtained crack maps to be compared, in order to analyze the propagation of cracks and other anomalies. 


\section{References}

1. Aggelis, D.G., and Shiotani, T. "Repair Evaluation of Concrete Cracks Using Surface and Through-transmission Wave Measurements." Journal of Cement and Concrete Composites (2007): 700-711.

2. Ainge, S.W. "Repair and Strengthening of Bridge Substructures." Thesis. University of Marquette (2009): 22-142.

3. Al-Ostaz, A. "Diagnostic Evaluation and Repair of Deteriorated Concrete Bridges." Thesis. University of Mississippi (2004): 82-109.

4. American Concrete Institute Committee. "Building code requirements for structural concrete (ACI 318-08) and commentary (ACI 318R-08)." ACI Committee 318 American Concrete Institute (2008).

5. American Concrete Institute Committee. "Control of Cracking in Concrete Structures (ACI 224R-01)." ACI Committee 224 American Concrete Institute (2001): 17-21.

6. Bazulin, E.G. "Imaging of Flaws with Allowance for Multiple Reflections of Ultrasonic Pulses from Plane-Parallel Boundaries of a Tested Object." Russian Journal of NDT (2007): 456-460.

7. Bell, J.F. "Mechanics of Solids: The Experimental Foundations of Solid Mechanics." Berlin: Springler-Verlag (1984).

8. Birgul, R. "Hilbert Transformation of Waveforms to Determine Shear Wave Velocity in Concrete." Journal of Cement and Concrete Research (2009): 696-700.

9. Bishko, A.V., Shevaldykin, V.G., and Sumokrutov A.A. "Ultrasonic Echo-Pulse Tomography of Concrete Using Shear Waves Low-Frequency Phased Antenna Arrays." 17th World Conference on Nondestructive Testing (2008): 25-28.

10. Buff, H., Friedmann, A., Koch, M., Bartel, T., and Kauba, M. "Design of a Random Decrement Method Based Structural Health Monitoring System." Shock and Vibration (2012): 787-794.

11. Canadian Standard Association. "S474-04 Concrete Structures." Canadian Standard Associations, Mississauga (2004).

12. Carino, N.J. "The Impact-Echo Method: An Overview." Journal of Building and Fire Research Laboratory (2001). 1-18.

13. Carino, N.J., and Clifton, J.R. "Prediction of Cracking in Reinforced Concrete Structures." Building and Fire Research Laboratory, National Institute of Standards and Technology (1995).

14. Carino, N.J., and Sansalone, M. "Flaw Detection in Concrete by Frequency Spectrum Analysis of Impact-Echo Waveforms." International Advances in Nondestructive Testing (1986): 117-146.

15. CEB-FIP. "CEB-FIP Model Code for Concrete Structures (MC-78)." Comité EuroInternational du Béton (CEB), Paris (1978): 348.

16. CEB-FIP. "CEB-FIP Model Code-1990 (MC-90)." Comite Euro International du Béton (CEB) Telford Services Ltd. London (1999): 240-255.

17. Chai, H.K., Momoki, S., Koabayashi, Y., Aggelis, D.G., and Shiotani, T. "Tomographic Reconstruction for Concrete Using Attenuation of Ultrasound." Nondestructive Testing International Conference (2011): 206-215.

18. Clark, A. "Cracking in Reinforced Concrete Flexural Members." ACI Structural Journal V52.I4 (1956): 851-862.

19. Cole Engineering, "Rebecca Street Bridge Rehabilitation, Oakville, Ontario Preliminary Bridge Inspection and Condition Survey." Report. (2013). 
20. Corus. "Corrosion Protection of Steel Bridges." Report. Corus Construction \& Industrial Manual (2010).

21. Dawood, N., Marzouk, H., Hussein, A., and Gillis, N. "Nondestructive Assessment of a Jetty Bridge Structure Using Impact-Echo and Shear-Wave Techniques." Journal of American Society of Civil Engineers (2013): 801-809.

22. Dawood, N., and Marzouk, H. "Crack Width Model for Thick Reinforced Concrete Plates Subjected to In-plane Forces." Canadian Journal of Civil Engineering (2011): 1262-1273.

23. Dexter, R.J., and Ocel, J.M. "Manual for Repair and Retrofit of Fatigue Cracks in Steel Bridges." Report. Federal Highway Administration (2013): 19-38.

24. Dong, Y., and Song, R. "Bridges Structural Health Monitoring and Deterioration Detection Synthesis of Knowledge and Technology." Thesis. Alaska University Transportation Center (2010): 22-49.

25. Elshafey, A.A., Dawood, N., Marzouk, H., and Haddara, M. "Predicting of Crack Spacing for Concrete by Using Neural Networks." Journal of Engineering Failure Analysis (2013): 344359.

26. Euro Code 2. "Design of Concrete Structures - Part I: General Rules and Rules for Buildings." European Committee for Standardization, Paris (2004).

27. Ferraro, C. C. "Detection and Assessment of Structural Flaws in Concrete Bridges with NDT Methods." Journal of Research in Nondestructive Evaluation (2007): 179-192.

28. Frantz, G.C., and Breen, J.E. "Cracking on the Side Faces of Large Reinforced Concrete Beams." ACI Structural Journal V77.I5 (1980): 307-313.

29. Frosch, R. "Modeling and Control of Side Face Beam Cracking." ACI Structural Journal V99.I3 (2002): 376-385.

30. Germann Instruments. "MIRA 3D Shear Wave Tomographer Manual". Report. Germann Instruments (2014).

31. Glisic, B., and Inaudi, D. "Fibre Optic Methods for Structural Health Monitoring." Chichester: John Wiley \& Sons, Inc (2007).

32. Goldsmith, W. "Impact: The Theory and Physical Behavior of Colliding Solids." Edward Arnold, Inc (1965): 24-50.

33. Government of Ontario. "Bill 79, Public Transportation and Highway Improvement Act." Report. Government of Ontario (2008).

34. Gucunski, N., and Nazarian, S. "Material Characterization and Condition Assessment of Reinforced Concrete Bridge Decks by Complementary NDE Technologies." Journal of American Society of Civil Engineers (2010): 429-39.

35. Hoegh, K., and Khazanovich, L. "Ultrasonic Tomography Evaluation of the Coolac Bypass Joint and Crack Subsurface Diagnostics." Report. Germann Instruments (2012): 2-4.

36. Hoegh, K., Khazanovich, L., Maser, K., and Tran, N. "Evaluation of an Ultrasonic Technique for Detecting Delamination in Asphalt Pavements." Transportation Research Board 91st Annual Conference (2012): 22-26.

37. Hughi, D., and Marzouk, H. "Crack Width Monitoring System for Reinforced Concrete Beams Using Piezo-Ceramic Sensors." Journal of Civil Structural Health Monitoring (2014): $1-10$.

38. Hughi, D. "Nondestructive Testing of Concrete Members Using Shear-Wave Tomography." Report. Ryerson University (2011): 9-38.

39. Hwan, B., and Jin, Y. "New Formulas for Maximum Crack Width and Crack Spacing in Reinforced Concrete Flexural Members." ACI Structural Journal V84.I10 (1987): 103-112.

40. Impact-Echo Instruments. "Instruments and Components Manual." Impact-Echo Instruments (2014).

41. Krause, M., Mielentz, F., Milman, B., Muller, W., Schmitz, V., and Wiggenhauser. H. 
"Ultrasonic Imaging of Concrete Members Using an Array System." Nondestructive Testing International Conference (2001): 403-408.

42. Krauss, P.D., Lawler, J.S., and Steiner, K.A. "Guidelines For Selection of Bridge Deck Overlays, Sealers and Treatments." Report. National Cooperative Highway Research Program (2009): 4-7.

43. Leet, K.M., and Bernal, D. "Reinforced Concrete Design 3rd Edition." New York: McGraw Hill Companies, Inc (1997).

44. Lin, Y., and Sansalone, M. "Detecting Flaws in Concrete Beams and Columns Using the Impact-Echo Method." ACI Materials Journal 89 (1992): 394-405.

45. Liu, C., Hammad, A., and Itoh, Y. "Maintenance Strategy Optimization of Bridge Decks Using Genetic Algorithm." Journal of Transportation Engineering (1997): 91-100.

46. Kimitoshi, M., Yamada, M., and Ohtsu, M. "On-site Measurement of Delamination and Surface Crack in Concrete Structure by Visualized NDT." Journal of Construction and Building Materials (2010): 2381-2387.

47. Michaels, J.E., and Michaels, T.E. "Ultrasonic Signal Processing for Structural Health Monitoring." Report. School of Electrical and Computer Engineering, Georgia Institute of Technology (2004): 1476-1483.

48. Michaux, C., and Grill, M. "NDT 3D Tomographic Testing Cases on Concrete." Report. Germann Instruments (2012): 1-8.

49. Ministry of Transportation of Ontario (MTO). "Bridge Condition Index Guideline." Report. Ministry of Transportation of Ontario (2014).

50. Ministry of Transportation of Ontario (MTO). "Bridge Inspection and Maintenance." Report. Ministry of Transportation of Ontario (2009).

51. Murray, M. A. "Epoxy Injection Welds Cracks Back Together." Report. Plant Engineering (1987): 1-3.

52. Neville, A.M. "Properties of Concrete 4th Edition." New York: John Wiley \& Sons, Inc (1997).

53. Norwegian Council for Building Standardization. "NS34773E Concrete Structures Design Rules.” Norwegian Council for Building Standardization, Norway (1992).

54. Obrebski, M., Allen, R.M., Zhang, F., Pan, J., Wu, O., and Hung, S. "Shear Wave Tomography of China Using Joint Inversion of Body and Surface Wave Constraints." Journal of Geophysical Research (2012): 1-15.

55. Oller, S., and Barbat, A.H. "Moment-curvature Damage Model for Bridges Subjected to Seismic Loads." Journal of Computer Methods in Applied Mechanics and Engineering (2006): 4490-4511.

56. Owen, J.S., and Pearson, S.R. "The Use of Dynamic Data for the Structural Health Monitoring of Bridges." $1^{\text {st }}$ International Conference on Engineering Surveys for Construction Works and Structural Engineering (2004): 1-14.

57. Popovics, J.S., Zemajtis, J., and Shkolnik, I. "A Study of Static and Dynamic Modulus of Elasticity of Concrete." ACI Materials Journal (2008): 1-8.

58. Rens, K.L., and Transue, D.J. "Tomographic Imaging of Cracked Pier Cap of Evans over Santa Fe Bridge." International Concrete Repair Institute Conference (2002): 12-15.

59. Sagar, V.R., and Raghu Prasad, B.K. "'Laboratory Investigations on Cracking in Reinforced Concrete Beams Using On-line Acoustic Emission Monitoring Technique." Journal of Civil Structural Health Monitoring (2013): 169-186.

60. Sansalone, M. "Impact-Echo: The Complete Story." ACI Structural Journal V94.I6 (1997): 777-786.

61. Sansalone, M., and Streett. W.B. "Impact-Echo: Non-Destructive Evaluation of Concrete and Masonry." Itacha, NY: Bullbrier Press, Inc (1997). 
62. Shabowicz, K., Hola J., and Stys D. "The Ultrasonic Tomography Tests of Concrete In Foundation Slab." Archives of Civil and Mechanical Engineering (2008): 1-9.

63. Shiotani, T., and Aggelis D.G. "Determination of Surface Crack Depth and Repair Effectiveness Using Rayleigh Waves." Journal of Environmental and Engineering Geophysics (2005): 295-306.

64. Shiotani, T., Ohtsu, H., Momoki, S., Kian Chai, H., Onishi, H., and Kamada, T. "Damage Evaluation for Concrete Bridge Deck by Means of Stress Wave Techniques." Journal of Bridge Engineering (2012): 847-856.

65. Sideris, K.K., and Manita, P. "Estimation of Ultimate Modulus of Elasticity and Poisson Ratio of Normal Concrete." Journal of Cement \& Concrete Composites (2004): 623-631.

66. Stapleton, J. "Structures Repair Manual." Report. RailCorp (2009): 23-39.

67. Stengel, T., and Schiebl, P. "Life Cycle Assessment of UHPC Bridge Construction: Sherbrook Footbridge, Kassel Gartnerplatz Footbridge and Wapello Road Bridge." Journal of Architecture Civil Engineering Environment (2008): 109-18.

68. Waheed, A., and Kowal, E. "Repair of Bridge Structural Steel Elements Manual." Report. Alberta Transportation: Bridge Engineering Section (2004): 1-9.

69. Wenzel, H. "Experience Made with the International Benchmark on Dynamic Bridge Monitoring and Assessment at the Wayne Bridge in New Jersey." International Conference on Structural Dynamics (2011): 1141-1148.

70. Wenzel, H. "The Role of SHM in Civil Lifecycle Engineering." European Workshop Conference on SHM (2010): 1-8.

71. Wenzel, H. "Management of Critical Infrastructures Based on Monitoring, Assessment Results and Lifetime Engineering." Civil Structural SHM Workshop Conference (2010): 1-13.

72. Wenzel, H., Veit-Egerer, R., and Widmann, M. "Life Cycle Analysis Addressing Maintenance and Repair Options and Its Affections on Remaining Lifetime." ACI Structural Journal (2011): 1-20.

73. Weyers, R.E., and Sprinkel, M.M. "Rapid Concrete Bridge Deck Protection, Repair and Rehabilitation." Report. Strategic Highway Research Program National Research Council (1993): 27-61.

74. Weyers, R.E., Prowell, B.D., Sprinkel, M.M., and Vorster, M. "Concrete Bridge Protection, Repair, and Rehabilitation Relative to Reinforcement Corrosion." Report. Strategic Highway Research Program National Research Council (1993): 47-98.

75. Wilcox, P.D., Lee, C.K., Scholey, J.J., Wisnom, M.I., and Drinkwater, B.W. "Quantitative Structural Health Monitoring Using Acoustic Emission." Journal of Smart Structures and Materials 6173 (2006): 1-10.

76. Yadav, R.K., Nadgouda, N.L., and Kumar, V. "Inspection and Maintenance of Steel Girders." Journal of Railway Institute of Civil Engineering (2006): 92-115.

77. Yasuda, N., Tsutsumi, T., Kawamura, T., Matsuho, S., and Shiraki, W. "Assessment of Deteriorating Reinforced Concrete Structures Using Artificial Neural Networks." Journal of Institute of Electrical and Electronis Engineers (1993): 581-586.

78. Yehia, S., Abudayyeh, O., Nabulsi, S., and Abdelqader, I. "Detection of Common Defects in Concrete Bridge Decks Using Nondestructive Evaluation Techniques." Journal of Bridge Engineering V12.I2 (2007): 215-225. 


\section{Appendix A Crack Width and Crack Spacing Computation}

Given the reinforcement detail drawings from the Town of Oakville, the diameter of rebar's $\left(d_{b}\right)$, rebar spacing $\left(S_{b}\right)$ and concrete cover $(c)$ was found and plugged into Equation 3.1. The crack spacing was then used in conjunction with the estimated strain to model the crack width. Selecting a concrete section, finding the centroid, and determining the strain at various levels of reinforcement, and using the highest strain to determine the crack width obtained the strain. Tables A1 highlights the crack width and spacing for all piers, which were detailed equally, resulting in equal crack widths and spacing's.

$$
\begin{gathered}
S_{a v}=1.90 d_{b}{ }^{0.062} S_{b}{ }^{0.514} C^{0.323}=1.90 \times 25^{0.062} \times 65^{0.514} \times 40^{0.323}=65.3 \mathrm{~mm} \\
w_{x}=\xi_{x} S_{m} \varepsilon_{s m}=0.9 \times 65 \times 0.00234138=0.137 \mathrm{~mm}
\end{gathered}
$$

\begin{tabular}{|c|c|c|c|c|c|c|c|}
\hline Pier & Column & $\mathrm{Db}(\mathrm{mm})$ & $\mathrm{Sb}(\mathrm{mm})$ & $\mathrm{C}(\mathrm{mm})$ & Sav (mm) & Esmax & $\mathbf{W X}_{\mathbf{X}}(\mathrm{mm})$ \\
\hline 1 & 1 & 25 & 65 & 40 & 65.27227111 & 0.002341379 & 0.152827145 \\
\hline 1 & 2 & 25 & 65 & 40 & 65.27227111 & 0.002341379 & 0.152827145 \\
\hline 1 & 3 & 25 & 65 & 40 & 65.27227111 & 0.002341379 & 0.152827145 \\
\hline 1 & 4 & 25 & 65 & 40 & 65.27227111 & 0.002341379 & 0.152827145 \\
\hline 2 & 1 & 25 & 65 & 40 & 65.27227111 & 0.002341379 & 0.152827145 \\
\hline 2 & 2 & 25 & 65 & 40 & 65.27227111 & 0.002341379 & 0.152827145 \\
\hline 2 & 3 & 25 & 65 & 40 & 65.27227111 & 0.002341379 & 0.152827145 \\
\hline 2 & 4 & 25 & 65 & 40 & 65.27227111 & 0.002341379 & 0.152827145 \\
\hline 3 & 1 & 25 & 65 & 40 & 65.27227111 & 0.002341379 & 0.152827145 \\
\hline 3 & 2 & 25 & 65 & 40 & 65.27227111 & 0.002341379 & 0.152827145 \\
\hline 3 & 3 & 25 & 65 & 40 & 65.27227111 & 0.002341379 & 0.152827145 \\
\hline 3 & 4 & 25 & 65 & 40 & 65.27227111 & 0.002341379 & 0.152827145 \\
\hline 4 & 1 & 25 & 65 & 40 & 65.27227111 & 0.002341379 & 0.152827145 \\
\hline 4 & 2 & 25 & 65 & 40 & 65.27227111 & 0.002341379 & 0.152827145 \\
\hline 4 & 3 & 25 & 65 & 40 & 65.27227111 & 0.002341379 & 0.152827145 \\
\hline 4 & 4 & 25 & 65 & 40 & 65.27227111 & 0.002341379 & 0.152827145 \\
\hline 5 & 1 & 25 & 65 & 40 & 65.27227111 & 0.002341379 & 0.152827145 \\
\hline 5 & 2 & 25 & 65 & 40 & 65.27227111 & 0.002341379 & 0.152827145 \\
\hline 5 & 3 & 25 & 65 & 40 & 65.27227111 & 0.002341379 & 0.152827145 \\
\hline 5 & 4 & 25 & 65 & 40 & 65.27227111 & 0.002341379 & 0.152827145 \\
\hline 6 & 1 & 25 & 65 & 40 & 65.27227111 & 0.002341379 & 0.152827145 \\
\hline 6 & 2 & 25 & 65 & 40 & 65.27227111 & 0.002341379 & 0.152827145 \\
\hline 6 & 3 & 25 & 65 & 40 & 65.27227111 & 0.002341379 & 0.152827145 \\
\hline 6 & 4 & 25 & 65 & 40 & 65.27227111 & 0.002341379 & 0.152827145 \\
\hline 7 & 1 & 25 & 65 & 40 & 65.27227111 & 0.002341379 & 0.152827145 \\
\hline 7 & 2 & 25 & 65 & 40 & 65.27227111 & 0.002341379 & 0.152827145 \\
\hline 7 & 3 & 25 & 65 & 40 & 65.27227111 & 0.002341379 & 0.152827145 \\
\hline 7 & 4 & 25 & 65 & 40 & 65.27227111 & 0.002341379 & 0.152827145 \\
\hline
\end{tabular}




\begin{tabular}{|r|r|r|r|r|r|r|r|}
8 & 1 & 25 & 65 & 40 & 65.27227111 & 0.002341379 & 0.152827145 \\
\hline 8 & 2 & 25 & 65 & 40 & 65.27227111 & 0.002341379 & 0.152827145 \\
\hline 8 & 3 & 25 & 65 & 40 & 65.27227111 & 0.002341379 & 0.152827145 \\
\hline 8 & 4 & 25 & 65 & 40 & 65.27227111 & 0.002341379 & 0.152827145 \\
\hline 9 & 1 & 25 & 65 & 40 & 65.27227111 & 0.002341379 & 0.152827145 \\
\hline 9 & 2 & 25 & 65 & 40 & 65.27227111 & 0.002341379 & 0.152827145 \\
\hline 9 & 3 & 25 & 65 & 40 & 65.27227111 & 0.002341379 & 0.152827145 \\
\hline 9 & 4 & 25 & 65 & 40 & 65.27227111 & 0.002341379 & 0.152827145 \\
\hline 10 & 1 & 25 & 65 & 40 & 65.27227111 & 0.002341379 & 0.152827145 \\
\hline 10 & 2 & 25 & 65 & 40 & 65.27227111 & 0.002341379 & 0.152827145 \\
\hline 10 & 3 & 25 & 65 & 40 & 65.27227111 & 0.002341379 & 0.152827145 \\
\hline 10 & 4 & 25 & 65 & 40 & 65.27227111 & 0.002341379 & 0.152827145 \\
\hline
\end{tabular}

Table A1 - Computation of Crack Width and Crack Spacing of the Bridge Piers 


\section{Appendix B Moment Curvature Computation}

The objective of obtaining the moment curvature is to determine the stresses at which initial cracking, steel yielding and ultimate failure occur.

1. Cross-Section: 4' x 4' piers (48" x 48")

2. Material Properties:

a) Steel: Intermediate Grade - Y.P $=47 \mathrm{ksi}$

b) Concrete: $f_{t}=400 \mathrm{ksi}, f_{r}=535 \mathrm{ksi}$

c) $\mathrm{K}_{3} f_{c}^{\prime}=4000 \mathrm{psi}$

d) $\mathrm{E}_{\mathrm{c}}=2.67 \times 10^{6} \mathrm{psi}$

e) $\mathrm{E}_{\mathrm{s}}=30 \times 10^{6} \mathrm{psi}$

f) $\mathrm{n}=\mathrm{E}_{\mathrm{s}} / \mathrm{E}_{\mathrm{c}}=11.3$

3. Point $\mathrm{A}$ - First Cracking $\left(\epsilon_{t}=0.0002\right)$ :

Two methods can be used to determine the moment $\left(\mathrm{M}_{\mathrm{cr}}\right)$ and curvature $\left(\phi_{c r}\right)$ at first cracking of the concrete member in tension.

\section{1) Actual Stress-Strain Curve of Concrete Method}

2) Modulus of Rupture and Transformed Area Method

The tension portion of the curve is assumed to be parabolic for which the average stress is

$\frac{2}{3} \times 400=267$ psi $=f_{\text {t ave }}$. The position of the neutral axis needs to be determined by using a trial and error procedure. The condition to be satisfied is the summation of horizontal force must be equal to zero. Table $\mathrm{B} 1$ summarizes the computation of $\mathrm{K}_{\mathrm{d}}$ for initial cracking.

Trial \#1 $-\mathbf{K}_{\mathbf{d}}=\mathbf{2 8}$ "

$$
\begin{gathered}
\epsilon_{c}=\frac{28}{20} \times 0.0002=0.00028 \\
\epsilon_{s}=\frac{18}{20} \times 0.0002=0.00028 \\
f_{c}=0.00028 \times 2.67 \times 10^{6}=747.6 \mathrm{psi} \\
f_{s}=0.00018 \times 30 \times 10^{6}=5400 \mathrm{psi}
\end{gathered}
$$




$$
\begin{gathered}
C_{c}=\frac{1}{2} \times 48 \times 28 \times 747.6=502,387 \mathrm{psi} \\
T_{c}=48 \times 20 \times 267=250,980 \mathrm{psi} \\
T_{S}=23 \times 4000=92,000 \mathrm{psi} \\
T=T_{c}+T_{s}=342,980 \mathrm{psi}
\end{gathered}
$$

Trial and error was used to establish the value of $\mathrm{K}_{\mathrm{d}}$, which was found to be 26.22" (Table B1).

Point B (Yield) and additional points were computed in a similar manner with the results shown in Tables B2 and B3.

\begin{tabular}{|ccccccccccc|}
\hline $\mathbf{K d}$ & $\mathbf{E c}$ & $\mathbf{E s}$ & $\mathbf{f c}$ & $\mathbf{f s}$ & $\mathbf{C c}$ & $\mathbf{T c}$ & $\mathbf{T s}$ & $\mathbf{T}$ & $\mathbf{M c r}$ & $\mathbf{T h e t a} \mathbf{C r}$ \\
\hline 30 & 0.000333333 & 0.000177778 & 890 & 5,333 & 640,800 & 230.69 & 122,667 & 122,897 & 221,380 & 0.000011111 \\
\hline 29 & 0.000305263 & 0.000178947 & 815 & 5,368 & 567,277 & 243.50 & 123,474 & 123,717 & 221,216 & 0.000010526 \\
\hline 28 & 0.00028 & 0.00018 & 748 & 5,400 & 502,387 & 256.32 & 124,200 & 124,456 & 220,887 & 0.000010000 \\
\hline 27 & 0.000257143 & 0.000180952 & 687 & 5,429 & 444,898 & 269.14 & 124,857 & 125,126 & 220,416 & 0.000009524 \\
\hline 26 & 0.000236364 & 0.000181818 & 631 & 5,455 & 393,801 & 281.95 & 125,455 & 125,736 & 219,823 & 0.000009091 \\
\hline 26.5 & 0.000246512 & 0.000181395 & 658 & 5,442 & 418,606 & 275.54 & 125,163 & 125,438 & 220,134 & 0.000009302 \\
\hline 26.3 & 0.000242396 & 0.000181567 & 647 & 5,447 & 408,511 & 278.11 & 125,281 & 125,559 & 220,012 & 0.000009217 \\
\hline 26.2 & 0.000240367 & 0.000181651 & 642 & 5,450 & 403,551 & 279.39 & 125,339 & 125,619 & 219,950 & 0.000009174 \\
\hline 26.22 & 0.000240771 & 0.000181635 & 643 & 5,449 & 404,539 & 279.13 & 125,328 & 125,607 & 219,963 & 0.000009183 \\
\hline
\end{tabular}

Table B1 - Computation of Kd for Initial Cracking

\begin{tabular}{|ccccccccccc|}
\hline $\mathbf{K d}$ & $\mathbf{E c}$ & $\mathbf{E s}$ & $\mathbf{f c}$ & $\mathbf{f s}$ & $\mathbf{C c}$ & $\mathbf{T c}$ & $\mathbf{T s}$ & $\mathbf{T}$ & Mcr & Theta Cr \\
\hline 30 & 0.002616 & 0.000177 & 3,800 & 47,000 & $1,840,320$ & 29,387 & $1,081,000$ & $1,110,387$ & 920,189 & 0.000011111 \\
\hline 29 & 0.002396 & 0.000178 & 3,800 & 47,000 & $1,778,976$ & 31,020 & $1,081,000$ & $1,112,020$ & 969,898 & 0.000010526 \\
\hline 28 & 0.002198 & 0.00018 & 3,950 & 47,000 & $1,717,632$ & 32,652 & $1,081,000$ & $1,113,652$ & $1,019,471$ & 0.000010000 \\
\hline 27 & 0.002018 & 0.000180952 & 4,000 & 47,000 & $1,656,288$ & 34,285 & $1,081,000$ & $1,115,285$ & $1,068,908$ & 0.000009524 \\
\hline 26 & 0.001855 & 0.000181818 & 3,900 & 47,000 & $1,594,944$ & 35,917 & $1,081,000$ & $1,116,917$ & $1,118,208$ & 0.000009091 \\
\hline 26.5 & 0.001935 & 0.000181395 & 4,000 & 47,000 & $1,625,616$ & 35,101 & $1,081,000$ & $1,116,101$ & $1,093,575$ & 0.000009302 \\
\hline 26.3 & 0.001902 & 0.000181 & 4,000 & 47,000 & $1,613,347$ & 35,428 & $1,081,000$ & $1,116,428$ & $1,103,432$ & 0.000009217 \\
\hline 26.2 & 0.001886 & 0.000181 & 4,000 & 47,000 & $1,607,213$ & 35,591 & $1,081,000$ & $1,116,591$ & $1,108,359$ & 0.000009174 \\
\hline 18.4 & 0.000975 & 0.000186 & 4,000 & 47,000 & $1,128,730$ & 48,325 & $1,081,000$ & $1,129,325$ & $1,488,449$ & 0.000006757 \\
\hline
\end{tabular}

Table B2 - Computation of Kd for Yielding of Steel 


\begin{tabular}{|cccccccccc|}
\hline $\mathbf{E c}$ & $\mathbf{p}$ & $\mathbf{E s}$ & $\mathbf{f c}$ & $\mathbf{f s}$ & $\mathbf{K d}$ & $\mathbf{C c}$ & $\mathbf{T}$ & $\mathbf{M c r}$ & $\mathbf{T h e t a} \mathbf{C r}$ \\
\hline 0.0015 & 0.009982639 & 0.004625 & 2,000 & 47,000 & 11.26530612 & $1,081,469$ & $1,081,000$ & $1,985,510$ & 0.000133152 \\
\hline 0.0025 & 0.009982639 & 0.011601 & 2,760 & 47,000 & 8.155449968 & $1,080,434$ & $1,081,000$ & $2,020,177$ & 0.000306543 \\
\hline 0.004 & 0.009982639 & 0.02032 & 3,040 & 48,000 & 7.565789474 & $1,104,000$ & $1,104,000$ & $2,073,632$ & 0.000528696 \\
\hline 0.006 & 0.009982639 & 0.0263 & 2,880 & 51,500 & 8.544891641 & $1,181,246$ & $1,184,500$ & $2,153,370$ & 0.000702174 \\
\hline 0.009 & 0.009982639 & 0.02360378 & 2,240 & 53,000 & 12.69791417 & $1,219,000$ & $1,219,000$ & $2,020,747$ & 0.000708778 \\
\hline
\end{tabular}

Table B3 - Computation of Additional Points for the Moment Curvature Plot 


\section{Appendix C Dynamic and Static Modulus Computation}

The dynamic and static moduli of elasticity were computed using Equations 3.3 (Popovics et al., 2008) and 3.4 and 3.5 (Birgul, 2009). The S-wave velocities of the piers and abutment were obtained using the shear wave tomographer during the scanning phase. The P-wave velocities were subsequently obtained using the impact-echo as a method of obtaining the P-wave velocity only. Although the initial elasticity of the concrete was not supplied by the Town of Oakville, a conservative value of $\mathrm{E}=30 \mathrm{GPa}$ was used in order to obtain a relative relationship between the in-place elasticity and the elasticity at the time of construction. The ratios were relatively high for all members, indicating minimal loss of strength. In addition, some of the in-place elasticity's were higher than $30 \mathrm{GPa}$, which is likely due to human error during the scanning phase while obtaining the shear or pressure velocities. However, the values are in the acceptable range, thus the error may be disregarded.

\begin{tabular}{|c|c|c|c|c|c|c|c|}
\hline Member & Vs & Vp & \multicolumn{1}{l|}{ V } & \multicolumn{1}{l|}{ Es } & Es/Es \\
\hline Pier 2-1 & 2,449 & 4,163 & 0.373950 & 2.4 & $34,609,686$ & 28.72603919 & 0.95753464 \\
\hline Pier 2-2 & 2,561 & 4,354 & 0.373950 & 2.4 & $37,847,678$ & 31.41357294 & 1.047119098 \\
\hline Pier 2-3 & 2,394 & 4,070 & 0.373950 & 2.4 & $33,072,603$ & 27.45026052 & 0.915008684 \\
\hline Pier 2-4 & 2,515 & 4,276 & 0.373950 & 2.4 & $36,500,269$ & 30.29522325 & 1.009840775 \\
\hline Pier 3-3 & 2,435 & 4,140 & 0.373950 & 2.4 & $34,215,116$ & 28.3985463 & 0.94661821 \\
\hline Pier 3-4 & 2,483 & 4,221 & 0.373950 & 2.4 & $35,577,344$ & 29.52919566 & 0.984306522 \\
\hline Pier 5-1 & 2,397 & 4,075 & 0.373950 & 2.4 & $33,155,544$ & 27.51910127 & 0.917303376 \\
\hline Pier 5-2 & 2,498 & 4,247 & 0.373950 & 2.4 & $36,008,494$ & 29.88704975 & 0.996234992 \\
\hline Pier 5-3 & 2,489 & 4,231 & 0.373950 & 2.4 & $35,749,492$ & 29.67207866 & 0.989069289 \\
\hline Pier 5-4 & 2,402 & 4,083 & 0.373950 & 2.4 & $33,294,009$ & 27.63402744 & 0.921134248 \\
\hline Pier 6-1 & 2,494 & 4,240 & 0.373950 & 2.4 & $35,893,267$ & 29.79141125 & 0.993047042 \\
\hline Pier 6-2 & 2,539 & 4,316 & 0.373950 & 2.4 & $37,200,218$ & 30.87618114 & 1.029206038 \\
\hline Pier 6-3 & 2,470 & 4,199 & 0.373950 & 2.4 & $35,205,782$ & 29.22079886 & 0.974026629 \\
\hline Pier 6-4 & 2,474 & 4,206 & 0.373950 & 2.4 & $35,319,901$ & 29.31551776 & 0.977183925 \\
\hline Pier 7-1 & 2,444 & 4,155 & 0.373950 & 2.4 & $34,468,508$ & 28.60886191 & 0.95362873 \\
\hline Pier 7-2 & 2,421 & 4,116 & 0.373950 & 2.4 & $33,822,808$ & 28.07293094 & 0.935764365 \\
\hline Pier 7-3 & 2,456 & 4,175 & 0.373950 & 2.4 & $34,807,819$ & 28.8904897 & 0.963016323 \\
\hline Pier 7-4 & 2,403 & 4,085 & 0.373950 & 2.4 & $33,321,737$ & 27.65704141 & 0.92190138 \\
\hline West Abutment & 2,487 & 4,228 & 0.373950 & 2.4 & $35,692,063$ & 29.62441268 & 0.987480423 \\
\hline
\end{tabular}

Table C1 - Computation of the Dynamic and Static Moduli of Elasticity 


\section{Appendix D Recommended Retrofit Measures}

The functionality and remaining life of the Rebecca Street Bridge is largely influenced by timely maintenance and retrofit measures. The maintenance strategy implemented is dependent on the members being addressed, the severity of damage and the repair budget. A total of four maintenance procedures have been studied and tailored for the Rebecca Street Bridge as shown in Table D1. The maintenance alternatives are discussed in the following sections addressing the repair of abutments, piers and pier caps, bridge deck, and steel girders (superstructure).

\begin{tabular}{|ccccc|}
\hline \multicolumn{7}{c|}{ Recommended Measures } & \\
\hline Strategy & Superstructure & Piers & Bridge Deck & Abutments \\
\hline $\mathbf{1}$ & & $\mathrm{X}$ & & \\
\hline $\mathbf{2}$ & & $\mathrm{X}$ & $\mathrm{X}$ & $\mathrm{X}$ \\
\hline $\mathbf{3}$ & $\mathrm{X}$ & $\mathrm{X}$ & & $\mathrm{X}$ \\
\hline $\mathbf{4}$ & $\mathrm{X}$ & $\mathrm{X}$ & $\mathrm{X}$ & \\
\hline
\end{tabular}

Table D1 - Rebecca Street Bridge Maintenance Strategies

\section{D1 Repair of Abutments and Expansion Joints}

The most common form of abutment deterioration involves concrete damage caused by leaking expansion joints. Repair procedures for expansion joints depend on the joint type (i.e. strip seal expansion joint, modular expansion joint, bolt-down expansion joint, or sliding plate expansion joint). Typical repair procedures for leaking expansion joints include replacing the expansion joints, repair of expansion joint armouring, or patch repairing the concrete. Some less common abutment deterioration mechanisms such as sliding or loss of stability require in depth inspections and major rehabilitation measures. However, since the bridge has aged significantly, no stability issues are to be expected. Figure D1 illustrates a flow chart of the monitoring prognosis model of the bridge abutments and expansion joints. 


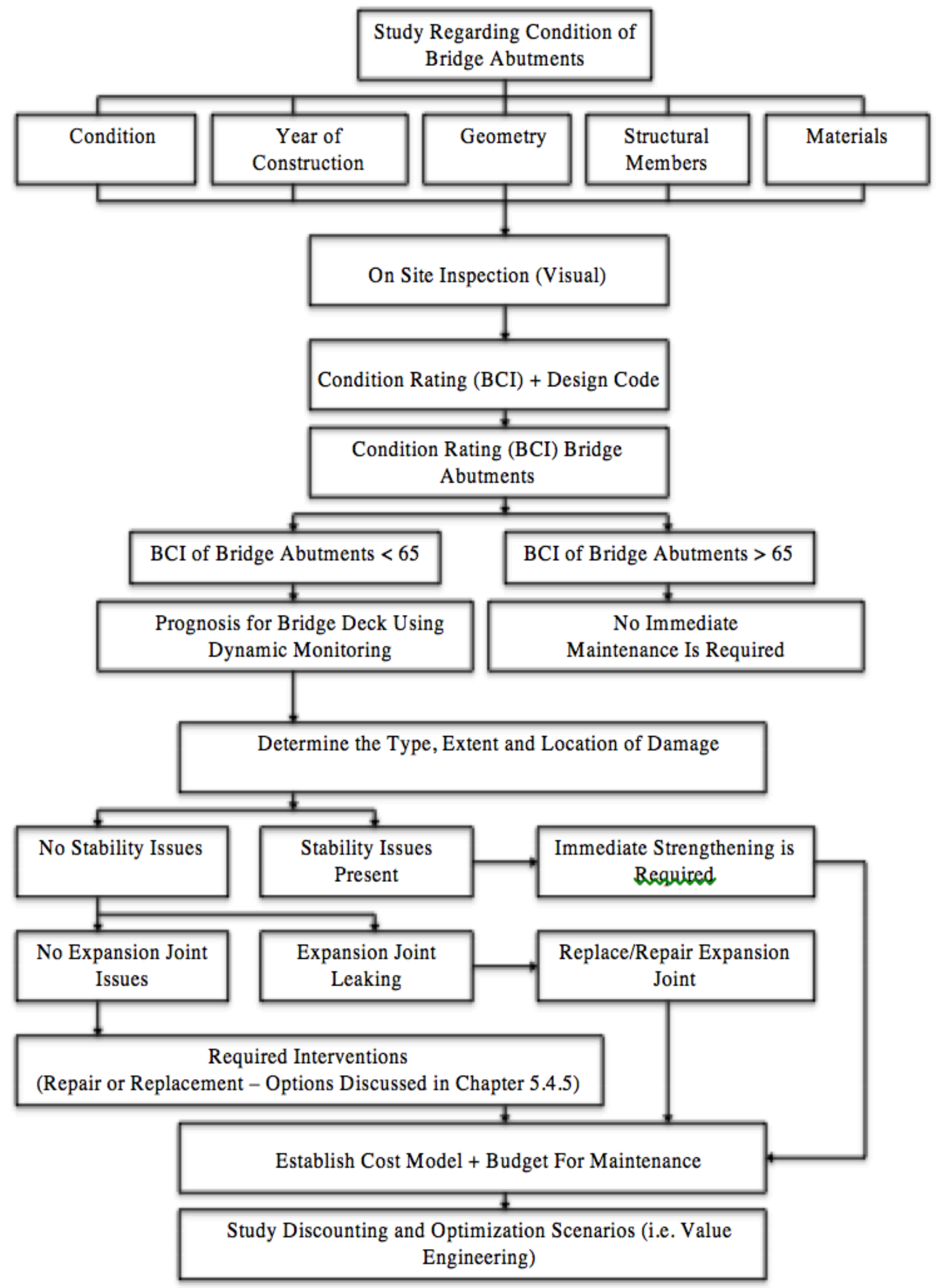

Figure D1 - Abutments and Expansion Joint Prognosis Model 


\section{D2 Repair of Piers and Pier Caps}

Repair of concrete piers and pier caps is one of the most frequent maintenance procedures. Chloride intrusion from de-icing chemical sprays can cause frequent reinforcement corrosion of concrete pier caps and columns. Repairing these elements is mainly dependent on the extent of damage and the budget for maintenance. The alternatives adopted in this report include patch repairs, epoxy injection of cracks, and shotcreting. A prognosis model for the pier columns and pier caps is shown in Figure D2.

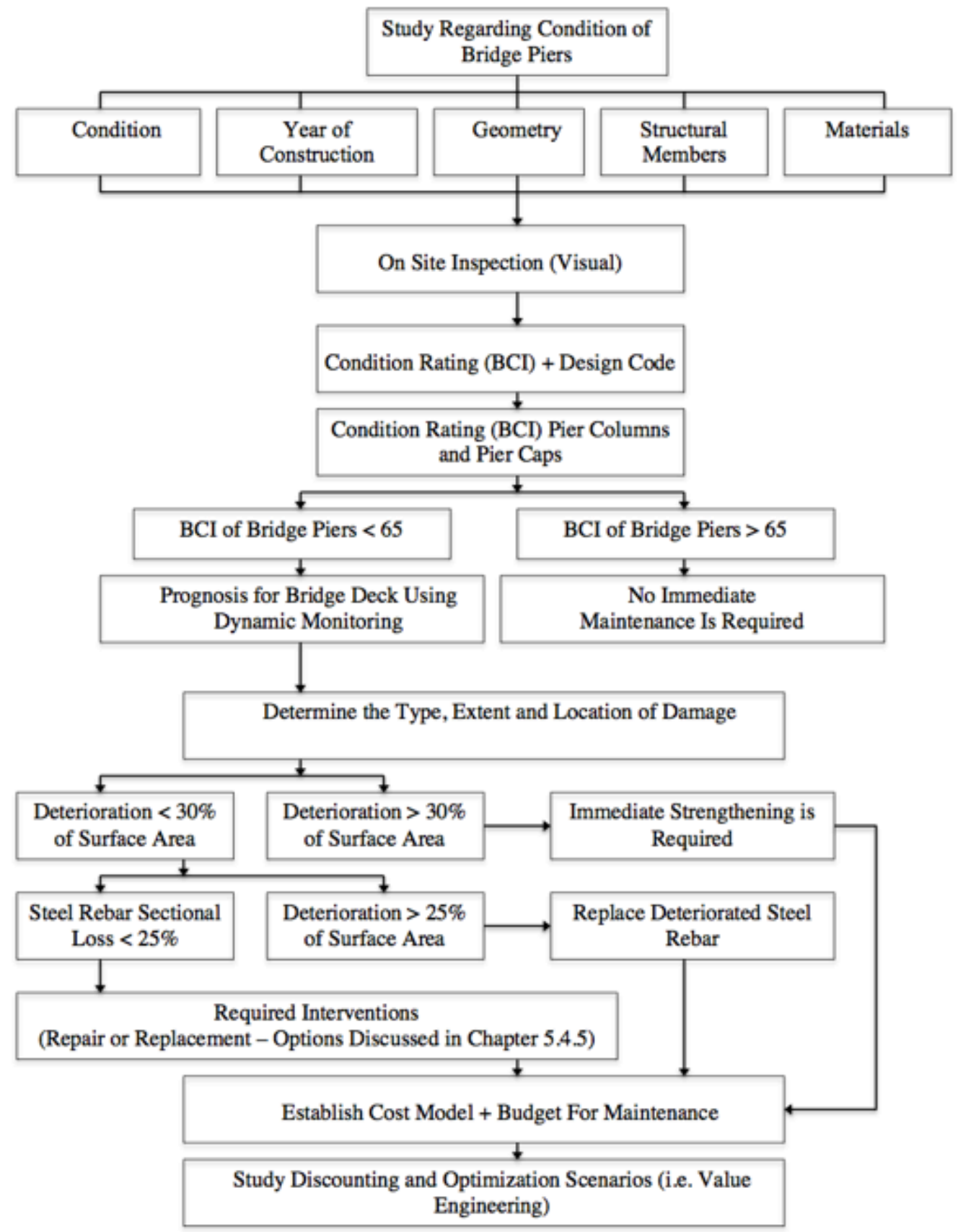

Figure D2 - Pier Column and Pier Caps Prognosis Model 


\section{Alternative 1 - Patch Repair Piers:}

The first alternative involves repair of the concrete substructure by providing patch repairing. The expected service life of this alternative is between 10 to 20 years, depending on the environmental conditions (i.e. chloride exposure). In addition, patching should only be provided for piers with deterioration not exceeding $30 \%$ of the surface area. Some keynotes to consider when adopting patching of concrete piers and piers caps include:

1. Unsound concrete should be removed beyond the mid-point of the main reinforcing steel rebars in the pier cap.

2. Removal of unsound concrete along the length of the cap should be staged in a manner that maintains stresses in the pier cap within tolerable limits.

3. In areas of restricted removal, steel mesh reinforcing and anchorage should be inserted to improve patch adhesion between the concrete and the reinforcing bars.

4. Removal of concrete from the vertical faces of the pier cap should be restricted to one face at a time to prevent loss of shear capacity.

5. Removals from the pier columns should be staged to maintain structural integrity during the maintenance procedures.

6. Wire brushing or high-pressure water or sand blasting should remove all scale, rust, corrosion and bonded concrete from the reinforcing bars.

7. If the reinforcing bar has a sectional loss greater than $25 \%$, the rebar should be replaced.

8. Concrete sealers should be used in areas subjected to continued chloride exposure.

\section{Alternative 2 - Epoxy Crack Injection Repair:}

Epoxy crack injection repair is an excellent procedure in treating both surface cracks and deep penetrating cracks. In general, surface cracks are chipped and patched, whereas deep penetrating cracks are injected with epoxy grout. The injection has two purposes, to restore the bond between the cracked concrete surfaces and to prevent future access of water and salts (contain chloride and alkalis) into the cracks. Epoxy injection is effective up to $2.75 \mathrm{~m}$ (9 feet) in crack depth, and $0.05 \mathrm{~mm}$ (0.002 in) in crack width (Murray, 1987). The grade and class of epoxy to be used is dependent on the crack size and placing temperature, with guidelines outlined in ASTM C-881. The viscosity of the injection fluid is important, since a viscosity too low will lead to a loss of fluid in larger cracks, and a viscosity too low will not fully penetrate the crack. In 
general, lower viscosity is recommended for finer cracks, and higher viscosity is recommended for larger cracks. Some keynotes regarding epoxy crack injection repair include:

1. The concrete surface around the crack must be cleaned prior to injection of fluids. The crack should be flushed with high-pressure water to remove loose debris, and any contaminants.

2. After flushing the cracks with high-pressure water, compressed air should be used to blow out the free water and dry the concrete.

3. The crack must be dry prior to injection of epoxy, since free water can interfere with the bonding capacity of the epoxy.

4. Epoxy or polyester sealers should be applied to the crack surface to prevent the liquid epoxy from leaking out of the crack prior to hardening.

5. The epoxy may be mixed using two methods, pre-mixing or in-line mixing. Pre-mixing is mixing done using a mechanical stirrer, whereas in-line mixing uses a special nozzle to mix the epoxy during pumping.

6. Vertical cracks should be filled either from the bottom of the crack first and moving upward, or filling the widest part first and moving to the finer parts.

7. Horizontal cracks should be filled starting at one end and moving towards the other end.

8. If any seepage occurs during the injection process, the crack must be re-injected.

9. The entry ports should not be removed until the epoxy has cured.

10. After the cracks have been sealed, a surface sealant should be applied to add additional protection against water and chlorides.

\section{Alternative 3 - Shotcreting:}

Shotcreting is a procedure involving the application of silica fume concrete to the deteriorated piers and pier caps. The anticipated life expectancy of shotcreting is between 15 to 25 years depending on exposure to future chlorides and whether all corroded rebar's and concrete have been removed during the repair. The long-term durability of this rehabilitation method is also highly influenced by the experience and care of the applicator. Shotcreting is a suitable procedure for piers with deterioration not exceeding $30 \%$ of the surface area. The long-term durability of this rehabilitation method is highly influenced by the experience of the applicator. 


\section{D3 Repair of Bridge Deck, Sidewalks and Barriers}

\section{Alternative 1 - Deck Patching:}

Deck patching methods are often used to chip and replace localized areas of deteriorated concrete such as spalls and delamination's. The depth of the deterioration is mainly dependent on the severity of the corrosion of reinforcing steel. In general, patching is grouped into three depth categories:

1. Type A - Patching is above the top layer of reinforcing steel

2. Type $\mathrm{B}-$ Patching is at least $25 \mathrm{~mm}(1 \mathrm{inch})$ below the top layer of reinforcing steel

3. Type $\mathrm{C}$ - Full deck depth patching

Deck patching is a temporary repair procedure, unless all chloride contaminated concrete is removed prior to patching. Partial-depth deck patching (Types A and B) materials include Portland cement concrete, quickset hydraulic mortar and concrete, and polymer mortar and concrete (Weyers et al., 1993). The service life of deck patching is between 4-10 years, depending on the type (partial-depth or full-depth) and the materials used. Some keynotes when utilizing deck patching include:

1. The deck should be assessed using one of the methods outlined in Table 5.3.

2. A $20 \mathrm{~mm}(3 / 4$ inch) saw cut around the perimeter of the hole should be used to provide a shoulder for the patch to bear against.

3. Laborers should be careful to not cut any reinforcing steel in the deck.

4. Patches within $0.6 \mathrm{~m}$ ( 2 feet) of each other should be combined.

5. The areas to be patched should be sand blasted or water blasted to remove any loose concrete, rust, or any other contaminants that would prevent proper bonding of the new concrete to the old concrete.

6. If the reinforcing steel has lost over 20 percent of its original cross section, it should be replaced, or an additional rebar should be welded for additional strength.

7. Type A requires attention to the depth of the hole, to ensure it is not too thin for concrete, or too thick for epoxy mortar. The maximum layer thickness of epoxy mortar should be between $20 \mathrm{~mm}$ to $25 \mathrm{~mm}$ (3/4 inch to 1 inch).

8. Type B patching requires at least a $25 \mathrm{~mm}$ (1 inch) gap under the top layer of reinforcing steel to allow the fresh concrete to flow and bond to the rebar.

9. Type $\mathrm{C}$ patching requires the inspection of a professional engineer to ensure the strength of the bridge is not affected by the large scale patching. 
10. The surface of the concrete adjacent to the patch should be damp but free of standing water for proper bonding.

\section{Alternative 2 - Deck Overlay and Repair of Concrete Side Walks and Barriers:}

Deck overlays are used to restore deck-riding surface to an acceptable limit and to provide additional cover over the reinforcing steel to mitigate corrosion. Typical deck overlays include cementitious overlays, bituminous concrete overlays with waterproofing, and polymer overlays. The service life of deck overlays is primarily dependent on the amount of unsound chloridecontaminated concrete removed. The additional weight of the overlay should be considered, since the extra dead load will reduce the structure's capacity to carry live loads. In practice, $13 \mathrm{~mm}(1 / 2$ inch) to $38 \mathrm{~mm}\left(1-\frac{1}{2} \mathrm{inch}\right)$ of existing concrete are removed to reduce the dead load. Concrete sidewalks and barriers are susceptible to freeze-thaw action, thus it is important to properly seal cracks and joints and fill or potholes. A drainage system should be provided to minimize surface ponding of water. Deteriorated concrete should be sandblasted prior to application of any patching.

\section{D4 Repair of Superstructure}

Steel girders not properly painted with epoxy paint can corrode severely, causing a severe reduction in service life, and requiring uneconomical strengthening or replacement. In order to properly maintain the steel girders, some preventive maintenance should be undertaken such as:

1. Visual inspection

2. Fracture assessment

3. Fatigue assessment

4. Cleaning and greasing of bearings

5. Protective painting (i.e. epoxy coating)

6. Joint maintenance

a. Reduces water exposure

b. Reduces debris accumulation

c. Reduces road salt exposure

Visual inspection, fatigue and fracture assessment determine the type and extent of any damage present. Since the bridge is subjected to cyclic loads, fatigue and fracture assessments will determine whether any cracks are present. The presence of any cracks should trigger an in- 
depth inspection of the bridge for similar cracks before conducting repair and retrofitting. The indepth inspection can integrate non-destructive evaluation such as the random decrement to evaluate the strains and dynamic signature of the girders. In general, elements in tension and high live-load stress ranges should be inspected closely for fatigue cracking. After the inspection phase, it is necessary the type and cause of any damage discovered in order to provide appropriate maintenance. Repair and retrofit techniques for fatigue of steel members can be categorized into three groups (Dexter and Ocel, 2013):

1. Surface treatments

2. Repair of through-thickness crack

3. Modification of the connection or global structure to reduce the cause of cracking The repair technique is intended to mitigate the propagation of fatigue cracks, whereas a retrofit is intended to upgrade the fatigue resistance and prevent future fatigue cracking (Dexter and Ocel, 2013). The choice of the alternative selected is dependent on the condition of the fatigue cracking and the availability of the required skills and tools from local repair contractors. The main girders are also likely to experience corrosion of the flanges and webs, resulting in a loss of cross-sectional area. A cross-sectional loss of up to $10 \%$ is permissible before any repair procedures are required. Figure D3 illustrates the prognosis model for the bridge superstructure. 


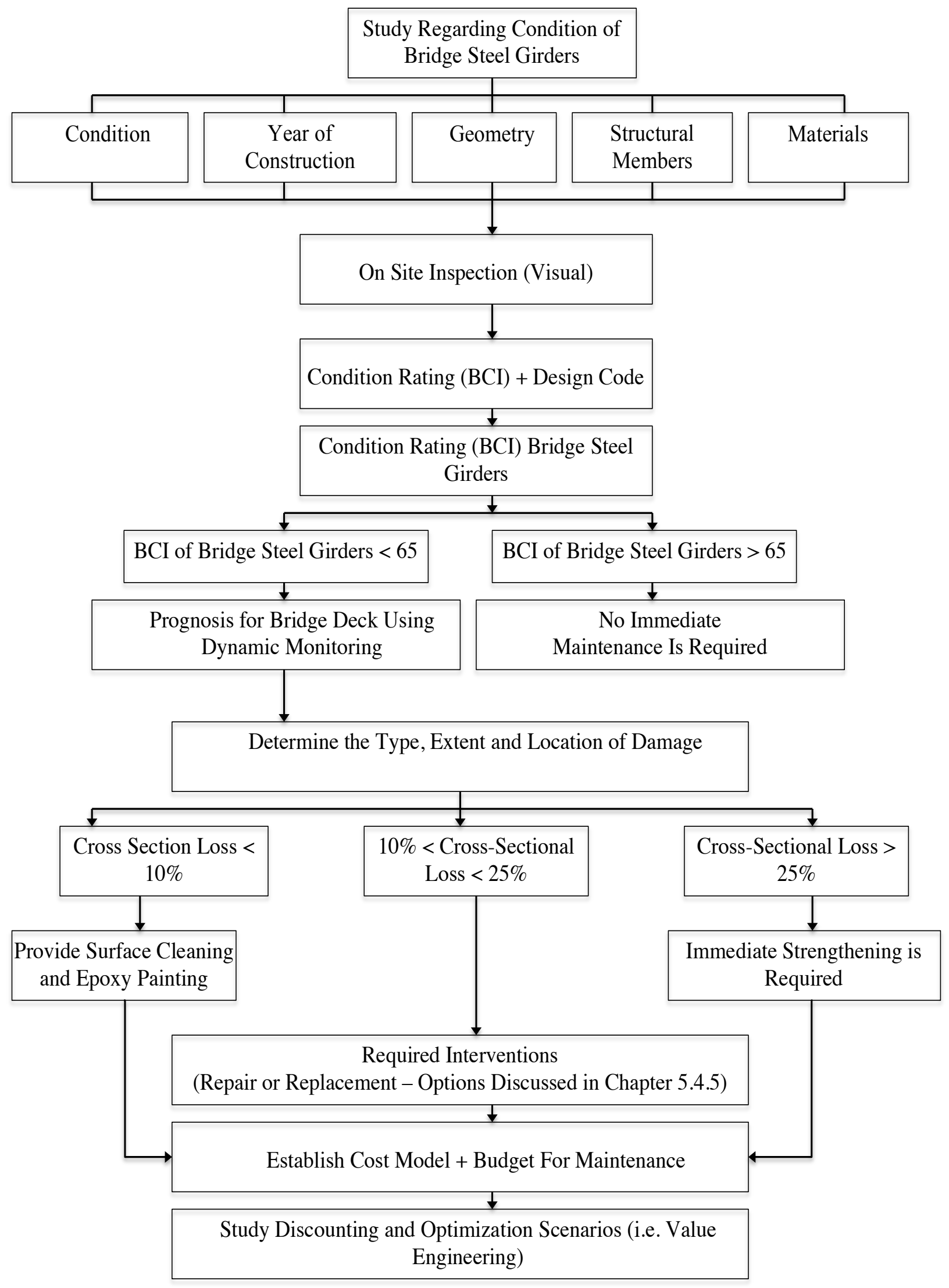

Figure D3 - Superstructure Prognosis Model 


\section{Alternative 1 - Repair of Corroded Flanges and Webs By Galvanized Cover Plates:}

The extent of cover plating in corroded flanges is determined by analyzing the transfer of load into the plate. Conservative guidelines for the number of fasteners required for maximum permissible stress in the plates is summarized in Table D2, demonstrating the number and size of bolts required base on the area of the cover plate $\left(A_{c n}\right)$ in $\mathrm{cm}^{2}$ (Stapleton, 2009). Figure D4 illustrates a typical flange repair procedure.

\begin{tabular}{|cc|}
\hline Bolt Size & Number of Bolts \\
\hline M20 & $5.4 A_{c n} / 1000$ \\
\hline M22 & $4.4 A_{c n} / 1000$ \\
\hline M24 & $3.7 A_{c n} / 1000$ \\
\hline M27 & $2.9 A_{c n} / 1000$ \\
\hline
\end{tabular}

Table D2 - Number of Bolts Required in Cover Plates (Stapleton, 2009)

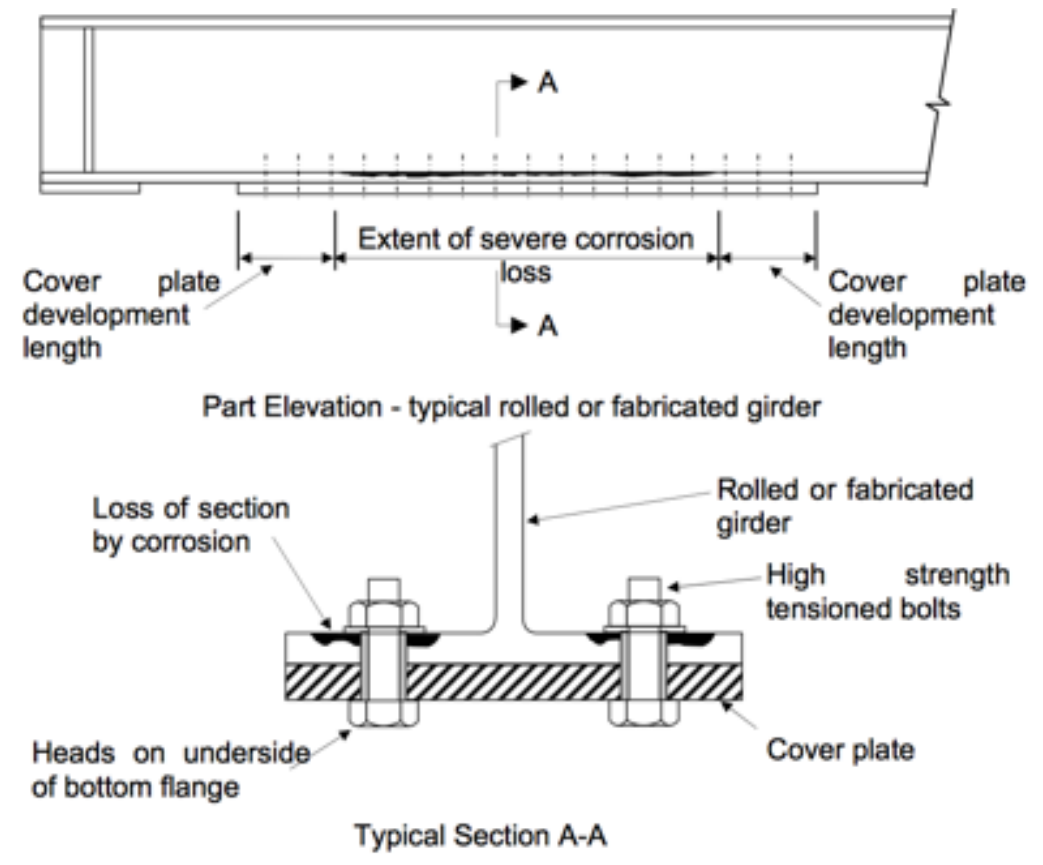

Figure D4 - Typical Flange Repair Procedure With Bolted Plates (Stapleton, 2009)

Corroded webs are repaired in a similar manner, with galvanized cover plates provided in regions where the cross-sectional loss exceeds $10 \%$. Welded steel metal plates are provided in scenarios where the corrosion is near the mid-height of the web. Figure D5 illustrates a typical web repair procedure. 


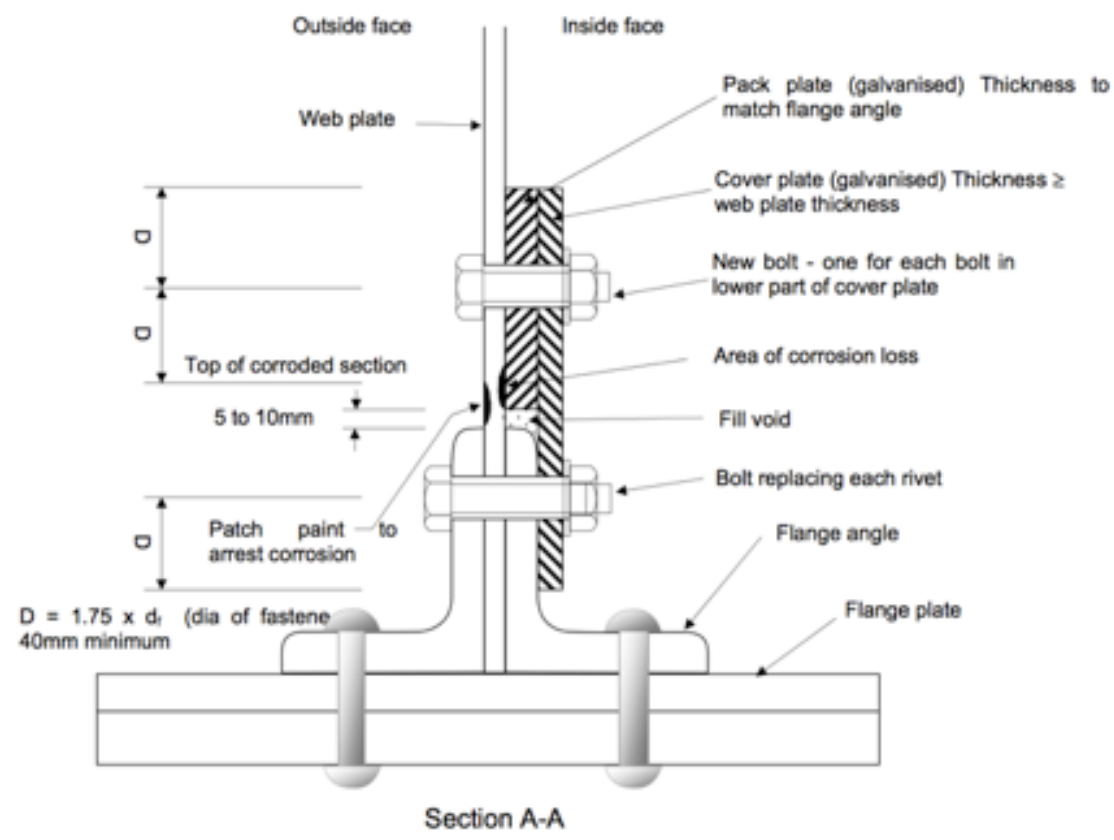

Figure D5 - Typical Web Repair Procedure With Bolted Plates (Stapleton, 2009)

\section{Alternative 2 -Painting of Steel Girder For Corrosion Protection:}

Painting of the girders is typically provided with steel repairs as a method of protecting the girders from future corrosion. However, patch painting is also used as a means of preventive maintenance in order to mitigate the corrosion process. Specifications provided by the manufacturer determine the procedure of paint application (i.e. number of coats). Surface preparation such as wire brushing is usually recommended in order to prepare the steel surface prior to paint application. Primer coats are applied directly onto the clean steel surface with the purpose of wetting the surface and providing proper adhesion for subsequent coats. Undercoats are applied after the prime coat to build the paint film thickness. In general, the corrosion resistance increases with the thickness of the film. Undercoats are designed to decrease permeability to oxygen and water, which mitigates the corrosion process. Laminar pigments such as micaceous iron oxide (MIO) or glass flakes are used to reduce moisture penetration in humid atmospheres and improve tensile strength. The finishing coat provides the appearance and surface resistance of the system. Figure D6 illustrates a schematic of a typical modern high performance coating system. 


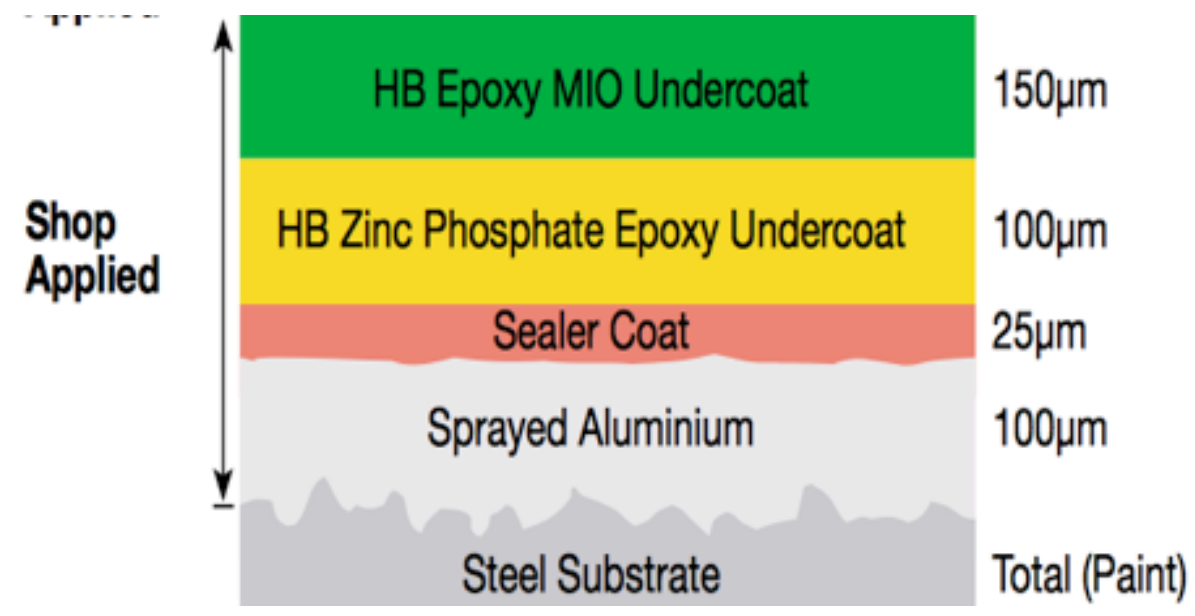

Figure D6 - Schematic Cross-Section of a Typical High Performance Coating System (Corus, 2005) 